Portland State University

PDXScholar

1995

\title{
A Non-decision-reaching Decision-making process
}

Wei Wei Lou

Portland State University

Follow this and additional works at: https://pdxscholar.library.pdx.edu/open_access_etds

Part of the Elementary and Middle and Secondary Education Administration Commons Let us know how access to this document benefits you.

\section{Recommended Citation}

Lou, Wei Wei, "A Non-decision-reaching Decision-making process" (1995). Dissertations and Theses. Paper 1193.

https://doi.org/10.15760/etd.1192

This Dissertation is brought to you for free and open access. It has been accepted for inclusion in Dissertations and Theses by an authorized administrator of PDXScholar. Please contact us if we can make this document more accessible: pdxscholar@pdx.edu. 
A NON-DECISION-REACHING DECISION-MAKING PROCESS

by

Wei Wei Lou

A Dissertation

in Partial Fulfillment of the Requirements for the Degree of

DOCTOR OF PHILOSOPHY

in

SYSTEMS SCIENCE: SOCIOLOGY

PORTLAND STATE UNIVERSITY

01995

Copyright by Wei Wei Lou, 1995

All Rights Reserved 
UMI Number: 9526361

Copyright 1995 by

Lou, Wei-Wei

All rights reserved.

OMI Microform 9526361

Copyright 1995, by UMI Company. All rights reserved.

This microform edition is protected against unauthorized copying under Title 17, United States Code.

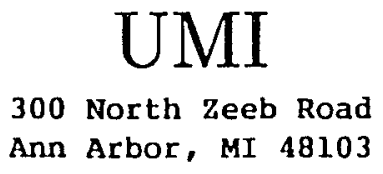




\section{DISSERTATION APPROVAL}

The abstract and dissertation of Wei Wei Lou for the Doctor of Philosophy in systems Science: Sociology were presented November 4, 1994, and accepted by the dissertation committee and the doctoral program.

COMMITTEE APPROVALS:

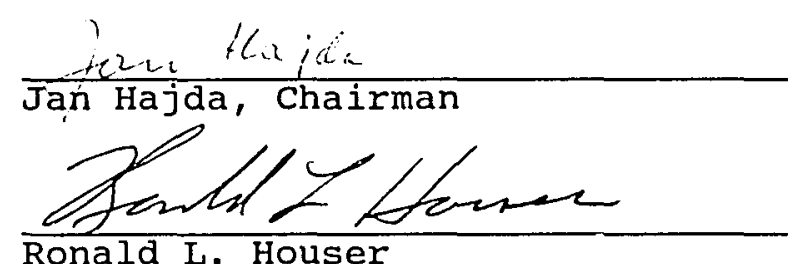

$\frac{\text { Otm } F=}{\text { Grant M. Farr }}$
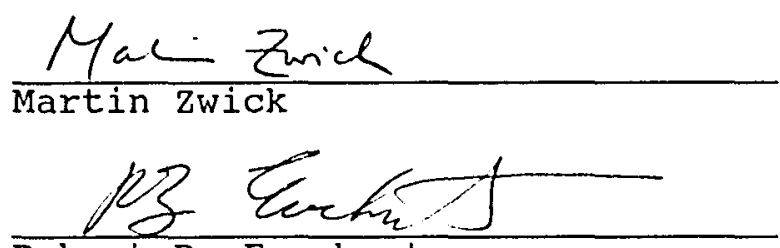

Robert B. Everhart

Representative of the office of Graduate studies

DOCTORAL PROGRAM APPROVAL:
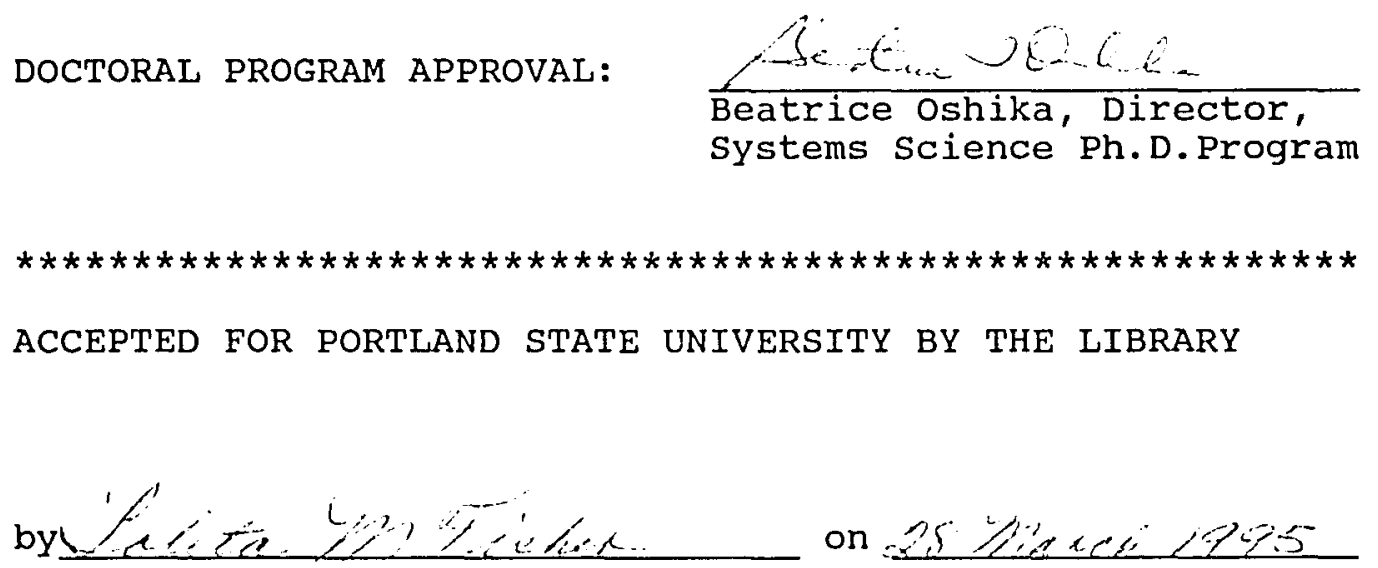


\section{ABSTRACT}

An abstract of the dissertation of Wei Wei Lou for the Doctor of Philosophy in Systems Science: Sociology presented November 4, 1994.

Title:A Non-Decision-Reaching Decision-Making Process. Decision-making processes are among the most important activities within human organizations. This dissertation is a case study of decision-making in the review of high school graduation standards in an urban school district. The review process lasted three years and was terminated before any decision was reached concerning graduation standards.

The purpose of this study is to answer three questions: Why would a decision-making process be terminated before any results are achieved? Under what circumstances do decision makers choose to let the process die? What do such decision-making processes reveal about the organization?

This case study employs the rational choice model, the process model, and the organizational decision-making model. These three models are constructed within the theoretical frameworks of systems science, sociology, and political science, and also draw upon the literatures of 
education reform and organization theory.

Define a NDR (non-decision-reaching) decision-making process as one which produces no outcome. The rational choice model suggests that the NDR outcome in this case was the best alternative under the circumstances. Two obstacles, insufficient resources and external uncertainties, were identified as important factors which led decision makers to choose the NDR outcome over other alternatives. The process model suggests that a decision outcome may not be necessary in many organizational decision-making processes, as the process itself is often significant and sufficient. The process accommodates, to some extent, the interests of the decision makers even without a definite outcome. The organizational decisionmaking model posits that organizational rules and procedures dictate decision-making processes, and that organizational interests will determine the nature and the outcome of such processes. In this model the NDR outcome is the result of organizational interests that no decision be reached.

The conclusions of this case study indicate that a loose structural relationship among the decision makers was a major cause of the NDR outcome. In addition, the decision makers had never fully reconciled their differences regarding the nature of the decision problem. The changing environment of public education is also 
identified as a factor leading to the NDR outcome. 


\section{ACKNOWLEDGEMENTS}

The completion of this dissertation was made possible by many people's contributions. I am especially indebted to Dr. Jan Hajda, my committee chair, who provided wisdom and guidance in the development of many ideas in this dissertation. He taught me, with generous assistance and tremendous patience, what it meant to be a serious scientist.

I also would like to express my thanks to Dr. Martin Zwick, Dr. Ronald L. Houser, Dr. Grant M. Farr and Dr. Robert B. Everhart, my committee members, whose expertise and efforts made this research project an exciting experience for me. I am especially grateful to walter Hathaway, late director of Research and Evaluation at Portland Public Schools, whose encouragement and support made this research possible.

I owe special thanks to the decision makers who participated in this study. Although I can not acknowledge them by name, I will always be inspired by their dedication and devotion to the excellence of education.

Special thanks also go to my friends and colleagues Carolyn Moilanen who listened to me and offered her 
insights; and Gerry Ann Mackinnon, who read through the early draft of this study and gave me constructive comments.

I save my final thanks to my family. My husband, Xiao-Guang $Q i$, and my daughter Meng $Q i$, always gave me love, warmth and support during the past few years. MY parents, Fu-Chang Lou and Shi-Ling Zhang, endured years of my physical absence and offered constant encouragements to this project. 
TABLE OF CONTENTS

PAGE

ACKNOWLEDGEMENTS.........................

LIST OF TABLES.........................

LIST OF FIGURES........................

CHAPTER

I

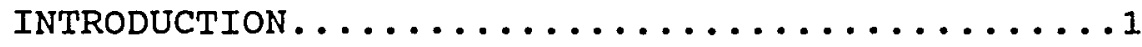

Statement of the Problem and

Research Goals

Theoretical Frameworks

Methodology

Organization of the Dissertation

II LITERATURE REVIEW.................. 18

A Dual Focus

The Rational Choice Model

Problem Solving Process

Rational Decisions

Decision Payoff

Rationality in Decision-Making

The Process Model

What Matters in organizational

Decision Making

Phases of Decision Making

Three Modes of Decision Making

Decision Making and An Ad Hoc

Committee

The Model of Organizational Decision Making

The organization Structures

The organizational Rules and Procedures

The organizations and Decision Making

Politics and Decision Making

The Organizational Environment

III METHODOLOGY..................... 51

Data Sources

Briefing Books I and II 
Meeting Minutes

Observation Notes

Instrumentation

Interview Questionnaires

Interview Varieties

Decision Initiators and Decision Makers Core Decision Makers and Decision

Makers

Board Members

School Administrators

Analysis

From Raw Data to Information

The Procedure of Model

Construction

The Relationship Between

Three Levels and Three Models

Research Categories

Definition of the Research Categories

THE PROCESS: A CHRONICLE.............79

The Background of This case study

High School Graduation Requirements

The current situation of Graduation standards

The Decision Participants

The Core Decision Makers

other Interested Parties

Relevant Events

A Chronicle of the Review Process

The Initiation stage

Mr. Carter's Proposal

The Developmental stage

Information

Curriculum, Assessment and Instruction

A Further Discussion on Graduation standards

Truman's Plan

Meetings with Instructional

Leaders

More Clarification

A Revised Plan

A Confusion 
The Responses

The outcome: the Finalization stage

A NDR outcome

A Reflection on the Process

V RATIONAL CHOICES IN THE REVIEW OF

GRADUATION STANDARDS.

Goal Directed Rationality

The Motivation of the Board

A Shared Belief

Review Challenged

Board's Initiation Questioned

A Different set of Alternatives

Obstacles in the Review of Graduation

Standards

Obstacle one: Lack of

Resources in the Review Process

Obstacle Two: Activities of state

Department of Education

NDR Outcome -- The Best Alternative

The Choice Situation

The Ultimate Alternative

VI THE TOPIC, THE PROCESS AND

THE ORGANIZATIONAL CONTEXT.....157

The Decision Interests and Problems

The Topic: Graduation Standards

Decision Interests

Decision Problems

The Process: Sporadic

The Phases of the Review Process

The Interruptions and Delays

in the Process

The Ad Hoc Committee for the Review Process

The Nature of the Roseville Ad Hoc

The Environment of the Ad Hoc

The outcome

A Process-Oriented Tendency

VII THE REALITY OF ORGANIZATIONAL

DECISION-MAKING............186

The Organizational Rules and Procedures 
The Academic Merit of Standard-Setting

The Political Aspect of standard-setting

Organizational Environment The State Authority other Forces in the Enviromment The Business Community

Organizational structure

The Board and the District staff

The Board and other Parts of the organization

An Inevitable outcome

The Review Process and the

Organizational Rules

A Structural Explanation

The NDR outcome

THE CONCLUSION..................219

The Findings

The Reasons

The Circumstances and the Characteristics

Implications to the organization

The Highlights of the Three Models Rational Choice with obstacles The Topic is the Most critical organizational Decision-making as Organizational Behavior

A Comparison of Decision-Making Studies The Three Models other-Case Comparison Limitations of This Case study Recommendations 


\section{LIST OF TABLES}

TABLE

PAGE

1.Decision Initiators and Decision Makers.......66

2.Narrative of Mr. Bruce..............68

3. Data Format After First Reduction Procedure.....69

4. Conceptual Categories.................70

5.Categories of Analysis...............71

6. Categories and Levels of Analysis..........75

7.The Decision Participants...............84

8.A Chronicle of the Review Process...........97

9. Eighth Grade Progress Towards Graduation.......106

10. Revised Timeline to

Review Graduation Standards.............120

11. Percent of students

Passing Graduation Standards..........160

12. Average Graduation Standards

Progress Report..................160

13. Graduation Progress Report of

Westernville High School..............161

14. Graduation Progress Report of Easternville High School.............162

15.A Comparison of Competence Areas..........202 


\section{LIST OF FIGURES}

1.Methodological Approach...............52

2.Organizational structure of Roseville.........85

3.Other Interested Parties................90

4.Stages of Decision-making Process............126

5. Decision Alternatives Perceived

by school Board.................138

6. Decision Alternatives Perceived

by District Staff................143

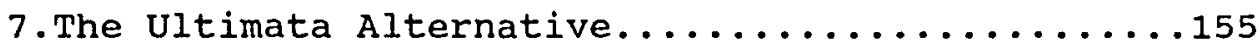

8.The NDR Outcome Explained by Process Model......182

9. The NDR outcome Explained

by Organizational Model.................. 


\section{CHAPTER I}

\section{INTRODUCTION}

Decision-making processes play a significant role in organizational life, since organizations make decisions constantly. Crucial events and social changes of the world are of consequences to organizational decision-making. However, while tremendous energy goes into decision-making activities, some decision-making processes are not sustained to produce any outcomes. Why would a decisionmaking process be terminated before any results are achieved? Under what circumstances do decision makers choose to let the process die? What do such decisionmaking processes reveal about the organization?

This study examines the decision-making process as it unfolds in the review of high school graduation standards in an urban public school district. In this context, the decision process ceased to exist before any decisions were reached. This dissertation intends to examine the decision process through three models: the rational choice model, the process model, and the organizational model.

The focus of this study is on not only the dynamic interaction of the decision makers but also the relevant 
organizational structures of public education. This study intends to explain why this decision-making process was put on hold before any decisions were reached. The phenomenon of non-decision-reaching decision-making, one of the least discussed topics in decision studies, deserves an explanation.

The study was conducted within the theoretical frameworks of sociology, organization theory, systems theory, political science, and an emergent theory of educational improvement. In specific, the rational choice model employed in this study lies within the framework of system science. The exchange theory in sociology is also a significant part of the rational choice model. The organizational decision-making model is a product of organizational theory, sociological theory of human interaction, and theories of organizational politics in political science. The process model, which draws from theories of political science and theories of business management is a result of numerous case studies on strategic decision-making processes. The focus of the process model includes decision problems and decision interests within the context of organizations.

The analysis draws upon multiple data sources: newspaper files, official documents, observation notes, organization publications, and structured interviews with decision-making participants and relevant parties. From 
its initiation to its end, the case under study lasted about three years. The participants included members of the school board, the superintendent, numerous district administrators, district staff members and invited participants.

STATEMENT OF THE PROBLEM AND RESEARCH GOALS

The case under study was initiated by the school board of education at Roseville School District, a large urban school district. There were two basic requirements for a high school student to graduate with a standard diploma at Roseville: the state requirement of twenty-one credits and the district requirement of twenty-two credits in addition to passing the graduation standards examinations. The process of decision-making in this case study was to review the high school graduation standards for further changes. Since the graduation standards were an important component of high school graduation requirements, reviewing the standards represented a decision-making topic that was both controversial and consequential.

Decision-making processes became a topic of interest for organizational scholars and social scientists several decades ago. The highlights of the field include studies such as Graham T. Allison's trio-model of Cuban Missile Crisis and Henry Mintzberg's observation of numerous 
cases. As a departure from the traditional "prescription" of decision-making models, recent studies tend to focus more on the empirical evidence of decision-making process. The challenge, however, is to collect the empirical evidence of the decision-making process and to explain the phenomenon.

There are three kinds of decision-making processes: those that lead to an outcome, those that are never implemented, and those that disappear before anything is achieved. A decision outcome is defined as the action taken as a result of the decision process. Implementation of the decision result is not a concern here.

It is important to distinguish a decision-making process that is abandoned and one that decides to do nothing. "To do nothing" is a decision outcome. A deserted decision does not produce any outcomes. Although both the non-decision-reaching decision and the decision to keep the status quo result in no action, the former keeps the topic open. In a non-decision-reaching decisionmaking process, the process dies. In this study, a nondecision-reaching decision-making process is abbreviated as NDR decision-making. NDR decision-making indicates a decision-making process that was abandoned before any outcome is achieved.

No matter what the outcome is, a NDR decision process is initiated as though a result will be reached. To 
organizational decision makers, decision-making processes are vehicles for achieving a decision outcome. The initiation of decision-making is always intentional. In other words, decision makers perceive a need for a decision prior to the initiation of a decision-making process. To an organization, the need to go through a decision-making process indicates a gap between the expected standard of operation and reality. The decisionmaking process is a means to bridge such a gap.

The NDR decision-making process becomes a problem to the organization if decision makers have to go through many such processes. To say the least, a NDR decisionmaking process is not productive even though the process itself could be useful and healthy for the organization. Also, a NDR decision-making process implies misjudgment of the organizational priorities on the part of the organizational decision makers. That is, organizational decision makers initiate a decision-making process which is not necessarily appropriate or the need to go through the process can soon go away. Finally, if organizational decision makers engage themselves in many NDR decisionmaking processes, a large amount of organizational resources can be wasted while many other business matters are neglected. Further, if the NDR process represents a majority of an organization's decision outcomes, this organization may have fundamental problems. Although a 
NDR decision-making process seems to be an inevitable part of the organizational life, the pros and cons of NDR processes should be examined.

Many questions are raised by these problems. Due to limited space, this study intends to answer three questions. Why is a decision-making process a NDR process? Under what circumstances do decision makers choose to let a decision-making process die? What do NDR processes reveal about the organization?

The first question concerns the characteristics of the NDR decision-making process. In specific, this study intends to identify the circumstances under which the NDR process was initiated and the decision topic was discussed. In addition, this study intends to explain the organizational context and the contributing factors to the NDR decision-making process. These factors could be the organizational constraints, environmental forces or factors unexpected by decision makers.

The second question concerns the interactions of the decision makers in this NDR process. For instance, this study identified the individual characteristics of the decision initiators and decision makers in addition to their behaviors and interactions during the decisionmaking process.

The third question concerns the organization within which the NDR decision process took place. For instance, 
a NDR process could be the indicator of the organization inefficiency or an implication of the state of affairs of the organization leadership. At the same time, NDR process could also reflect a rapidly chariging environment of the organization.

To answer the above questions, this research intends to achieve the following goals:

First of all, a description of the NDR decisionmaking process regarding a review of graduation standards will be developed. This description will identify a chronicle of the decision process, the participants in the process, and the actual events that highlighted the process. This description will serve as an aid to understanding the process of NDR decision-making and a validity check of the analysis, but most importantly, this description is a useful tool for the analysis.

second, this research attempts to provide an explanation of this decision process, using three models of organizational decision-making. With a focus on the termination of a three-year decision-making process, the author hopes to examine the differences between these three models. A cross-checking of different data sources is intended to validate the evidence of the findings. Finally, this research intends to fill a gap in decision studies: NDR decision-making processes. Through an examination of the NDR case from three different 
angles, this research intends to provide clues to the mystery of NDR decision-making process.

\section{THEORETICAL FRAMEWORK}

Decision-making process is an important and a complicated part of organizational life. Yet, "in spite of the obvious importance of decision-making as an organizational process, there has been only a limited amount of empirical research on the subject" (Yukl and Wexley 1971). The limitations are due to many reasons: diverse theoretical concepts and explanations of human organization, little understanding of human decisionmaking behaviors, and restricted access to empirical data on decision-making processes.

At the heart of social organizations is the organizational headquarter where decisions are made. It is in this part of the organization that social scientists can untangle the mystery of social/organizational changes. The behavior of decision makers, be it the president and his staff or the superintendent and his district administrators, determines the development of organizational changes. Such behavior is best illustrated in decision-making processes.

Being at the center of organizational changes, the behavior of decision-making is of great significance to social scientists. The result of decision-making 
determines specific steps regarding how and why changes occur within an organization. Also, decision-making behaviors are directed by specific organizational rules within the organizational framework. Since decisionmaking has the potential to generate further changes, clues regarding such changes can be found in the decisionmaking processes within the context of organizational structures. Therefore, a decision-making study requires a dual focus: the organizational structure as a whole and the dynamic interaction of the decision makers during the decision process. The organizational structure provides the specific context for decision makers' behavior. The decision makers, in turn, perpetuate or change organizational structures as they put forth their best efforts to achieve organizational goal.

Social scientists from many disciplines have developed several approaches to decision studies. The rational choice model "specifies a well-defined authority structure and well-defined objectives for the organization, which tend to result in the use of a computational, optimizing, or more rational type of decision strategy" (Pfeffer and Salancik 1972). Furthermore, the rational model assumes a calculated choice process of decision-making, during which decision makers seek optimal choices and statistical calculations 
in "narrowly constrained, neatly defined situations" (Allison 1967). It is a theory of an ideal type.

Jon Elster identifies three basic elements of rational choice theory. The three elements include the feasible set of all courses of action, a set of rational belief about the causal structure of the situation, and a subjective ranking of the feasible alternatives. The first element, feasibility of the choices, states that the courses of action are "rationally believed to satisfy various logical, physical and economic constraints." The second element, the causal structure of the situation, "determines what courses of action will lead to what outcomes." The third element, the subjective ranking of the alternatives, is "usually derived from a ranking of the outcomes to which they are expected to lead" (Elster 1986). A by-product of the rational model is the methodology wherein decision trees, flow charts, and decision maps are used to outline a decision-making process.

An organizational model, on the other hand, is "frequently a more accurate description of decisionmaking" (Pfeffer \& Salancik, 1972; Allison 1967). Power, empirical conditions, and social agents are important variables in this model. Subunits, departments, and decision makers compete for their own interests. 
Alternatives and choices are sought via compromises more than rational calculation. Decision-making behavior in organizations should be understood "less as deliberate choices and more as outputs of large organizations functioning according to standard patterns of behavior" (Allison 1967). The standard patterns of behavior are a "fixed set of standard operating procedures and programs." Therefore, decision-making processes "are determined primarily by routines established in these organizations prior to that instance" (Allison 1967). In other words, standard organizational rules and procedures primarily determine the nature of a specific decision-making process. The methodology accompanying this theoretical model includes document analysis and participant or nonparticipant observation. A description of "substantive instances" of the decision-making process and a "conceptual argument" are important parts of this model (Bass, 1985). Significant episodes of the decision-making process are substantive instances that illustrate important conceptual arguments.

Some scholars look at decision-making processes with a focus on the process. By definition, the process model holds that a decision topic generates decision problems and decision interests. Within the organizational context where a decision topic is born, decision problems must be 
solved and decision interests must be promoted. Further, "the framework of organization in which strategic decisions originate forms the rules for decision-making. It establishes the internal division of work and of authority which fix the interests involved and the scope of decisions" (Hickson et al. 1986). In the absence of "universalistic values" or "rational choices" that are so typical of the traditional/rational model, the process model takes a naturalistic approach to decision studies. With some overlapping concepts with the organizational model, the process model focuses on the process itself, identifying three modes of decision-making processes. These modes are determined by the nature of a decision topic, which is identified as the most important factor in a decision-making process. A vortex matter/topic which is characterized by high degrees of complexity and politicality leads to a sporadic process full of confrontations and conflicts. A familiar matter/topic, on the other hand, produces a constricted process less political and less complicated than a vortex matter. A tractable matter/topic shapes the decisionmaking process in a fluid fashion. In a fluid process, decision makers tend to agree with each other since the matter for decision tends to be a novelty. In addition to the decision topic, the nature of the organization also 
contributes to the modes of decision-making process. For instance, public sectors are more likely to be involved in a sporadic process than a fluid process.

Although the process model holds that organizations provide important contexts to organizational decisionmaking, it looks at organizations less as a structure than as a flexible combination of rules, procedures, and interactions. Garbage-Can theory, a concept of the process model, suggests that organizations are organized anarchies (Cohen, March and Olson 1972) which describe a contradictory yet extreme phenomenon in organizational life. Dual rational theorists state that an organization "is a prescription of the terms on which the games are played" (Hickson al et. 1986), indicating a preestablished procedure for the process of decision-making and a flexible nature of such processes as well. Since many decision-making processes take place in an ad hoc committee, decision makers have opportunities to make decisions creatively.

The organizational model, however, perceives the process of decision-making as less important than the structure and the nature of the organization. According to this model, decision-making behaviors are first of all organizational behaviors. 
METHODOLOGY

This research employs a multi-dimensional methodology to the decision-making process as it applies to a review of graduation standards. The research design consists of two parts: descriptive and analytical. The description portion intends to provide a chronicle of the actual events during the decision-making process regarding the review of graduation standards. The analytical portion intends to examine the decision-making process through a construction of three different models.

Case studies provide the richest and the most accurate information for analyzing decision-making processes (Hickson et al. 1986; Mintzberg et al. 1976; Mintzberg et al. 1985; March and olson 1984). To capture the essential choices of the decision-making process, a naturalistic inquiry is employed in this study. An inductive analysis of the research data provides means to search for patterns of the decision-making process and to make sense of such patterns.

Three levels of analysis are identified. The first level of analysis focuses on the decision makers. Since all players contributed to the decision-making process in a unique way, their relevant behaviors were examined on an individual basis. The second level includes the decision topic, decision problems, and decision interests. Group 
behaviors were also examined since some decision makers shared similar interests in the decision-making process. The third level of analysis is at the organizational level. The school district under study is the focus of this analysis. The organization structure, operating procedures, and standards as well as the organizational environment are relevant variables at this level of analysis. Finally, a synthesis of the three levels is developed for the purpose of constructing the models for this case study.

Three concurrent flows of qualitative data analysis were employed: data reduction, data analysis, and conclusion drawing. Raw data, which were bulky narrative forms, were analyzed by grouping the evidence into conceptual categories according to theoretical concepts. Some of these categories apply to one model and others apply to more than one models. Values or numbers are assigned to these categories when it is appropriate. Data display includes the steps of sifting through these categories presented in tables and charts. The construction of the three models is the final procedure. Multiple sources of data were collected during the decision process. Two sets of interviews were conducted to capture the detailed happenings of the process. In an attempt to overcome memory failure or memory distortion on 
the part of the decision makers, thirty percent of the interview questions in both interviews addressed similar issues. Documents regarding the decision process were collected and analyzed. The author collected data from fifteen decision-making activities as a non-participant observer.

ORGANIZATION OF THE DISSERTATION

This dissertation has eight chapters. Chapter I is an introduction of the study. Chapter II is a literature review, which draws upon diverse sources. A discussion of the three theoretical models is the major part of this chapter. Chapter III discusses the methodological issues in this research in detail.

Chapter IV is a description of the decision-making process. This chapter contains a chronicle of the events, a discussion of the decision-makers, and a list of events considered to be the highlights of the decision-making process.

Chapter $\mathrm{V}$ examines the decision process through the lenses of the rational choice model, which identifies the problems and the best solutions of this decision process. Chapter VI employs the process model which examines this process in light of the decision topic, and the topic generated problems and interests. Finally, Chapter VII discusses the decision process from an organizational 
approach. The organizational structure, the subunits, and the relevant political interests are the topics of discussion.

Chapter VIII is a brief summary of the three models, with a synthesis of the three models and recommendations for future research. 
Decision-making is one of the most important aspects of organizational life. The making and processing of decisions shape organization development. The process of decision-making happens at all levels of an organization and has long term impacts. Unlike the structure of organization, the decision-making process reflects the dynamic nature of the organization. A NDR decision-making process is an important indicator of the state of affairs for the organization.

"Games of maneuver," as many researchers define decision-making (Hickson et al. 1986; March 1981; Allison 1967; Elster 1986), are a common and routine phenomenon of human organizations. The process of decision-making is undoubtedly the single most important activity which is under control of the decision makers. Through maneuver, negotiations, and bargains, decision makers achieve what they consider to be the best results based on their criteria.

The games of organizational decision-making are embedded in the routine life of an organization and its 
decision makers. An interpretation of how and why decisions are made within an organization can be derived from the multiple dimensions of human organizations. Both the organizational structure and the relationship of these structures to the players are important variables. In many cases, decision-making is a daily routine that requires complete devotion of the participants' time and energy. A decision-making process is an organizational investment which the organizational leaders take on or abandon according to the organizational circumstances. organizational needs, organizational resources, and the particular organizational situation determine whether the decision-making process is worth being carried on.

In searching for an explanation regarding why certain decisions are made, one puts himself or herself in the position of the decision-makers. However, decision-making is a complex organizational behavior: "There will always be the dark and tangled stretches in the decision-making process--mysterious even to those who may be most intimately involved," claimed John F. Kennedy (Allison 1967). Analysts employ diverse approaches to explain the mystery of "the dark and tangled stretches" of organizational decision-making. The three models employed in this study, the rational choice, organizational, and process models, embrace the complex decision-making issue from three different perspectives. Since a single model 
tells only part of the story, a shift of lenses is essential to understanding the whole picture of organizational decision-making.

\section{A Dual Focus}

The three models of organizational decision-making offer different yet compatible explanations of why the decision-making process of this study was terminated before anything was achieved. Each offers interpretation for part of the story. In addition to these three models, this research employs a dual focus: the organization and the decision-making process within this organization. The multiple perspective on decision-making process is based on the three models but it also represents a step further from the three models. This results from a recognition of the limitations of the three models and a belief that an adequate research in organizational decision-making needs more than one model.

THE RATIONAL CHOICE MODEL

Logical thinking and rational choice make up the heart of the rational choice model. Theorists, as well as laymen, believe that a decision can be explained by logic and reason. Goals, aims, and objectives are frequently mentioned as the motivation of the decision-making behavior. For instance, in order to explain why the educational leaders in this study started the process to 
review the graduation standards, a rational choice analyst would identify the objectives, the purposes, and the logic to do so. The justification of the decision-making behavior is made in terms of maximum payoff.

The structure of the system

organizations are perceived as social systems (Robertshaw 1978; Coleman 1990). Be it a family or a corporation, this system is defined in terms of relevance. Such systems have components and parts that are decomposable. A good example of such a system is the public education system in America. This system has many parts which are hierarchically arranged. At the district level, the superintendent and his/her staff form the top of this hierarchy, functioning as the leader to the teachers in the classrooms. At the same time, the superintendent and his/her staff also function as liaisons between the teachers and the state authorities who oversee the school district as part of the state-wide public education system. The unique identity of this system is the business of education. Under the superintendent, there are area superintendents and school principals who conduct business at different levels.

James S. Coleman considers large-scale organizations such as public schools in America, as "corporate actors inasmuch the people form a constitution of basic norms 
that define rights and obligations and an authority structure that allocates responsibilities" (Munch 1993). People will create and accept a constitution and authority structure according to the benefits they expect from this constitution. The essence of the corporate actor lies in the "existence of a separate set of rights and responsibilities and a set of resources and interests, which can neither be allocated to a single physical person nor be allocated among a set of persons" (Coleman 1990). Coleman also believes that there exists a power relationship which is based on the distribution of the organizational resources. Players are motivated to be involved in this power relationship within the system because they expect to benefit from such a relationship. since the resources are unequally distributed, the power relationship is characterized by uneven power distributions as well. Furthermore, since no one player has the complete control over the system resources, interaction processes are characterized by power struggles, conflicts, and negotiations of the players.

\section{Problem Solving Process}

According to systems theory, problem solving is an essential part of systems. "Decision theory, similarly analyzing rational choices, within human organizations," is "based upon examination of a given situation and its 
possible outcomes" (Bertalanffy 1962). In order to survive, an organization or a system solves emerging problems within the system and interacts with its environment.

By definition, "the system of interest in contemporary problem solving include people in addition to rules and things" (Robertshaw 1978). This combination of players and rules defines a unique system with goal-directed problem solving. For example, a combination of the superintendent, his/her staff, area superintendents, principals and classroom teachers working in an public education system with rules, regulations and traditions, defines the system whose sole mission is to educate the young people. The activities of this system are problem solving processes which ensure the achievement of the system goal. However, at times, problem solving can be extremely difficult since the rules of the system pose restrictions on how the problems should be solved. Sometimes, a system is not able to solve any problems. In such a situation, the system fails to function effectively. or it can become totally dysfunctional. The task of problem solving becomes more and more difficult as systems organize themselves "by way of progressive differentiation, evolving from states of lower to states of higher complexity" (Bertalanffy 1962). Higher levels of complexity within a system are reflected 
in increasing numbers of parts, specialized functions, and a changing environment. Compared to a system of lower level complexity, a system with higher level complexity has more multi-dimensional problems.

Environment is another variable in the process of problem solving. In the process to interact with its environment, a system or an organization struggles to define and keep its boundary. These two tasks are extremely important since they are closely related to the function and performance of the system. For instance, today's public education system is constantly challenged to take on more responsibilities and to redefine its mission. The system no longer has the sole responsibility of teaching the youngsters how to read and write. In addition, schools are responsible for feeding the youngsters, checking their eyes and ears, etc. Between the state and federal authorities and the general public, today's public education system is charged with responsibility for students' work preparation, work ethics, and personal well-being. While these responsibilities are wonderful missions, they blur the boundaries of today's public education system, creating a case of extreme confusion in America. Since "the environment of the system consists of these element which affect the system performance but are not under the direct control of the decision makers" (Robertshaw 1978), the 
problem of defining the system's boundary is a major challenge for today's educators.

\section{Rational Decisions}

Robertshaw defines rational decisions as those "characterized by the use of logic and common sense. Reasons are given to decisions, analysis is performed, and evidence is exhibited. Cause and effect relationships are developed and used to find solutions" (Robertshaw 1978). one must assume that decision makers act reasonably, based on their analysis and real evidence. One must also assume that decision makers' behavior is directed by "clearly defined goals of the system they work for." Their action taken is a "calculated solution to a strategic problem" (Allison 1967). Furthermore, these rational actors "learn to evaluate the solutions by considering the total goodness or badness associated with a solution " (Robertshaw 1978).

Rational choices are based on many other criteria as well. For instance, decision makers choose to cooperate with others as they perceive the choices as beneficial to them under the circumstances. In addition, individual rationality is a common phenomenon in rational choice decision-making. A "like-me" tendency, which occurs when a player expects what is rational for others is also rational for himself/herself, and vice versa (Elster 
1990), is a likely behavior of rational decision makers. However, what is rational for one individual player is not necessarily rational for others. On the contrary, what is rational for one player may be irrational for the organization as well as for other players. In other words, individual rationality may lead to collective irrationality.

Incentives also play an important part in rational choice decision-making. On the one hand, strong personal incentives and weak group incentives create a situation of imbalance in decision-making. This imbalance is caused by personal incentives to achieve a personal goal which may be questionable for the group. Such situation creates a lack of consensus on group incentives. On the other hand, a powerful collective motive, a desire to achieve maximization of the overall outcome for the group, also creates a difficult situation for individual players to achieve their personal goals. Although a perfect match between personal and collective incentives does exist, competitive motive is found to be a frequent case. occasionally, an individual decision maker finds his decision motives fit exactly other players' interests. When decision makers are actively seeking maximum payoffs for themselves, conflicts occur and overall outcome for the group may never be achieved (Rapoport and Chammah 1965). Under such a circumstance, termination may be the 
best choice for the decision-making process.

Jon Elster defines choice situations along two main dimensions. The first dimension is a distinction "between perfect and imperfect information about the outcomes that will follow the alternative courses of action. ... Choice situation with genuinely incomplete information may be characterized by risk or by uncertainty." The other distinction is "between parametric and strategic decision, a situation which is characterized by interdependence of decisions." An equilibrium point could be reached when "a set of choices that are optimal against each other" occurs. At this point, nobody in the decision-making process can improve his/her situation by "deviating from his equilibrium choice as long as the others stick to theirs" (Elster 1986).

\section{Decision Payoff}

Based on the three elements of rational choices, that is, the set of feasible actions, the causal structure of the situation and the subjective ranking of the feasible alternatives, a rational decision maker simply chooses the "highest-ranked element in the feasible set" (Elster 1986).

Rational decision makers are expected to achieve their preferred outcome or the highest-ranked element based on criteria that maximize payoffs. Many decision- 
making behaviors can be interpreted in terms of the intended goals and purposes of the decision makers. Throughout the decision-making process, decision makers actively collect information to reduce uncertainty. Thus they clear away the obstacles to reaching a decision outcome. When information provides enough evidence for a rational choice, decision makers calculate the pros and cons of the alternatives and make a decision. The chosen outcome reflects the organizational goals and is the maximum payoff for decision makers under the particular circumstances.

The termination of a decision-making process is a unique case of decision outcome. A decision-making process that produces a null decision outcome is perceived as no different from a decision-making process with a decision outcome. The difference is that the NDR decision-making process presents the decision makers with overwhelming uncertainty to reach any decisions. Efforts to pursue more information to reduce the uncertainty are not useful since the cost far exceeds the benefits of obtaining it. In other words, abandoning the process is the best choice under the circumstances. Although the efforts so far are wasted since there is no outcome, to drop the process is the most sensible choice because it prevents further waste of system resources. 


\section{Rationality in Decisien-Making}

The rational choice model asserts that decisionmaking behaviors are motivated by "value-maximizing reckoning." To achieve the maximum payoff, decision makers "select the most efficient alternative." That is, in the process of selecting the alternative that maximizes output for a given input or minimizes input for a given standards, the decision makers reduce the decision topic to a simpler matter than it is by decomposing the problem. Information is sought to reduce uncertainty and a set of alternatives is given them to choose from. For instance, among the alternatives in the case of reviewing the graduation standards was the choice to abandon the decision-making process because the effort to continue far exceeded the payoff of the decision outcome.

The concepts in the rational choice model in this study include several theories. The rational actor model discussed by Allison (1967, 1971) and the rational choice model developed by Jon Elster (1983) were the major part of this model. The essence of these two perspectives is a series of criteria that provide guidance to decision makers on a rational basis. These criteria can be presented as inter-related variables that are discussed later in this study. An additional perspective to the rational choice model is the rational choice theory developed by James Coleman (Coleman 1990). Coleman 
believes that human beings are capable of being rational and human interaction depends mostly upon an exchange of resources.

The synthesis of these perspectives forms the basic concepts of the rational choice model in this model. The relationships of these concepts are illustrated in Figure 1. As Figure 1 indicates decision makers develop alternatives based on the goals and objectives. Constraints are usually important considerations in developing these alternatives. Then the decision makers anticipate the consequences to evaluate the situation. The ultimate alternative is chosen as the best, valuemaximizing decision results.

THE PROCESS MODEL

strikingly different assumptions about organizations lead the process model to focus on decision-making processes. By definition, an organization is a "mobilization of bias before any decision-making games begin. In other words, an organization is a prescription of the terms on which the games are played" (Hickson et al. 1986). The organizational rules and procedures provide a framework within which the decision-making processes take place. The decision-making processes are bounded by "rules of game" which are "social norms governing behavior in an organization" (Hickson et al. 1986). Therefore, 
decision-making processes and behaviors are vital to organizational life. Organization decision-making can be perceived as "games of maneuver characterized by obstacles, power, and muddle" (Hickson et al. 1986).

However, the process model holds that the processes of organizational decision-making have lives of their own. The process, not the organization, is the focus of decision-making studies. Further, the process model rejects the idea that the mystery of decision-making processes can be revealed at the organizational level, suggesting that the process to make a certain decision must be examined as an unique organizational experience. For instance, a decision-making process over production must be understood as a process involving relevant parties and factors unique to this process. Since one topic of a decision-making process is different from other topics, the process has to be different and unique.

The decision-making process can be tractable-fluid, vortex-sporadic or familiar-constricted, depending on variables such as decision topic, decision problems, and decision interests. "Although the trajectory of the topic as it moves towards a decision may meander and even double back on itself, a satisfying incremental outcome will eventually be reached that few may wholly like but most can live with" (Hickson et al. 1986). Process theory also believes that decision-making processes go through three 
phases in general: an identification phase, a developmental phase, and a finalization phase (Mintzberg et al. 1976).

Concepts such as decision topic, decision interests, decision problems, garbage can phenomenon and modes of decision process were developed by Hickson and his colleagues (Hickson et al. 1986), Cohen, March and Olson (1972). These concepts focus on the specific topic and the topic related issues. According to this model, controversial and complex topics usually lead to sporadic processes because of serious consequences and high levels of complexity of the topic. Mintzberg's contribution to this model includes his discussion of the "adhocracy," or an ad hoc group which is a temporary committee for decision-making processes. The nature of this ad hoc committee explains many issues in a sporadic decision process. Organizational interest is the starting point of a decision topic which generates decision interests and decision problems. Decision interests are different from the organizational interests since decision interests are immediate, short term interests that pertain to a particular decision topic. The organizational interest also generates a decision environment which leads to the establishment of an ad hoc committee. Through the ad hoc committee, the decision topic, decision interests, and decision problems are processed and an outcome is 
produced. The nature of the process is determined by the decision topic, decision interests, decision problems, and the ad hoc committee. Further more, the nature of the process, the combination of the ad hoc committee, the decision environment, decision interests, and decision problems are contributing factors to the specific outcome.

What Matters in organizational Decision-Making

"An organization is less the result of deliberate design than it is the only partly intended accumulated result of decision-making games over the years." Therefore, "an organization can be regarded as a collection of such games" (Hickson et al. 1986). This tendency to perceive organizations as dynamic interactions is carried even further by the Garbage-Can concept which uses garbage-can as the analogy of organizational decision-making (Cohen, March and Olson 1972). According to Cohen and his colleagues, organizations are "organized anarchies" characterized by "problematic preferences," and "a loose collection of ideas" with "uncertain and changing boundaries" (Cohen, March and Olson 1972). Although organizational structure and organizational rules play an important role in organizational decision-making, decision makers have to deal with individual decision topics which differ from occasion to occasion. Therefore, organizational decision-making is anything but "rational" 
(Hickson et al. 1986; Cohen, March and Olson 1972; Quinn 1980) .

Hickson and his colleagues believe that organizational decision-making focuses on "process" because "every matter that arises for decision must both raise problems and implicate interests" (Hickson et al. 1986). Derived from a stimulus or a proposal that triggers the decision-making process, decision problems and decision interests represent a mixture of decision focus (Mintzberg 1979). In other words, decision makers solve problems and accommodate interests in a decision-making process. Therefore, a decision-making process is both "problem directed" and "interest-directed" (Hickson et al. 1986; Mintzberg 1979).

\section{Phases of Decision-Making}

"Strategic decisions are not made in a moment with a snap of fingers. They take time, usually quite a lot of time" (Hickson et al. 1986). There is a start-up or identification phase wherein the topic to be decided is recognized as such, a developmental phase wherein the search for relevant information and the development of alternatives takes place, and a finalization or selection phase wherein the choice is narrowed down and selected (Mintzberg 1976; Hickson et al. 1986).

The recognition of a decision topic is the very first 
step in the identification phase. organizational leaders, who are also decision makers in most cases, initiate the decision-making process based on a tentative agreement that a problem exists that needs to be addressed. As a group, the decision makers must agree that this need to respond to the problem and interest inherent in the matter for decision are important issues worth looking into. As individuals, the decision makers may not be the decision initiators, thus they differ greatly toward the matter for decision in terms of attitude, enthusiasm, and response. Those involved in the process, some eager, some indifferent, some reluctant, raise questions and respond to the concern of the decision initiators. Once the decision matter is perceived as significant, a decisionmaking process officially begins.

"Most of the action is thought to be during the central developmental phase which lasts longest and has the most conflict, as information and views are sought and attempts are made to set out alternatives" (Hickson et al. 1986; Mintzberg 1976). It becomes difficult for decision makers or outside researchers to recognize the steps taken in this phase because many things happen randomly. As more information is sought, the original concerns may disappear and new concerns occur. The nature of the original problems and interests takes a different turn and becomes strange to the decision makers. Negotiations and 
bargains are frequent since decision makers are anxious to persuade others to change their minds. Compromises are made to gain preferred outcomes. Depending on the combination of the decision topic, problems and interests, and the individual decision makers and their positions in the organization, there is no foreseeable pattern for this phase. For instance, some revisiting of the same topic may occur when new information is brought in. or new parties may be included because of a need for expertise to address an emerging challenge during the process.

Finally, a decision-making process ends when an outcome is achieved. This phase can be very short, following immediately after the developmental phase. The outcome can be the one expected or a total surprise to decision makers. Since the decision-making process is the focus of this model, the implementation of the decision outcome is not of concern here.

It is important to recognize that these three phases are a rough generalization of organizational decisionmaking processes. In fact, empirical studies do not indicate any "simple sequential relations in what happens" in organizational decision-making. One phase does not lead to another in a logical order, so that processes as a whole do not move steadily onwards phase by phase in an inexorable progression. They jump about. They hop to and fro. They turn back. Fresh information forces a rethink, 
something unforeseen happens which opens up a new alternative, powerful voices close off an otherwise attractive course of action.

An extreme example of such a phenomenon is the "garbage can" phenomenon when the decision-making processes can be best described as "organized anarchies" (Hickson et al. 1986; Cohen, March and Olson 1976; Mintzberg 1976).

\section{Three Modes of Decision-Making}

According to the characteristics of the decisionmaking processes, three modes -- the vortex-sporadic, the tractable-fluid, and the familiar-constricted -- are identified as typical decision-making processes. Scholars believe that decision topics/matters, or the behavior of the decision makers in response to these topic and matters, drive the process down one mode of route rather than another (Hickson et al. 1986). Although many factors contribute to the direction of decision-making processes, decision topics and decision matters are the most important (Mintzberg 1976).

Vortex-sporadic decision-making involves a "weighty controversial matter from which eddies run throughout the higher echelons to suck everyone and everything into swirls of activity" (Hickson et al. 1986). The characteristics of such matters include diversely involved 
parties with serious interests and uneven influences, which contribute to the complex and political dimensions of vortex matters. The decision-making processes dealing with vortex matters are highly likely to be sporadic, that is, characterized by shifting pluralistic interests and conflicts of political power, disagreement about the outcome, and how to achieve a certain outcome.

Frequently, such a decision-making process looks like a garbage can from the outside. "Participants vary in the amount of time and effort that devote to different domains; involvement varies from time to time" (Cohen, March and olson 1972). Decision makers float in and out of the process with unclear goals. Furthermore, the decision makers are faced with choice opportunities that can be illogical and inconsistent at times. Since no one decision maker can attend to everything at once or all the time, "choice opportunities do not come to everyone" (Cohen, March and Olson 1972). Instead, if one comes at the right time, he or she may get the right deal. On the other hand, if one does not come at the right time, he or she may never get any choice opportunities. Usually, vortex-sporadic decision-making processes are highly complex and political.

Tractable-fluid decision-making is more manageable than a vortex-sporadic decision-making process. Tractable decision matters are usually rare with consequences that 
are not too serious. Since the topic is novel, the parties involved are a rare combination of decision makers. The opportunity to set a precedents makes the task easier since there is no tradition to follow. Since it is unlikely that the decision makers will step on someone else's toe and the information is fresh to everyone and so are the evenly distributed influences, a tractable matter is less political than a vortex matter. The decision-making process, under such circumstances, is usually fluid with low degrees of complexity and politicality (Hickson et al. 1986).

"Familiar decisions, the third kind, concern the more recognizable and limited matters. They have neither the seriousness and contending influences of vortex matters, nor the rarity of tractable matters, since sometning much the same has occurred before" (Hickson et al. 1986). Familiar decision matters are characterized by limited consequences, and an absence of external influences. Since the topic is so familiar, the processes are "less political than a vortex decision and the least complex of strategic decisions, a matter that follows a constricted rather than a sporadic or fluid route because it has been dealt with before, and the way in which it will be handled is widely understood and accepted" (Hickson et al. 1986). Usually, the consequences are not of concern of the decision makers. 


\section{Decision-Making and an Ad Hoc Committee}

Decision makers are, by definition, participants of a decision-making process. As individuals, they are responsible for their routine work loads, which may or may not be part of the decision-making process in which they participate. In many cases, organizational decision makers participate in decision-making processes that include both their routine jobs as well as new projects they are obligated to offer their expertise (Mintzberg 1979). Except very few cases where single decision maker is sufficient, decision-making in organizations is a group activity. Such a group, ad hoc committee at best, is found to be quite common in organizational decision-making processes.

An ad hoc committee places several constraints on decision makers. First, an ad hoc committee is temporary. A high school principal may be called in to sit on the review committee for graduation standards for only as long as the process continues. This principal has the obligation to be there for all the activities yet he also has a high school to run. Furthermore, sitting on the committee does not guarantee him all the information necessary to make good decisions about the issues. Second, an ad hoc committee does not have to follow any organizational rules when it conducts its "own" business. 
In many cases, "in this [ad hoc] structure, information and decision process flow flexibly and informally, wherever they must promote innovation. And that means overriding the chain of authority if need to be" (Mintzberg 1979). Finally, an ad hoc committee is not responsible for its behaviors or actions. A decisionmaking process carried out by an ad hoc committee or task force has possibilities of going in many directions, some innovative, some disastrous. As long as the decision outcome is acceptable to the decision makers and the authority that appointed the ad hoc committee, the task is completed. Once the task is completed the ad hoc committee is disbanded.

THE MODEL OF ORGANIZATIONAL DECISION-MAKING The evolution of human history is a direct consequence of organization decision-making, resulting in "all human beings socialized into some socio-cultural organizations" (Linstone 1983). In the social and political arena, "highly technical information is usually, and properly, discounted in favor of social interests and considerations of organizational values involved" (Linstone 1983). The most important criterion in the organizational decision-making is the organizational goals and interests, and decision-making is part of the general organizational behavior. Decision makers in this system 
are guided by organizational goals and their decision behaviors are restricted by organizational procedures. The primary principles of organizational decision-making are the organization's rules. The focus of the organizational decision-making model is the organization.

Focusing on the organization, the organizational model employs concepts such as organizational structure, official positions, organizational procedures, and bounded rationality. These concepts were developed by simon (1956), Allison (1969), Bass (1983) and Linstone (1984). An addition to these, the concept of loose-coupling (Weick 1976), helps to explain the structure of educational organizations which are characterized by loosely-coupled parts. The organizational decision-making is thus examined through the lenses of a synthesis of these organizational theories. Within the structure of the organization, there are two important components that are parallel to each other: the organizational hierarchy and the rules and procedures of the organization. The organizational hierarchy is a combination of the positions and the individuals who occupy these positions. The rules and procedures of the organization are the guidelines produced and reinforced by the individuals who are in these positions. The environment and the interested parties generate organizational interests which are processed through the organizational hierarchy and the 
rules and procedures of the organization. At the same time, the hierarchy, the rules and procedures, and the organizational interests contribute to the politics of the organization. At this point, the organization arrived at the conclusion that a decision is necessary to further address the issue concerned. Therefore a decision process is in motion and then an outcome is produced. The nature of the decision-making process and the outcome is determined by the organizational interests and dictated by the rules and procedures of the organization.

\section{Organizational structure}

Organizational structure plays an important role in the organizational decision-making process. Since the structure of an organization represents the rules, procedures, and power relationships of the daily organizational operation, the nature of this structure must be considered when one examines organizational decision-making.

Educational organizations are characterized by "loosely-coupled" parts, according to many scholars (Weick 1976; Glassman 1973; March and Olson 1975). The concept of "loose-coupling" intends to convey the image that coupled events are responsive, but that each event also preserves its own identity and some evidence of its physical or logical separateness. Thus, in the case of an educational organization, it may be the case that the counselor's office is loosely coupled to the principal's office. The image is that the 
counselor and the principal are somewhat attached, but that each retains some identity and separateness and that their attachment may be circumscribed, infrequent, weak in its mutual effects, unimportant, and/or slow to respond (Weick 1976).

A loosely-coupled system or organization, such as education, has to make decisions in an incremental manner because coordination is not the strongest point of such a system. When the parts of the organizational structure in education are not tightly coupled, departments and schools share very little in common. In other words, a school board member and a teacher live in very different worlds. Each has his or her daily routines. The fact that they both work for the same school district does not necessarily make them connected within this looselycoupled organizational structure.

The concept of "loose-coupling" reveals an important dimension of decision-making in educational organizations. Although a loose-coupled structure has advantages, such as being highly stable, its disadvantages include a lack of coordination to the process of decision-making. For instance, the large number of task-force committees in educational organizations is a result of emerging issues which can not be dealt with in the daily operations.

\section{organizational Rules and Procedures}

$$
\text { organizations, large organizations in particular, }
$$
conduct business as institutions with numerous units, 
subunits, and individuals. To perform complex routines, "coordination requires standard operating procedures: rules according to which things are done" (Allison 1967). Channels of communication are established, standards are set, and individual actions are bound by steps which are logical within the organizational context. Committees, task forces, and teams are common subunits within the organization. These organizations within organizations specify operating procedures for short-term tasks and decision-making.

In addition to the organizational rules, i.e., a school district, a many procedures are established to complete a task, i.e., a review of graduation standards. For instance, a school district usually follows the direction of the school board in terms of the policy issues. Yet when it comes to the daily routine, the superintendent and the deputy-superintendent make the decision. Such a division of labor is one of many standard procedures in education organizations. According to the organizational decision-making model, organizational decision-making is "determined primarily by routines established in these organizations prior to that instance" (Allison 1967). Explicit rules and procedures are such routines that guide the daily organizational activities. At times, organizational procedures function as constraints and restrictions in the process of decision- 
making. For instance, organization rules dictate that the decision makers obey their authorities along the organizational hierarchies.

\section{Organizations and Decision-Making}

organizational decision-making is triggered by

problems that need to be solved to complete an

organizational task. Yet, decision-making is more than

problem solving. To solve a problem or a set of problems, an organization goes through a learning and possibly a changing process which is "influenced by existing organizational capabilities and procedures" (Allison 1967). In other words, because organizational decisionmaking has long term impact on the organization, it is restricted by organizational rules and standards. The goal of organizational decision-making is to achieve what Simon terms as "bounded rationality" (Simon 1956). According to Simon, "the physical and psychological limits of man's capacity as alternative generator, information processor, and problem solver constrain the decisionmaking processes of individuals and organizations" (Allison 1967). To perform complicated tasks, organizations "extract the main features of a problem without capturing all of its complexity" (Allison 1967). "Bounded rationality" is found to be a common phenomenon in organizational decision-making. For instance, 
individual "split up" problems into quasi-independent parts and deal with the parts one by one. To review the graduation standards, the decision makers in this study made incremental steps to tackle the problem. When the problem appeared too big for them to handle, many decision makers choose the most acceptable, although not the best, outcome. As a result, organizational decision-making achieves "satisfying" outcomes rather than "maximizing" ones.

\section{Politics and Decision-Making}

A related problem that contributes to "bounded rationality" is the political nature of organizational leadership. Organizational structures, filled with rules of operations, standards, promotions and rewards, resource distribution, information accounting-control procedures, recruitment and socialization to the norms of the organizations, represent a complex coordination of competing interests, conflicts, and power struggles. In addition to the complex problems to be solved in the decision-making process, the nature of organizational structures and the dynamics of these structures tend to add more dimensions to the decision-making process. As individuals, the decision makers have primary power, which comes from their primary responsibilities. Each decision maker, "in his own right, is a player in a central, 
competitive game" (Allison 1967).

since decision makers differ about what must be done, decision priorities are hot items on the agenda. The nature of today's public education permits fundamental disagreement among reasonable, educated human beings about how to solve many important problems. In general, educational leaders in public education share power without much consensus regarding priorities. Since educational organizations are characterized by rapid changes, the instances of disagreement far exceed those of peaceful agreements in regard to educational issues (Schaffarzick and sykes 1979; Cuban and Boyd 1983; Kirst and wirt 1963). As a group, decision makers are required to come up with a solution acceptable to everyone. This mission, impossible at times, forces decision makers to make sacrifices and compromises on some issues or give in completely on others. Applied to relations between departments and department heads, the organizational model directs attention to intra-departmental games. "The name of the game is Politics [sic]" (Allison 1967). At least two dilemmas must be solved simultaneously in this game: "the problem itself, and a set of viable organizational arrangements, compatible with the problem solution and organizational interrelationships" (Bass 1983). 


\section{The Organizational Environment}

Environment is perceived as one of several constraints on organizational decision-making. A constraint is defined as "a driving force or a restraining force, exogenous to the decision process, which modifies the process. Constraints can curb, check, hold back and narrow the process, but they can also push, facilitate, stimulate, and expand it" (Bass 1983). Although the environment makes a difference to organizational decisionmaking, it is beyond the immediate, complete control of the decision makers. Ironically, the decision makers must estimate the future behavior of the environment since "decisions are future-oriented" (Bass 1983).

A variety of institutions and forces external to public schools limits organizational actions, and controls the outcomes of the organization's decisions. These institutions and forces included the general public, the state/federal authorities, the parents and students, and the business community. For McWhinney, "these differing environments determine what aspects of the environment are to be of concern, what phenomena should be noticed, and what variables should be introduced into the criteria function for the organization's performance" (McWhinney, 1968). It becomes extremely difficult for decision makers to determine these aspects when the organization faces a complex and changing environment. A complex environment 
contains numerous institutions and contributes greatly to decision complexity. But an environment with rapid rate of change "generates more uncertainty than it does environmental complexity" (Bass 1983). For instance, the environment of today's public education is complicated by the increasing social and economic problems which are blamed on the schools. The fast development of technology also puts pressure on educators. 


\section{METHODOLOGY}

The research design of this study consists of several parts, summarized in figure 1. The descriptive part provides a chronicle of events for an accurate understanding of the decision initiation, the role of information, and the interaction of the key players. The product of the descriptive part is an outline of the process phases. Decision episodes were described in detail, highlighting the important events on the calendar. The explanatory part includes three analytical models: the rational choice model, the process model, and the organizational decision-making model. Since the three decision-making models employ different methodology, the data were organized to meet the needs of the specific models.

Model construction is the last part of this research design. In this part, the author outlines the variables of each model, the relationships between these categories and discusses the results of the analysis. The variables are based on the theoretical models and the evidence found in the data. The purposes of the model construction include a) a summary of the descriptive and the analytical 


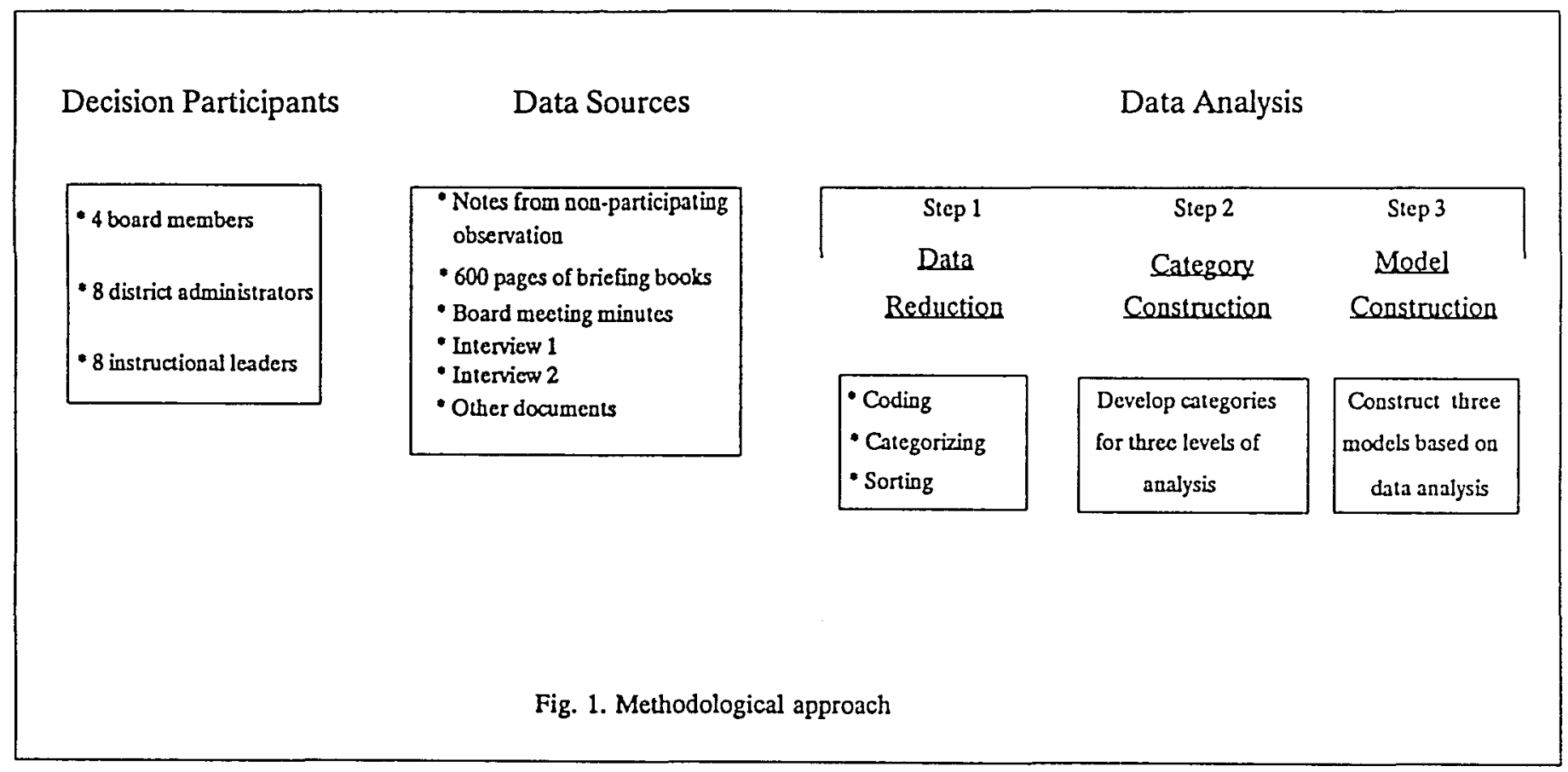


parts, b) an illustration of the major points of each model, and c) a comparison of three models.

The three models of decision-making research approach decision studies from different yet compatible perspectives. In this study, the rational choice model emphasizes choice situations and alternatives, the process model focuses on the process itself, and the organizational model explains the decision-making process in terms of organizational procedures and structures. These diverse theoretical frameworks required a wide variety of data sources and an innovative methodology to provide the evidence needed for each.

Case studies provide the richest and the most accurate information for analysis of decision processes (Hickson et al.1985; Mintzberg et al.1976; Mintzberg et al.1985; March and olson 1984). To capture the essential factors of decision process, a naturalistic inquiry is the best approach to the problem (Yin 1984). Such an inquiry, a departure from the traditional studies in sociology and quantitative analysis in system science, embraced the unfolding process of decision-making process from a holistic point of view (Yin 1984).

\section{DATA SOURCES}

Multiple data sources were used to obtain research findings. The data were generated from school board 
meeting minutes, newspaper files, observation notes, interview findings, and briefing books for the decision process.

\section{Interviews}

Two interviews were conducted to collect information from key players in the decision process. Each interview had different focus, with overlapping questions covering the most important issues, which were revisited in both interviews as a reliability check. The first interview focused on the identification and developmental phases of the decision process, including variables such as organizational and personal interests. Open ended questions in this interview intended to collect information on descriptions of how the decision process was initiated from the perspective of the decision initiators and decision makers. Attention was paid to informal and formal discussions among the decision makers as well as personal comments regarding the decision initiation. Opportunities were provided for additional comments.

Based on the findings of the first interview, the purpose of the second interview was to identify the interested parties involved in the developmental and finalization phases. The open-ended questions targeted on episodes of interruption, conflict and delay in the 
decision-making cycle. To avoid bias, interview questions were worded in neutral terms. For instance, questions concerning conflicts started with "Did you notice any conflicts during decision process?." If yes, "Would you please describe accurately what happened?" This piece, together with the description of the decision process, provided evidence of the interaction between the interested parties during the decision process.

\section{Briefing Books I and II}

The role of information was identified and analyzed through categorizing Briefing Book For Graduation Standards Planning and Briefing Book For Graduation Standards Task Force. Both books, containing about 500 pages of articles, data reports, and state regulations, were prepared by curriculum and assessment departments for the decision-making process. Briefing Book I was prepared so that the decision makers could plan the time line, learn about the decision topic, and outline the steps/phases. The position papers contained opinions and suggestions about high school graduation standards. A few research papers were also included with evidence and concerns regarding issues such as reform-generated standard-setting. Briefing Book II included a timeline, mission 
statement, and anticipated consequences of changes in the graduation standards. The analysis of the briefing books includes tables showing the sources, types, and topics of information provided to the decision makers. This part of the analysis was cross-checked with the description findings of the research to see what information was used or not used in decision process and whether any information was referenced by decision makers. Since the briefing books were prepared by a few decision makers for the others, these books were also analyzed according to "who was who" in preparing them, reflecting the intention of the authors. This analysis also contributed to identify the research categories at all three levels of analysis, which is discussed in detail later in this chapter.

\section{Meeting Minutes}

The minutes of school board and education committee meetings were collected to obtain decision process descriptions. Meeting documents relevant to graduation standards were selected from the publications of the school board meeting minutes. There were approximately 800 pages of board minutes. The topic of high school graduation must be on the meeting agenda for the minutes to be included for analysis. The formal and informal 
discussions were matched with descriptive data of the interviews. The end product of this match was a chronicle of decision process from its beginning to its ending.

\section{Observation Notes}

The author took observation notes as a nonparticipating observer during the decision-making activities proceeded over a time period of three years. The activities observed were those that related to graduation standards, and high school curriculum issues. Some of these activities provided information on graduation standards and some provided information on related issues. Some activities had little to do with high school graduation standards and such information was not included in the analysis.

The observation notes from fifteen decision-related activities were additional data for descriptive as well as explanatory analysis.

\section{INSTRUMENTATION}

The two sequential interviews focused on the perceptions, descriptions, opinions, and attitudes of the interviewees towards the decision process regarding graduation standards. The interview questionnaires were constructed according to the theoretical frameworks of 
this study, which include the rational choice, the process, and the organizational decision-making models. open-ended questions invited in depth answers, leading to an identification of indicators of research categories.

\section{The First Interview}

The first interview (see Appendix) had nine questions and was intended to identify the following dimensions of this research:

1. the stimuli that provoked the initiation

2. the sources of information

3. the organizational interests

4. the personal motivations

5. the personal/professional interests

6. the anticipated consequences of the decision process

7. involved parties in the process

The provoking stimuli to initiate the decision were very important to an understanding of why the decisionmaking process was started. Therefore, two questions were designed to get this piece of information. The first question solicited information on how the decision process was initiated and whether the decision makers were pressured to initiate the process. To identify organizational interests, two questions were asked 
regarding organizational concerns and organizational interests.

Sources of information were identified to examine the role of information in the decision process. At the initiation phase, information could determine the next step of the process. Decision consequences were also identified to seek explanation and indication of why the decision was initiated and the possible outcome of the process.

Other questions on such topics as "personal or professional interests" and "technical concerns" intended to collect information on personal preferences. Since it is unlikely that decision makers initiated the decision process out of personal motivation only, these questions provided supporting information to the research questions. The question regarding to "who should be involved in the process" intended to identify the decision makers and other involved parties.

The second Interview

The second interview (see Appendix) focused on the actual events of the decision process. At the same time, some questions from the first interview were revisited. The interviewees were asked to identify both the organizational interests and how the decision-making 
process started. They were also asked to describe their relationship to other decision makers during the process. Finally, they were asked to reiterate their intended goal of the process.

The second interview had fourteen questions, covering topics such as the process in general, rules of the game, interruptions, delays, and conflicts. Emphasis was placed on the details of the decision episodes. The final question was about the decision outcome and why the decision-making process was terminated. The fourteen questions were intended to identify specifics in the following areas,

1. revisit of the initiation

2. revisit of the organizational and personal

\section{concerns}

3. the involved parties

4. the involvement of the interviewee

5. one interruption, conflict, problem, or event

6. interactions between the decision makers

7. decision outcome

8. the reason why the decision was terminated

The interview instrument was a combination of a general interview guide and standardized open-ended questions. The general interview guide was used so that 
essentially the same information would be obtained from every interviewee by covering the same basic material. It also provided topics or subject areas about which the author was free to explore, probe, and ask questions to elucidate and illuminate a particular subject. The interview guide made it possible to keep the interviews focused and to complete them within a limited time period. The standardized open-ended questions consisted of questions carefully worded and arranged for the purpose of taking all the interviewees through the same sequence of questions with same words. This part of the interview minimized the variation in the questions addressed to the interviewees, reduced the possibility of bias that could occur from posing different questions to different individuals, and addressed the problem of obtaining a lot information from one individual but not others.

\section{Interview Varieties}

Due to different settings and situations of the interviews, the length of interview time varied from 40 minutes to 120 minutes. Some longer interviews were disturbed by telephone calls or routine businesses in the office. At the end of the interview, each interviewee was asked to make comments or ask questions regarding the study. 
Variations existed in the interview answers. Since some terms in the questions were unfamiliar to some interviewees, the author developed a standard answer to explain them. For instance, one variation of question number two in the first interview, "Do you have any organizational interests in this decision process" was "Do you think the review of graduation standards could benefit the school district?" The interviewees who participated in only one or two decision activities did not provide relevant answers to some descriptive questions. Their answers were not included in the data analysis since they did not contribute significantly to what actually happened in the decision process. The first and second interview were three months apart. The interviewees were informed of what the interview was about and how long it would take. They were reminded of the content of the first interview briefly at the beginning of the second interview.

\section{DECISION INITIATORS AND DECISION MAKERS}

In this case, the decision participants were defined as decision initiators and decision makers. By definition, decision initiators were those who proposed to review graduation standards and successfully brought the review to a start. Decision makers included those who took part in the activities of the decision process. Some 
decision initiators were also decision makers, for example, board members who proposed the decision and stayed on throughout the whole process. But not all decision makers were initiators, for example, the school professionals who did not participate in initiating the process.

\section{Core Decision Makers and Decision Makers}

From the analysis of the documentation, the names of the core decision makers were collected and verified with the decision participants. In this case study, "core decision makers" were defined as those whose official position in the school district made them the regular participants of this process, regardless of their personal opinions as to whether or how the process should be carried out. These core decision makers attended most meetings, voiced their opinions, and saw some of their opinions implemented.

Although the participation of the decision makers in the decision-making process varied greatly from attending one meeting to attending all thirty-five meetings over a period of three years, all were contacted by phone for interviews. Of the twenty-three decision makers, three refused to participate in the interview. One of them was a former school board member who claimed that his 
"participation was inappropriate." Another was an area superintendent who called back after receiving the message and said that he had "nothing to say about THAT process" with noticeable accents on the word "that." The third was the deputy-superintendent who claimed his busy schedule "never allowed" him to participate in any research studies.

\section{Board Members}

Four former school board members were identified as decision initiators and three participated in the interviews. One of these three was the first initiator of the decision process since he was the one that put the topic into the "board Goals" of 1988-1989. Another school board member was the chairman of the educational subcommittee when the goal was defined, and the third board member became the chairman of the same committee as the process was carried out. The former board member who refused to participate was actively pushing the process as it became the board goal of the year. Since this board member resigned shortly after the process was started, his input might have provided more insights into how the process was initiated. As to the process itself, it is unlikely that his contribution was critical. 


\section{School Administrators}

Nineteen individuals from the school district, including district administrators, principals, and professionals, were identified as decision makers in the process. of the nineteen, two refused to participate in the process. One was the area superintendent who participated in certain activities relating to the decision process with limited input. Since the data were available from four other area superintendents with similar experience, his contribution would have been minimal. The real loss of data was caused by the refusal of the deputy-superintendent who was an active participant in the decision process. Since he was the number two man in the district, his input would have been significant. He was officially the "inside man of all happenings in the district," according to one of the interviewees. Data collected on his behavior in the decision-making process were mainly from meeting minutes, memos, interviews with other participants and activity observations. Without his personal account of how and why he did what he did, his behavior in this decision process was interpreted from indirect sources. 
TABLE 1

Decision Initiators and Decision Makers

\begin{tabular}{lcc} 
Decision Makers & $\begin{array}{c}\text { Number } \\
\text { Contacted }\end{array}$ & $\begin{array}{l}\text { Number } \\
\text { interviewed }\end{array}$ \\
\hline School board Members & 4 & 3 \\
Area Superintendents & 5 & 4 \\
High School Principals & 3 & 3 \\
Other School & 8 & 8 \\
Administrators & & 18 \\
Total & 20 & \\
\hline
\end{tabular}

The refusal of participants to be interviewed was anticipated and cautions were taken in analyzing the data. For instance, data on the deputy-superintendent were reconstructed by using different sources to find a pattern. Via information from interviews with other participants and through a check on other data pieces, the deputy-superintendent's intentions in the decision process were clearly indicated.

\section{ANALYSIS}

The analysis of this study includes three major procedures, the data reduction procedure, the transformation of the raw data to information and finally 
model construction. This is a process of selecting, sorting, focusing, simplifying, abstracting, and transforming the raw data into manageable and useful information.

Data_Reduction

The first procedure, the data reduction, is a process similar to that of a frequency analysis in statistical procedures. In this process, the raw data in a narrative format were grouped into categories according to theoretical concepts. For instance, the reduction of the interview data was accomplished by sorting the large amount of narratives according to the interviewees first. Then the data were examined by separating the answers which were on target from the answers which were not. The criteria for "answers on target" were based on the theoretical concepts of each model. The "answers not on target" were then selected to develop categories that were not covered by the concepts but were potentially useful to the study.

Table 2 represents an example of the raw data and Table 3 represents the data format after the first reduction process. 
TABLE 2

NARRATIVE OF MR. BRUCE

(Raw Data)

Q: Did you think the district could benefit from the review of the graduation standards?

A: Yes. Well, I think that we needed to look at the courses as they are taught across the district. And some kind of communication amongst the high schools as to what is in those courses, and that somehow I haven't given much thought to it... but some kind of monitoring of the planned course statement implementation, so that planned course statements drive the course, as they should, then the standards ought to come out of those planned course statements. ... I also believe the whole issue was a political one in which the board members wanted to . I have not checked this out -- it is my reading of the situation ... wanted to involve parents in setting some standards, getting some input into the curriculum and standards, it was a political motivation because many folks across the nation believe they -- themselves are not involved enough in schools. ... I think this process will improve our image as being more rigorous. Being more rigorous is always a relative term.

Q: Could you tell me one conflict that occurred during the process?

A: With what the board wanted and what we wanted ... that was the major conflict ... and I think Mr. Copelin ... and I know Mr. Copelin representing the board ... and Mr. Truman and Mr. Davis and I representing the curriculum and assessment. ... We were in conflict because Mr. Copelin, I think, had a personal and public goal, whereas we had a management goal ... and they were not compatible at the time. 
TABLE 3

THE DATA FORMAT AFTER THE FIRST REDUCTION PROCEDURE

Questions

Do you think the review process will benefit the school district? If yes, how?

Can you tell me one conflict/confrontat ion that occurred during the process?
The process could improve the image of the school district but the improvement has to be made in the area of curriculum.

The board members and the district staff members did not share a consensus regarding what to do.

\section{Erom Raw Data to Information}

The next procedure is to transform the large quantity of raw data into useful information for analysis. This process includes sorting the roughly reduced data into more refined format and then grouping the data into research categories to match with the theoretical concepts of the three models. During this process, the data with no relevancy to the study were discarded and the definitions of the categories were developed. At the same time, values were assigned to the categories where appropriate. For instance, values are assigned to the resources each decision maker brought to the decisionmaking process. These values indicate how much influence 
a decision maker carried in the decision-making process. Subsequently, the data were reorganized to check on reliability and validity. For instance, the refined data were organized by interview questions, rather than by interviewees. This is to make sure that the questions were understood accurately by the interviewees and the answers were worded in uniform or close to uniform fashion. Furthermore, the data were checked against the definitions of the research categories to ensure that the answers were valid.

Finally, the hypothetical models were built to guide the drawing of conclusions. These models function as links between the theoretical concepts and the final conclusions. Discussions of the categories and the hypothetical models are provided later in this chapter. Table 3 is an example of the data format after the first reduction procedure.

TABLE 4

CONCEPTUAL CATEGORIES

Categories Description

$\begin{array}{ll}\text { Organizational } & \begin{array}{l}\text { Improve the political standing of } \\ \text { the school district. } \\ \text { Improve curriculum in the high } \\ \text { schools. }\end{array} \\ \text { Conflicts/ } & \text { Disagreement regarding the goal of } \\ \text { Confrontations } & \text { the review process. }\end{array}$


Table 4 shows the subsequent reduction and Table 5 is an example of the final data reduction, through which the categories were developed.

TABLE 5

CATEGORIES OF ANALYSIS

\begin{tabular}{lll} 
Categories & Values & $\begin{array}{l}\text { Levels of } \\
\text { Analysis }\end{array}$ \\
\hline $\begin{array}{l}\text { Organizational } \\
\text { Interests }\end{array}$ & Nominal & Level II \& III \\
$\begin{array}{l}\text { Conflicts/ } \\
\text { Confrontations }\end{array}$ & Nominal & Level I, II \& III
\end{tabular}

The procedure of Model construction

The final process in the analysis is the conclusion drawing. Based on the research categories and the hypothetical models, more analysis is conducted in chapters V, VI, and VII and the models are constructed to draw conclusions. Causal relationships are identified and final conclusions are displayed in formats such as diagrams, tables, charts and figures.

The essence of this process includes a review of the theoretical concepts of each model, the raw data, and the categories. A comparison is constructed to show how these three models can be integrated to better illustrate organizational decision-making. The three levels of 
lenses to look at this case study. In general, the three levels are used in all three models.

The Relationship Between Three Levels and Three Models

The levels and the models of this research have their separate functions. The levels are used to organize the large amount of data collected in various formats. Since the data are not useful in their original bulky formats, steps such as data reduction and data transformation are used to categorize the data into categories according to the three levels discussed earlier in this chapter. These level categories are useful methodological and analytical tools, similar to a path analysis or multiple regression in statistical analysis with quantitative data.

The categories are the product of the data reduction and data transformation procedures. These categories are further organized into levels, which are corresponding to the circumstances of this case study. The criteria to put one variable into one level rather than another are based on the three theoretical concepts of the three models and the relevancy of the data collected. For instance, information concerning the individual decision makers is categorized as level one categories. Information concerning the organization interests is grouped as level three categories.

The models are the product of the final data 
analysis. Based on the theoretical concepts of this research, the models are built as the final products from which the conclusions are developed. These models use level categories when they are applied. The levels provide a convenient way to build these models. Although the level categories are products of the first steps of the data analysis, they serve as tools and materials for the model construction. While the relationship of the level categories remains hypothetical, the models are based on the data analysis which are discussed in chapters $V, V I$, and VII.

\section{RESEARCH CATEGORIES}

Unlike quantitative studies, causal relationships in qualitative studies are not proved by numerical evidences. Rather, quotes and observations are indicators of why certain things happen in a certain way. Conceptual categories were developed according to the theoretical framework of this study. These conceptual categories functioned as tools/vehicles to analyze the large quantity of information collected. In each model, these categories function as indicators to findings. Some categories are used for all three models, and some are used for one model or two models only. 
Definition of the Research Categories

Research categories are important tools for analyzing and explaining behaviors of decision makers, the episodes in the decision-making process, and the characteristics of the organizational context. These categories help identify the decision-making details which were characteristic of the decision makers. Categories such as "personal influence" have implicit values therefore they are coded as "very strong influence" or "no influence." other categories such as "decision topic" are coded as normative data.

Table 6 shows the categories, their values and their level of analysis in this study. Nine categories are used for Level I analysis, nine are used for Level II, and eleven are used for Level III. Ten categories are used for only one level, eight are used for two levels and three categories are used for all three levels of analysis.

Briefly, the categories are defined as the following: 1. Official position: This was the official title of the decision maker in the school district. This variable was important since such positions identified the standing of the players in the decision-making process.

2. Personal influence: This was the effectiveness of the decision makers in making things happen during the process. Indicators of personal influence included 
TABLE 6

CATEGORIES AND THE LEVELS OF ANALYSIS

\begin{tabular}{|c|c|c|}
\hline Categories & Values & $\begin{array}{l}\text { Levels of } \\
\text { Analysis }\end{array}$ \\
\hline 1. Official Position & Nominal & Level I \& III \\
\hline 2. Personal influence & $\begin{array}{l}\text { Very strong } \\
\text { influence ... No } \\
\text { Influence }\end{array}$ & Level I \& III \\
\hline 3. Personal Interests & Nominal & Level I \\
\hline 4. Decision motives & Nominal & Level I \\
\hline 5. Decision topic & Nominal & $\begin{array}{l}\text { Level II \& } \\
\text { III }\end{array}$ \\
\hline 6. Decision interests & Nominal & $\begin{array}{l}\text { Level II \& } \\
\text { III }\end{array}$ \\
\hline 7. Decision problem & Nominal & Level II \\
\hline 8. Information & Nominal & Level I \& III \\
\hline $\begin{array}{l}\text { 9. Interruptions \& } \\
\text { delays }\end{array}$ & Nominal & Level II \\
\hline $\begin{array}{l}\text { 10. Conflicts \& } \\
\text { confrontations }\end{array}$ & Nominal & $\begin{array}{l}\text { Level I, II \& } \\
\text { III }\end{array}$ \\
\hline 11. Decision outcome & Nominal & $\begin{array}{l}\text { Level I, II \& } \\
\text { III }\end{array}$ \\
\hline $\begin{array}{l}\text { 12. Organizational } \\
\text { context }\end{array}$ & $\mathrm{NA}$ & $\begin{array}{l}\text { Level I, II \& } \\
\text { III }\end{array}$ \\
\hline $\begin{array}{l}\text { 13. Organizational } \\
\text { rules and } \\
\text { procedures }\end{array}$ & Nominal & Level III \\
\hline $\begin{array}{l}\text { 14. Organizational } \\
\text { interests }\end{array}$ & Nominal & $\begin{array}{l}\text { Level II \& } \\
\text { III }\end{array}$ \\
\hline $\begin{array}{l}\text { 15. Decision } \\
\text { environment }\end{array}$ & $\mathrm{NA}$ & Level II \\
\hline
\end{tabular}


intentional persuasion or strong resistance.

3. Personal interests: This was defined as the benefits a decision maker would obtain during the process. This variable explained a decision maker's goals to initiate certain moves in the decision-making process.

4. Decision motives: These were reasons and intentions why certain decisions makers made certain moves in the process, indicated by quotations, interview statement and speeches at meetings. Decision motives do not necessarily produce decision outcomes.

5. Decision topic: This was defined as the subject matter of the process. The decision topic in this case study was "a review of high school graduation standards." The decision topic generated topic related interests and problems. The interests in this topic caused the decision process to start.

6. Decision interests: These were benefits attached to the immediate circumstances in the decision process. Decision interests can be different from organizational interests and personal interests.

7. Decision problems: These were obstacles and barriers to reach a decision, generated by decision topic, these problems must be solved before the decision makers considered alternatives of the decision choices.

8. Information: This included necessary ingredients for decision makers in the decision process. Information 
can be collected through formal channels and informal channels.

9. Interruptions and delays: These were events which slowed down the decision process to some extent. These can be caused by the organizational routines, new information, other contextual issues related to the decision topic, or event that disturbed the decision process. These could also be caused by the organizational context, decision topic, external influences and rules of game.

10. Conflicts and confrontations: These were obvious disagreement and explicit argument, caused by decision topic, conflict of interest, mis-communication, or differing perceptions.

11. Decision outcome: This was the result of the decision-making process. Decision outcomes were determined by the decision topic, the combination of the decision makers, unexpected incidents and other factors.

12. Organizational context: This was the organizational context within which the decision process took place. This is defined as the general function, basic structure, and operational goals of the organization. These functions, structures, and goals have impacts on the decision-making process.

13. Organizational rules and procedures: These were defined as written or unwritten norms regulating 
information channel, decision channels, and divisions of labor in the decision-making process. They shaped how the decision process was carried out.

14. Organizational interests: These were the benefits brought to the organization by the decision-making process for the long-term or the short-term. These were different from the decision interests in as much as organizational interests could be achieved through the decision-making process or decision-making outcome. Such interests were beyond the scope of the decision-making process and were not within the scope of the task ahead of these decision makers.

15. Decision environment: This included the relevant forces external to the school district and the decision makers, represented by interest groups, state authorities, and other organizations. 
CHAPTER IV

THE PROCESS: A CHRONICLE

From the time when Mr. Carter raised the issue of graduation standards to the time when the review was put "on hold," the process to review the graduation standards lasted for three years. During this process, numerous meetings and activities were held and many people were involved.

This chapter describes a chronicle of the decisionmaking process regarding the review of graduation standards at Roseville School District. This chronicle consists of meetings, memos, and activities.

This chapter also provides a detailed description of the decision participants and the interested parties of this decision-making process. The decision participants were those who attended activities during the three year period of the review process.

other parts of this chapter include a description of the initiation stage, the developmental stage and the finalization stage. The description of these phases includes a detailed description of important highlights of the decision-making episodes. 
THE BACKGROUND OF THIS CASE STUDY

Many events happened while the decision makers went through the review process. This section discusses the background events that existed during the decision-making process. These events are included in this study according to the following criteria: a) they were somehow related to the school district, b) they had some impact on the life of the decision makers, and c) they provided the context for the review of the graduation standards. Although some of these events did not have direct bearings on the review process, their presence during the three years of the review made a difference in the review process one way or the other. In general, these events form a background picture that cannot be ignored for this study.

\section{High School Graduation Reguirements}

High school students at Roseville must complete twenty-one credits to graduate, according to the state requirements. In addition, the Roseville school District required students to complete one more credit and pass the high school graduation standards, a test score of 212 in reading and 222 in mathematics. So, the high school graduation requirements at Roseville included the completion of twenty-two credits and the passing of high school graduation standards. Roseville School District issued standard diplomas to students who fulfilled the 
requirements and modified diplomas to special education students who were exempted from the regular requirements. In 1980, Roseville School District developed its first graduation standards which defined the passing points at ninth-grade achievement level for reading, language usage and computation. The multiple-choice exams were "correlated to ninth-grade norms for the California Test of Basic Skills, a nationally standardized test" (Collins 1980). The acting superintendent at the time, Mr. James, declared that he was optimistic "to guarantee that our graduates are functioning at a high school level" (Collins 1980). "The gentleman's 'C' syndrome -advancing students without adequate evaluation," would be corrected by a "heightened level of expectation systemwide" (Collins 1980). The school district was among the very few school districts of the state that insured a test of the high school graduates.

\section{The current situation of Graduation Standards}

Mr. Truman, a district administrator in charge of assessment, was aware that the board's intention for the review process was to examine the norming of the graduation cut points and possibly raise it. After examining the data in the past ten years, Truman's department found out that the original cut points of graduation standards were no longer adequate to measure 
the achievement of the students. Instead, many students of fifth and sixth grades passed the reading and math cut points.

Mr. Truman held a meeting with his staff in April of 1989. At the meeting, Truman discussed the new board goals for the 1989-90 school year and emphasized the review of graduation standards. He pointed out that at least fifty percent of the fifth graders passed the high school graduation reading cut point and at least fifty percent of the sixth graders passed the graduation mathematics cut point in the 1989-90 school year. He also pointed out that although "we as educators do a good job of improving students achievement score in this district, this kind of score does not sound very good to the general public." But, he went on, "this is minimum competency score; we should let people know that it is minimum standards." Truman shared his information at a board educational committee meeting, at which Mr. Carter and a few other board members were present. Although the percent of students passing the current graduation standards was increasing, the board members were very concerned that $t \in n$ percent high school seniors failed to pass the standards.

The Decision Participants

The decision-making process involved district administrators of all levels: the superintendent, the 
deputy-superintendent, the area superintendents, school board members, some high school principals, and directors in the central office. In addition, a few external parties were interested in the issue and became uninvited "organizations-in-contact" (Hickson 1986). The participation in the decision-making was part of district staff members's administrative duties.

Twenty individuals were identified as the participants of the decision-making process (Table 7). These participants were present at one or more decision activities throughout the three-year period. of the twenty participants, four board members were decision initiators as well as decision makers; seven district administrators, five area superintendents, and three high school principals were decision makers. The head of the Teacher's Union invited himself to a few meetings during the process. He was not considered as a decision maker since his input was minimal.

Eleven decision makers were identified as core decision makers since these eleven individuals were present at most meetings and activities. The organizational chart (see Figure 2) indicates an overall picture of the hierarchy of the district. The areasuperintendents reported to the deputy superintendent and other administrators reported to the superintendent. The superintendent reported to the school board. The nature 
TABLE 7

THE DECISION PARTICIPANTS

\begin{tabular}{|c|c|c|c|}
\hline Name & official Position & $\begin{array}{l}\text { Decision } \\
\text { Initiator }\end{array}$ & $\begin{array}{l}\text { Core Decision } \\
\text { Maker }\end{array}$ \\
\hline Mr. Carter & Board Member & Yes & Yes \\
\hline Mr. Copelin & Board Member & Yes & Yes \\
\hline Mr. Kennedy & Board Member & Yes & Yes \\
\hline Mr. Smith & Board Member & Yeg & No \\
\hline Mr. Jefferson & Superintendent & No & Yes \\
\hline Mr. Madison & $\begin{array}{l}\text { Deputy } \\
\text { Superintendent }\end{array}$ & No & Yes \\
\hline Mr. Truman & $\begin{array}{l}\text { Director of } \\
\text { Assessment }\end{array}$ & No & Yes \\
\hline Mr. Poorman & $\begin{array}{l}\text { Director of } \\
\text { Curriculum }\end{array}$ & No & Yes \\
\hline Mr. Monroe & $\begin{array}{l}\text { Director of Special } \\
\text { Instruction }\end{array}$ & No & No \\
\hline Mr. Jackson & Head of the Union & No & No \\
\hline Mr. Davis & $\begin{array}{l}\text { Assessment } \\
\text { Specialist }\end{array}$ & No & Yes \\
\hline Mr. Bruce & $\begin{array}{l}\text { Assistant Director } \\
\text { of Curriculum }\end{array}$ & No & Yes \\
\hline Mr. Lee & Area Superintendent & No & Yes \\
\hline Mr. Larry & Area Superintendent & No & No \\
\hline Mr. Taft & Area Superintendent & No & No \\
\hline Mr. Hoover & Area Superintendent & No & No \\
\hline Mr. Harrison & Area Superintendent & No & No \\
\hline Mr. Adams & $\begin{array}{l}\text { High School } \\
\text { Principal }\end{array}$ & No & Yes \\
\hline Mr. Roosevelt & $\begin{array}{l}\text { High School } \\
\text { Principal }\end{array}$ & No & No \\
\hline Mr. Harding & $\begin{array}{l}\text { High School } \\
\text { Principal }\end{array}$ & No & No \\
\hline
\end{tabular}




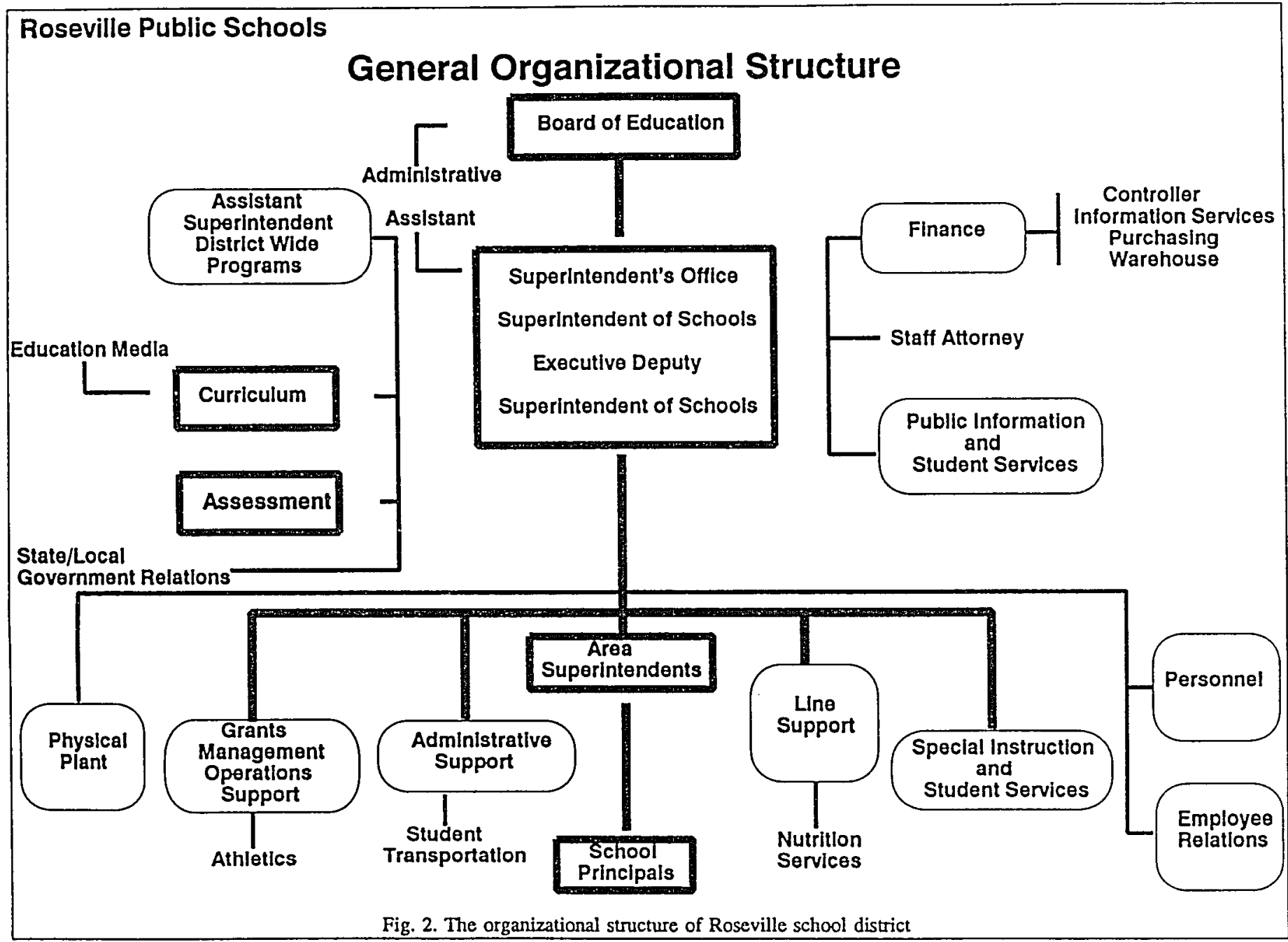


of the decision topic invited many players with diverse interests to the process. This chart reflects the daily routines which were scheduled through different supervisory offices, where authority was clearly defined concerning the one who received the order. At the same time, this chart shows the positions of the decision makers.

The Core Decision Makers

The "core group" of decision makers was assigned to review the graduation standards. As the most devoted and committed to the decision process, this "core group" more or less decided on many issues through their interactions with other decision makers, who were peripheral to the decision issues.

of the eleven participants in the "core group," five parties of interests can be identified. Mr. Truman and Mr. Davis represented the assessment experts. Mr. Poorman and Mr. Bruce represented the curriculum specialty. Mr. Copelin, Mr. Carter, and Mr. Kennedy were on behalf of the school board, or the "general public," in their words. Mr.Lee and Mr.Adams were representatives from instruction. Mr. Jefferson, the superintendent and Mr. Madison, the deputy superintendent, were also part of the core decision makers. It was a structurally balanced committee. However, the members of this group did not carry 
equal weight in the decision-making. First, Truman's department prepared three information packages for the decision process. The content of the information packages was based more on the needs of assessment than curriculum and instruction. Since the review of graduation standards was basically a standard-setting process, it was a logical division of labor. Although the areas of competence belonged to curriculum domain, they were assessment issues as well. In general, information in this decision process was based on and driven by assessment needs. Truman's department carried more weight in this process because Truman and his department was relatively stable throughout the whole process, while Mr. Poorman and Mr. Bruce were both new to their positions. Mr. Poorman continued the assignment as he was promoted from assistant director to director of Curriculum Department. Mr. Bruce, who was a vice high school principal before, was assigned the assistant director of the Curriculum Department and assumed the responsibility to work on the graduation standards. Without the experience of the initiation stage, Mr. Poorman and Mr. Bruce were at a disadvantage. They relied on Mr. Truman and Mr. Davis for expertise and information.

$\mathrm{Mr}$. Lee and $\mathrm{Mr}$. Adams were involved in the process on and off. As instructional leaders, they both had tremendous responsibility in their own office. Mr. Lee, 
who was one of the few area superintendents who had a very good understanding of assessment issues, was in charge of a big area in the district where most students came from affluent families. Although he did not have problems typical of low socioeconomic areas, he was challenged by affluent parents who demanded more accountability from public education. Mr. Adams, on the other hand, was the leader of an inner city high school where forty percent of the students came from minority and non-English speaking families. Youth gang problems and racial tensions were common in his school. Due to their major responsibilities, both $\mathrm{Mr}$. Lee and $\mathrm{Mr}$.Adams attended only meetings regarding graduation standards review. The fact that they were there did not assure that they were equal participants in the decision-making process although they were members of the "core group."

Mr. Copelin was an important participant of the core group. He was an attorney by profession and was the chair of the sub-committee. His involvement as a core group member was limited to meetings and phone calls. Yet his commitment to the review process made him an important voice on the committee. For most of the time, his suggestions and opinions were respected by the committee and accepted eventually.

Mr. Carter and Mr. Kennedy participated in the review process most of the time, carrying less weight than Mr. 
Copelin did. Mr. Carter later focused his attention on parental involvement issues and Mr. Kennedy had lots of learning to do since he was new to the school board. Although Mr. Kennedy went to many meetings, he did not offer much because he was "learning the trade."

Mr. Jefferson and Mr. Madison were not involved as much since both of them had the major responsibilities of the school district daily business. Instead, they attended meetings when they were needed. For instance, when Mr. Truman and Mr. Copelin had a confrontation over Truman's plan earlier in the decision process, both Mr. Jefferson and Mr. Madison were present. Facing the confrontation, both defended Mr. Truman, pointing out to the board members that the review process was not identified as a priority.

\section{other Interested Parties}

Several "uninvited" participants, such as the President of the Teachers' Union, appeared in the review of graduation standards decision process. As Figure 3 indicates, another of these organizations-in-contact was the Leaders' Round Table, an organization of local business leaders, city government leaders, and other community leaders. This organization proposed to "identify the competencies needed for employability, recommended how to demonstrate their attainment and 
우

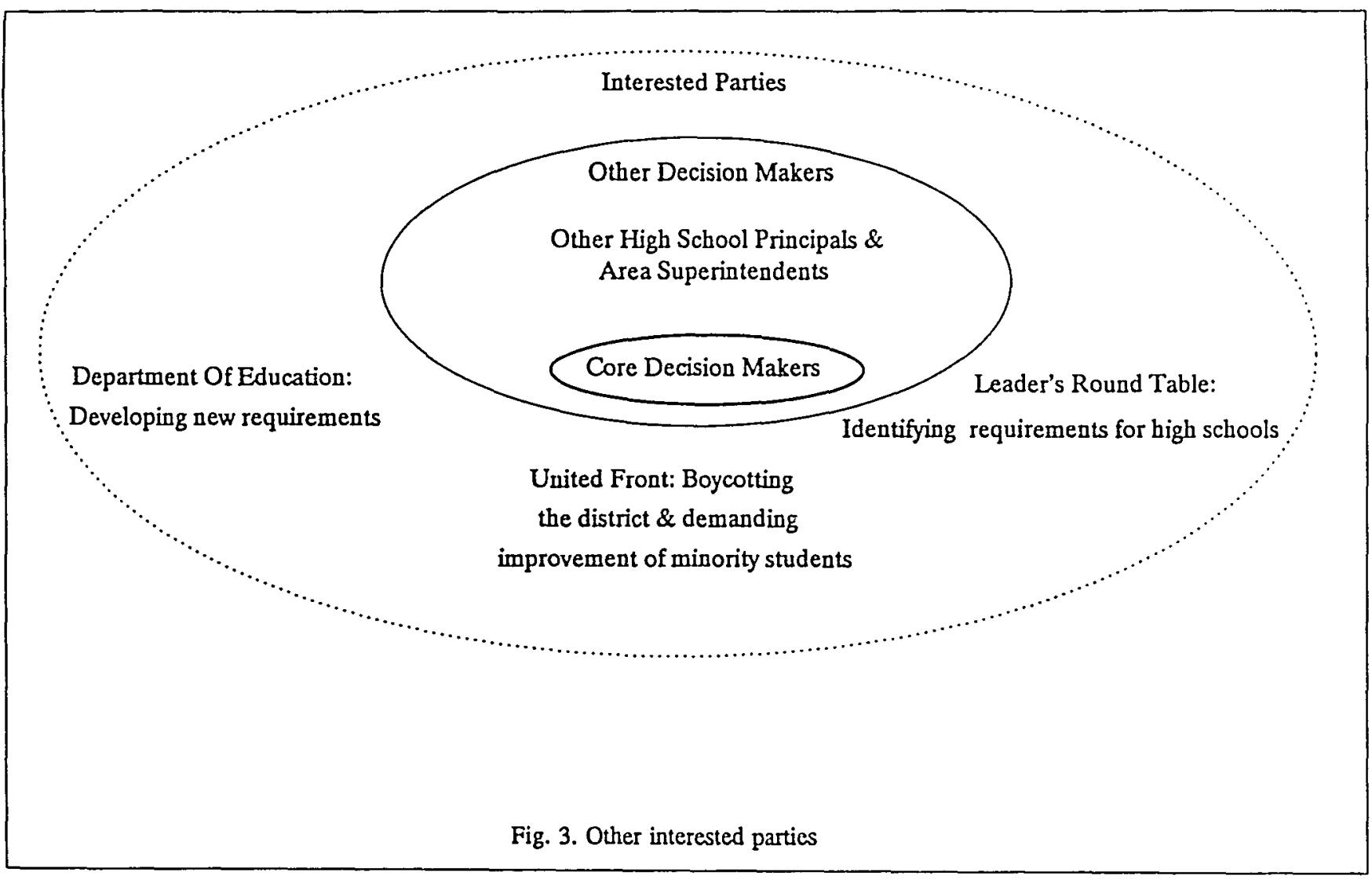


ensured that these competencies were required for graduation" of high school students. The committee decided to a) "compile national and local findings on the competencies most needed by employers and ways to measure their attainment"; b) to "support the recommendations from the National Commission on the skills of the American Work Force for educational performance standards and certificate of mastery as requirements for high school completion"; and c) to "present findings with school boards," beginning with the school district. Two important people from the district were on this committee: Mr. Jefferson, the superintendent and Mr. Copelin, the school board member. Another important person relevant to the review of graduation standards on this committee was Ms. Karr, the senator who proposed the new state requirements for high school graduates. The Leader's Round Table took it as their own task to develop a policy like document for the local schools to follow. Their criteria were to fulfill the requirements of "employability of high school graduates."

In January of 1991, Roseville United Front, an ethnic organization, became dissatisfied with the school district after the test scores were published. The school district "did not work hard enough for its ethnic minorities," accused the Roseville United Front. The gap between the Ininority students and the white students was widening. 
That was not acceptable by Roseville United Front. The school district was asked to respond to the demand of the United front within the next month. Specifically, the United Front asked the school district to make out a plan to narrow the gap between the minorities and the white students. If the school district failed to do so, Roseville United Front was to organize a boycott sometime in February against the school district.

The warning of the coming boycott added more pressure to the school administrators and the review process. The school board and the superintendent started talking to the United Front and attempted to prevent the boycott from happening. Yet their efforts failed since their explanations of the widening gap between the majority and the minority students were not accepted by the ethnic organization.

On February 12,1991, Roseville United Front organized the boycott against the school district. A Special Task Force was constituted to work out the differences between the two sides afterwards. By the end of February, the Special Task Force announced its "widened mission discussion" results. Among the "widened missions," to "raise the high school graduation standards" was a goal that the school district was asked to achieve. At the meantime, the state legislatures were in the process of discussing House Bill 2000 which intended to 
redesign $\mathrm{K}$ through 12 education in the state. The major component of this bill was a reform of the high school education. According to the House Bill 2000, students would get a Certificate of Initial Mastery by 10th grade and a Certificate of Advanced Mastery by 12 th grade. The purpose of the Certificate of Initial Mastery was to help students choose the direction of their last two years of high school. They could either choose to go to a fouryear college or to get some vocational training. House Bill 2000 was being developed as the school district was preparing a review of graduation standards.

Although the impact of this bill on the local school district was not clear, decision makers in the review of graduation standards reacted very differently. Mr. Truman, aware of the changes in the bigger reform picture, warned the school board of the coming activities of the state. He felt strongly that he couldn't quite see the "rationale for our jumping out ahead" when a new high school graduation requirement was being developed by the state. Yet Mr. Copelin did not agree with Truman. To Mr. Copelin, the state might develop something new, but the school district always enjoyed local control over important issues such as graduation standards. Mr. Copelin was reluctant to recognize the fact that the state would eventually gain increasing control of the local districts. The school boards, as the major players of the local 
school district politics, would have to give up some of their control.

\section{Relevant Events}

In November of 1989 , the voters passed a tax limit on the property tax in support of local school district. As a result, the state became the sole source of financial control for $\mathrm{K}$ through 12 education. The local control, represented by the school board, was being challenged. In addition, the school district no longer enjoyed the generous financial support of the local tax payers. However, the impact of such a measure was not immediately felt.

Truman shared the assessment information regarding the current development in education assessment with the decision makers. The state Department of Education was launching its new statewide assessment which would test "all students in the state in grades $3,5,8$, and 11 in the Essential Learning Skills of Reading, Mathematics, Writing, study Skills, and Listening skills." A complementary part of this statewide Assessment was the state's effort to define "a basic education." In addition, there was "considerable activity in the state and in the city region aimed at developing an operational definition of 'literacy' and identifying and developing tests and other indicators of the minimum levels required 
for productive employment." Both activities would have some impacts on how the district defines its new performance standards at all grade levels.

There were other trends nationally and internationally that needed to be watched closely. Mr. Truman believed that one of the new trends, which suggested "senior projects" as part of education assessment system, had significant impact on secondary education. If that was to become the way to conduct education assessment, the current graduation standards needed to be reviewed in a different light. Since the current graduation standards measured only two subjects, they were too narrow against today's standards.

Based on the information, Mr. Truman reminded the decision makers that "whatever new graduation standards we set need to be 'minimum' standards only for students to receive a standard diploma, or whether we can set standards in a way that calls forth the best effort in us all, including students of whatever ability levels and backgrounds, while presenting a harmful and disconcerting barrier to no one." He proposed three types of diplomas for the minimum standards: Basic Diploma for those that passed the state and district requirements; Proficiency Diploma for those who passed above the state and District requirements as indicated by proficient performance; and Honors Diploma awarded to those who passed above the state 
and District requirements as indicated by superlative performance.

\section{A Chronicle of the Reyiew Process}

This chronicle was a sequence of events during the decision process in a calendar format. column one indicated the chronicle stage of the happenings. "IS" means "Initiation Phase," "DS" means "Developmental Phase" and "FS" means "Finalization Phase."

The events were a simple description of every decision-making activity that occurred during a period of three years. Important episodes were described later in detail.

\section{INITIATION STAGE}

The initiation stage was the starting point of the decision-making process. It included the birth of an idea to review the graduation standards to the point when the idea became a formally written board goal. This period lasted from September 1988 to September 1989.

The general rule that governed the policy-making process in Roseville school district was the domination by an active school board and the submission of the superintendent to the board. The school board members "establish guidelines and regulations concerning 
TABLE 8

A CHRONICLE OF THE REVIEW PROCESS

Stage Time Line Decision Activities

\begin{tabular}{|c|c|c|}
\hline IS * & $\begin{array}{l}\text { September } \\
1988\end{array}$ & $\begin{array}{l}\text { Mr. Carter proposed to put "review } \\
\text { of high school graduation standards" } \\
\text { in the board planning book. }\end{array}$ \\
\hline IS & $\begin{array}{l}\text { January } \\
1989\end{array}$ & $\begin{array}{l}\text { Mr. Carter raised the topic of high } \\
\text { school graduation standards at the } \\
\text { board meeting. }\end{array}$ \\
\hline Is & $\begin{array}{l}\text { February } \\
1989\end{array}$ & $\begin{array}{l}\text { School board of Education voted on } \\
\text { the issue: six members voted "Yes" } \\
\text { and two voted to have "further } \\
\text { discussion." }\end{array}$ \\
\hline IS & $\begin{array}{l}\text { March } \\
1989\end{array}$ & $\begin{array}{l}\text { "Review of high school graduation } \\
\text { standards" was written as a short } \\
\text { term goal of } 1989-90 \text { school year. }\end{array}$ \\
\hline DS * & $\begin{array}{l}\text { April } \\
1989\end{array}$ & $\begin{array}{l}\text { Mr. Truman and his staff examined } \\
\text { the longitudinal data of high school } \\
\text { graduation standards. }\end{array}$ \\
\hline DS & May 1989 & $\begin{array}{l}\text { Mr. Truman brought the review of } \\
\text { graduation standards to Mr. } \\
\text { Washington's curriculum-assessment } \\
\text { meeting. }\end{array}$ \\
\hline DS & May 1989 & $\begin{array}{l}\text { Mr. Truman and his staff began } \\
\text { collecting information on graduation } \\
\text { standards to compose "Briefing Book } \\
\text { I." }\end{array}$ \\
\hline DS & $\begin{array}{l}\text { September } \\
1989\end{array}$ & $\begin{array}{l}\text { Mr. Truman's department produced a } \\
\text { report on recent trends of students } \\
\text { progress towards high school } \\
\text { graduation standards. }\end{array}$ \\
\hline DS & $\begin{array}{l}\text { September } \\
1989\end{array}$ & $\begin{array}{l}\text { Mr. Truman's department examined the } \\
1989-90 \text { data with the question "if } \\
\text { high school graduation standards are } \\
\text { raised." }\end{array}$ \\
\hline DS & $\begin{array}{l}\text { October } \\
1989\end{array}$ & $\begin{array}{l}\text { School board of Education discussed } \\
\text { the board Goal of the } 1990-91 \text { school } \\
\text { year. The measurement of "student } \\
\text { progress" was discussed. }\end{array}$ \\
\hline
\end{tabular}


TABLE 8

A CHRONICLE OF THE REVIEW PROCESS (continued)

\begin{tabular}{|c|c|c|}
\hline DS & $\begin{array}{l}\text { November } \\
1989\end{array}$ & $\begin{array}{l}\text { Voters passed a tax limit on the } \\
\text { financial support to the local } \\
\text { schools. }\end{array}$ \\
\hline DS & $\begin{array}{l}\text { January } \\
1990\end{array}$ & $\begin{array}{l}\text { Mr. Truman started to develop a draft } \\
\text { "plan for revision of graduation } \\
\text { standards." }\end{array}$ \\
\hline DS & $\begin{array}{l}\text { April } \\
1990\end{array}$ & $\begin{array}{l}\text { Mr. Truman provided discussion } \\
\text { questions for the Education } \\
\text { Committee's meeting regarding } \\
\text { graduation standards. }\end{array}$ \\
\hline DS & $\begin{array}{l}\text { September } \\
1990\end{array}$ & $\begin{array}{l}\text { Mr. Truman presented his draft plan to } \\
\text { the school board of education } \\
\text { committee. }\end{array}$ \\
\hline DS & $\begin{array}{l}\text { September } \\
1990\end{array}$ & $\begin{array}{l}\text { Mr. Poorman was assigned the task to } \\
\text { lead the review of graduation } \\
\text { standards. }\end{array}$ \\
\hline DS & $\begin{array}{l}\text { October } \\
1990\end{array}$ & $\begin{array}{l}\text { School board of Education discussed } \\
\text { Truman's plan. }\end{array}$ \\
\hline DS & $\begin{array}{l}\text { October } \\
1990\end{array}$ & $\begin{array}{l}\text { Mr. Copelin invited the high school } \\
\text { principals to discuss the graduation } \\
\text { standards and rate the highs schools. }\end{array}$ \\
\hline DS & $\begin{array}{l}\text { October } \\
1990\end{array}$ & $\begin{array}{l}\text { Mr. Poorman discussed the review the } \\
\text { graduation standards with high school } \\
\text { principals. }\end{array}$ \\
\hline DS & $\begin{array}{l}\text { November } \\
1990\end{array}$ & $\begin{array}{l}\text { A committee was set up to examine the } \\
\text { graduation standards. }\end{array}$ \\
\hline DS & $\begin{array}{l}\text { November } \\
1990\end{array}$ & $\begin{array}{l}\text { Mr. Poorman requested clarification } \\
\text { regarding graduation standards. }\end{array}$ \\
\hline DS & $\begin{array}{l}\text { January } \\
1991\end{array}$ & $\begin{array}{l}\text { Roseville United Front boycott against } \\
\text { the school district: educational gap } \\
\text { between minority and majority } \\
\text { students. }\end{array}$ \\
\hline
\end{tabular}


business. One high school principal said,

The board had a lot of influence to initiate the process. I see the superintendent as an agent to the board, and he has fairly good relationship with the board. There are too many board goals, so by having so many board goals, most line administrators and principals included, say I cannot meet all of those. They are too overwhelming. If they really take the graduation standards seriously, other than a political process, and put some resources in the schools to reach those graduation standards, we would have an impact. The review was trendy. That's what the school boards do.

The organizational structure of Roseville School

District reflected the dominance of the school board. The board oversaw the district operation closely by defining board goals every year and having reports written to check on those goals.

In October of $1988, \mathrm{Mr}$. Carter raised the issue of the graduation standards for the first time at a board planning session. The planning sessions were among the most important activities that the school board conducted during the year. When the board decided on the important goals of the year, these goals were written in the district planning book for the school administrators to follow.

School administrators were usually invited to these planning sessions, as listeners rather than participants. The settings of such planning sessions put the school board members in the dominant position and the school administrators as subordinates. The school board members 
discussed the goals and issues among themselves without inviting any opinions or comments from the school administrators. Since there were six to eight board members at one time, and each of them had their own goals, the number of goals for each school year could amount to fj.fteen major goals and numerous sub-goals. School administrators were required to report to the board regarding the progress and the status of the goals at the end of the school year.

Goals such as "a review of graduation standards" was part of a general goal that stated "increase the percent of students reaching the graduation standards." Many goals in the District Goal Book appeared from year to year since they covered the general mission of the school district. Also, since the specifics of these goals were not clear, they were not easily implemented. Without a step to step procedure to achieve the goals, they became annual board procedures rather than anything substantial. Once a goal was created by individual board members, a continuous discussion would go on among the board members until the goal became a formal board goal.

The characteristics of the school board goals raised many questions in district administrators' mind. one challenging issue for the administrators was to implement the board goals, regardless of their personal preferences or opinions. 
Mr. Carter's Proposal

In January of 1989, the topic of graduation standards was raised again at a board meeting. The purpose was to "apply graduation standards" to high school graduates. In February, when the board met again to discuss "educational effectiveness," eight board members voted on the goal to "review graduation standards." six board members voted "yes" and two voted "for further discussion." For the six board members who voted "yes," the explanation was that "our achievement test levels were normed in 1980, and no master standards now are in the process of being normed" (Board Goals, 1989). By March of 1989, a goal to "review graduation standards" was formally written as a short term goal for the 1989-90 school year.

Mr. Carter pointed out that "we do not really have a good sense of what our students were knowing, and what we wanted them to know." He "felt that it was high time that we clarify that." Out of this concern, he wrote a long memo to the superintendent after a visit to all the high schools in Roseville. In his memo, he expressed his concern that we did not "have a good handle on some of the issues" and "we were missing a lot of kids." Since "not much came out of that memo and there were no real changes that occurred," he decided "to turn up the heat and make it a little more concrete and a little more directed." He also felt a "definite" support he might get from other 
board members. Mr. Copelin was one of them.

The target year to achieve the goal was not specified, although all the goals set up in 1988-89 were supposed to aim at the 1989-1990 school year.

The exact wording of this goal was to "review the levels of graduation standards and re-norm our achievement tests." The achievement tests mentioned here referred to a testing system developed by the district locally in the past fifteen years. The test was administered twice every school year during both fall and spring term to students of grade three to eight.

\section{DEVELOPMENTAL STAGE}

The developmental stage started after the goal to review graduation standards was officially written in the board goal book. This stage included the most activities in the decision-making process and lasted from April 1989 to April 1991.

\section{Information}

Information is an important tool for decision makers to assess the impeding situation and make a judgement. In other words, information is "anything that alters subjective (or objective) probabilities or utilities" (Driver and streufert 1968), which include the amount of uncertainty and certainty, new knowledge, and new assignment of resources. Information makes new 
expectations available to the decision makers and it can also alter the previous understanding of certain issues. Information played an important role in the review process of graduation standards. Being very acute of assessment issues, Truman assigned Mr. Davis to collect information on a full time basis. Briefing Book I became the first one for this decision process, followed by Briefing Book II. Book I had articles, position papers, research data and documents of 50 states high school graduation requirements and standards.

As Truman pointed out repeatedly, the review process had to be a carefully thought-out, open process which "lets the public in, lets the professional staff in, lets the business community in, lets everybody have their say, and then, after we have listened, we professional staff have listened, and the policy makers have listened then get direction from policy makers, and present something to them for their review and gratification." His intention in producing a 600-page briefing book was to start a conversation and thinking process. Hopefully, a thoughtful product of this thinking process would yield a new graduation standards that everyone was happy about.

However, Briefing Book I also raised many questions. For instance, in the process of preparing Briefing Book I, Mr. James discovered that there was not enough information on how well the current graduation standards measured the 
achievement of high school graduates. In other words, there was no information on how many students met the requirements to receive a standard diploma or modified diploma in the district. Based on the discussions of Briefing Book I the education sub-committee of the school board decided that a task force was needed to look into the review details. Mr. Truman and his staff were to prepare another information package for this task force. other information in Briefing Book I (see Table 9) included the board goal of the year, the state requirement for high school graduates, the district requirements for high school graduates, literature on ininimum competency, surveys of the business community, and the achievement literature. The most important information of all was the consequences if the graduate standards were raised.

As Table 9 shows, if the cut points of the graduation standards were raised to 219 from 212 for reading, twentynine percent of the students were below the cut points; if the cut points were to be raised to 222 , that number would be thirty-four percent. For mathematics, twenty-eight point six percent of the students were below the cut point. If the cut points were raised to 223 from 222 currently, that number would be thirty-eight point seven percent. 
TABLE 9

Eighth Grade Progress Towards Graduation Spring 1989, Percentage of students Below selected cut points

\begin{tabular}{|c|c|c|c|c|}
\hline Subject & cut point & $\begin{array}{l}\text { Cut Point } \\
\text { Score }\end{array}$ & $\begin{array}{l}\text { Percent } \\
\text { Below Cut } \\
\text { Point }\end{array}$ & $\begin{array}{l}\text { Number } \\
\text { Below Cut } \\
\text { Point }\end{array}$ \\
\hline \multirow[t]{3}{*}{ Reading } & $\begin{array}{l}\text { Graduation } \\
\text { standard }\end{array}$ & 212 & $16.0 \%$ & 488 \\
\hline & $\begin{array}{l}\text { Fall } 1980 \\
8 \text { th Grade } \\
\text { Mean }\end{array}$ & 219 & $29.0 \%$ & 883 \\
\hline & $\begin{array}{l}\text { Spring } \\
1981 \text { 8th } \\
\text { Grade Mean }\end{array}$ & 222 & $34.7 \%$ & 1,058 \\
\hline \multirow[t]{3}{*}{ Mathematics } & $\begin{array}{l}\text { Graduation } \\
\text { standard }\end{array}$ & 222 & $25.7 \%$ & 789 \\
\hline & $\begin{array}{l}\text { Fall } 1980 \\
8 \text { th Grade } \\
\text { Mean }\end{array}$ & 223 & $28.6 \%$ & 879 \\
\hline & $\begin{array}{l}\text { Spring } \\
19818 \text { th } \\
\text { Grade Mean }\end{array}$ & 228 & $38.7 \%$ & 1,190 \\
\hline
\end{tabular}

These numbers, based on the test score distribution of spring 1989, were disturbing but not surprising to Mr. Truman. Since the cut points of the graduation standards were the major components, it was a possibility that if these scores were raised, more students would need remedial services at the high school level. Mr. Poorman pointed out right away upon hearing the news, "technically speaking raising ten points or twenty points wouldn't 
really improve anybody's quality."

In addition to his concerns over the current standards, Mr. Poorman was worried that the emphasis on the cut points was problematic, "To say that a kid scored 212 on the reading test [meant] that that person had met minimum competencies, I think that was too narrow of a measure. There were many, many other things that we should be looking at in addition to that."

The access to information prior to other decision makers gave Mr. Truman and Mr. Poorman some advantage to gain a better understanding of the review process. Mr. Truman realized early on that this review process would take longer than Mr. Carter and Mr. Copelin assumed. As a result, Mr. Truman planed to finish the review process in two years and developed a plan based on his understanding of the information. To Mr. Truman, the plan was logical and reasonable.

Titled as "The Briefing Book for The Task Force in Review of Graduation Standards," Briefing Book II was a literature review rich in articles, position papers, international reports and test measurements. Truman's intention was to provide the decision makers plenty of material for the coming activities.

Briefing Book II provided some overlapping information with Briefing Book $I$, since Book II was meant to provide information for a task force. Additional 
information in Book II included skills that employees expected from high school graduates. These expectations, listed in Table 15, reflected a diverse discrepancy between the expectations of the business community and the educators.

curriculum, Assessment and Instruction

The assessment department and the curriculum department had regular monthly meetings to "carry on a communication between the two departments." One reason that such a meeting existed was because the two departments had different responsibilities and some overlapping responsibilities to provide support to classroom instruction. on May 24, 1989, Truman talked about the new board goal to review the graduation standards and solicited opinions from the specialists. He asked the following questions:

1. Should we adjust graduation standards?

2. Should we raise graduation standards?

3. Should we expand graduation standards?

4. If we expand graduation standards, do we look at employability skills?

Mr. Truman pointed out that he would like to "hold on" to these questions and take some time to think them through, because these were very complicated and important questions regarding the well being of the students. 
In Roseville School District, graduation standards were not the responsibility of Truman's department only. Rather, Mr. Washington's curriculum department was in charge of the course credits. The assessment department was in charge of the test scores and the curriculum department was in charge of the course credits. As gatekeepers, the cut-point and the credits were important accountability checks in the school district.

Conflicts over school curriculum are notoriously complicated in America (Clune 1988; Cohen 1982).

Different interest groups and political influences interact and counteract constantly over what should or should not be taught in schools. With increasing demands of education reform, the pressure from those forces is overwhelming to curriculum specialists. While the stateof-the-art in testing technology makes rapid progress to perfection, the content of tests is completely curriculum directed. Curriculum goals should be clearly reflected through testing and the test should measure what students know through a strong instructional program. Therefore, a cooperation of curriculum, instruction and assessment is vital to the success of student learning. Without improvement in curriculum and instruction, it is not sufficient for the assessment component to carry on a constructive education reform.

The curriculum, instruction and assessment triad in 
Roseville School District was not in perfect harmony, a situation common in many other school districts. Assessment had been accused of being the driving force of test-driven curriculum in many schools, since it is possible for some teachers to teach to the test. At the same time, the curriculum department was criticized as being short-sighted in introducing the latest fashion in curriculum with very little regard to the impact of these programs. Finally, teachers in charge of instruction were sensitive to the low achievement scores, which may be caused by many factors. To review graduation standards meant a close cooperation of the triad in an intense fashion. Was this cooperation possible?

\section{A Further Discussion on Graduation standards}

Very little was done until the board planning session in October of 1989. The subject of school effectiveness was raised and the topic was to set up a goal regarding how many students should pass the graduation standards and by what time. Mr. Copelin, a board member who supported the goal to review the graduation standards, pointed out that

we will need to pay attention to what is happening in the society. All the attention we give to achievement scores relates to past levels of learning. The issue of schools is not how you have done compared to the past, but how you are doing compared to what your kids will need to know in order to function productively in society. 
Another board member, Mr. Light, expressed his disagreement to "bring the statistics to 100 percent by forcing some kids out of school." Instead, the goal regarding graduation standards should be phrased as "increasing the percentage of students making satisfactory progress toward meeting district's basic skill standards for high school graduation." As reported by Truman, of the eighth graders, the percentage passing the graduation standards was seventy-seven percent in the district. The surprising news to those at the meeting was that twentythree percent of the high school freshmen did not pass graduation standards.

Mr. Garfield, a board member, suggested that the district aimed at "reducing the youngsters that drop out by five percent who fall this year in the category of the twenty-three percent." His suggestion of quantifying students achievement was not welcome by other board members. Mr. Smith, who was leaving the school board in a year, pointed out that "it is unwise to quantify it [achievement outcome]." Instead, "we set a goal and don't say how much." However, Mr. Copelin argued that "all of our goals are not process; they are outcome goals." Mr. Garfield, who became upset, expressed his concern that "we are on the defensive attack as to whether or not we are competitive, which seems to be set on unrealistic standards that are measured external to us and have very 
little to do with our kids." Mr. Kennedy agreed with the "competitiveness." Yet, he also strongly disagreed with this goal, because "[this goal] creates an expectation that cannot be met and it may be unwise to try to meet it, and when we don't meet it, [it] will set us back further politically and competitively." Although the focus of the debate shifted from goal to goal and other issues, at the end of the discussion, Mr. Carter said that the educational committee, which was a sub committee of the school board, was "going to have a conversation reviewing the graduation standards and it may be a beginning of the conversation of what we want our students to know by the time they leave high school."

\section{Truman's Plan}

Mr. Truman developed a plan to review the graduation standards in January of 1990 to present to the board education sub-committee. In his status report to the school board of education regarding the review plan, Mr. Truman stated that he attempted to "establish an agreed upon framework of issues and processes for this critically important long-range planning effort." So far, his department had created a "Briefing Book for Graduation Standards Planning" which was available to all major participants in the decision process.

Mr. Truman also reported to the committee that the 
state department of education was in the process of developing the new high school requirement which might have an impact on the review process. His report received 2 minutes of silence from those at the meeting. It was obvious that if the state was getting more and more control of the financial distribution of the school districts, it could also get more and more control over the standards of the high school graduates, Truman pointed out.

Mr. Copelin responded that he did not see why "this news has anything to do with our graduation standards." other board members did not respond. In the interviews, none of the board members remembered the incident. The superintendent made a remark in the interview that it was hard for local school districts to react to the state Department simply because the issues and their plans were so vague. However, Mr. Truman strongly disagreed. He said that with all the activities in the media, it was hard for anyone not to notice anything.

Mr. Truman's plan was not very well received by Mr. Copelin. While reading it, he became irritated that the timeline was stretched for a year and a half. He not only became impatient with Mr. Truman, but also wondered why it took the school district so long to develop a plan. At this point, Mr. Jefferson, the superintendent, pointed out that the review of high school graduation standards was 
"one of the 150 tasks" that the district was doing. The school board, he continued, had "more than 50 goals" for the school year. "If you tell me that the review of graduation standards was the top priority of my tasks, I will get it done," he told Mr. Copelin and Mr. Kennedy. As a result, Mr. Poorman was assigned to carry on the project together with Mr. Truman. Mr. Copelin wanted something done by January of 1990. That was in three months.

The passive resistance on Mr. Truman's part reflected the general feelings of the school administrators in regard to the review process. As has been discussed earlier in this chapter, there was no consensus why the district needed to go through the process to review the standards. The school board, Mr. Carter and Mr. Copelin in particular, felt that they had responsibility to take on this important task. The school administrators, noticeably Mr. Truman and the three high school principals, believed that a responsible reaction to the review process was to do it slowly but right. The reluctance of Mr. Truman not to do much, and the impatience of $\mathrm{Mr}$. Copelin to push the process became a focal point in the decision process.

This confrontation was a turning point in the review process. Mr. Truman was removed from the leading role in the review process and was perceived as a "foot dragger." 
Mr. Poorman, who was new as the director of the curriculum, was assigned to lead the process.

\section{Meetings with Instructional Leaders}

In January of 1991, Mr. Truman proposed to speak to the area superintendents at their monthly meeting. He started by talking about the board goal regarding graduation standards and invited comments and opinions of the area superintendents. Very few area superintendents said anything.

Mr. Poorman started to work on the project by bringing it to the meetings at different levels of the district. He, together with Mr. Truman, brought the revised plan to the area superintendents' meetings, high school principals' meetings and district administrators' meetings.

The area superintendents were not very enthusiastic about the idea. One asked a trivial question, and another asked when the board expected the "whole thing" to get done. Most of them sat there listening. When asked later in the interviews, many area-superintendents defined their own involvement as "minimal." To many, one or two meetings was the only activity they had ever participated regarding the review of graduation standards.

After the short presentation at the area superintendent's meeting, Truman went directly to the high 
school principals' monthly meeting, accompanied by the staff from assessment and curriculum departments. It was almost 4:00 pm in the afternoon. At the meeting, Truman went through the same process and invited the high school principles to respond. Mr. Harding, the principal whose school was located in the most affluent residential areas of the town asked why the board became interested in the high schools. No one answered his questions. Mr. Johnson, whose school was in the low social economic areas of the town, made a comment that whatever the principals said would not make any difference. Mr. Adams, whose school had many English as Second Language students, pointed out that they did not have any say before because nobody asked them anything. Now, since "we are asked," pointed out Mr. Adams, we "better say something about it." Two high school principals left the meeting early without saying anything.

Mr. Poorman also brought the review of graduation standards to a high school principals' meeting. More discussion was carried on at this meeting. Mr. Adams pointed out that the current graduation standards had nothing to do with the high schools because middle schools were responsible for the eighth graders who could not pass the test by the time they leave middle school. Mr. Harding believed that the current graduation standards meant very little to the students in his school because 
ninety-seven percent of them passed the graduation standards at middle level, before they even got to his school. Mr. Roosevelt disagreed because in his school, only 55 percent of the freshmen class passed the graduation standards.

Meanwhile, Mr. Copelin invited three high school principals to discuss graduation standards, Mr. Harding, Mr. Adams and Mr. Roosevelt. At this meeting, Mr. Harding pointed out that setting the cutting point higher than the current one was a simplistic way to solve a complicated problem. Mr. Copelin, meanwhile, invited them to "rate how they thought high schools were doing," using letters from $A$ to $F$. The responses from the high school principals were strong expressions of dissatisfaction towards the mission of high schools today. The mission of high schools, they pointed out, was not correctly defined. High schools should attempt to help all the students to achieve theix best, not doing remedial work to get the low achieving students passing a minimum competency standards. Further, high schools are thought of as "place holder" for teenagers, and high school teachers were seen as "babysitters" for society.

\section{More clarification}

In November of $1990, \mathrm{Mr}$. Poorman pointed out at another meeting that he needed more clarification 
regarding the graduation standards. He was not sure whether Mr. Truman's plan was adopted by the board or he was supposed to develop another plan or to modify Truman's plan. Further more, he was not sure if his staff should move forward with the project. At first, Mr. Kennedy did not respond to the question. Instead, he went on to point out that the school district should go through the process every $10-15$ years. This was a good time to do it. Mr. Poorman reminded him that some direction was badly needed in this project. Mr. Copelin, who was impatient at the delay, suggested a sub-committee be organized so relevant groups could have their representatives on the committee. Mr. Copelin's suggestion was well received and a committee was set up. At the time, seven people were appointed as regular participants in the decision process:

Mr. Truman and Mr. Davis from Assessment Department

Mr. Poorman and Mr. Bruce from Curriculum Department

Mr. Copelin from the school board of education

Mr. Adams, a high school principal

Mr. Lee, an area superintendent

Mr. Truman and Mr. Davis participated in the process because the Assessment Department was assigned the task at the very beginning of the process. Mr. Poorman and Mr. Bruce came along when Mr. Truman's plan was not acceptable to the school board. Mr. Copelin was the chairman of the sub-committee. Mr. Lee's and Mr. Adams' involvement was 
an assignment from Mr. Madison, the deputy superintendent. Mr. Lee was one of the eight area superintendents and Mr. Adams was one of the ten high school principals. The reason why they were selected rather than any of their peers was unknown to themselves. The best explanation, from Mr. Lee, was that "there was always someone from my level on these issues." Mr. Adams believed that he was selected to be on this committee for his "expressed interests in graduation standards issues."

\section{A_Revised Plan}

Mr. Copelin and Mr. Kennedy both thought that Truman's plan needed to be revised so the review process could be completed in a year's time. Accordingly, Mr. Poorman developed a shorter and simpler plan which covered a time period of one year (see Table 10).

On April Fool's Day of 1991, Mr. Poorman wrote a memo to $\mathrm{Mr}$. Copelin asking him to verify several issues. First of all, Mr. Poorman informed Mr. Copelin that "the timeline on the graduation standards is fast approaching and all the details needed to proceed are not yet in place." The "timeline" referred to by Mr. Poorman was the June of 1991 deadline set up by Mr. Truman's original plan. According to that plan, the district should have 
TABLE 10

REVISED TIMELINE TO REVIEW GRADUATION STANDARDS

\begin{tabular}{|c|c|}
\hline Date & Activity \\
\hline $\begin{array}{l}\text { Feb.20 - } \\
\text { Apr.30, } \\
1991\end{array}$ & $\begin{array}{l}\text { High schools confer with LSAC's and write } \\
\text { reports for Task Force Committee. }\end{array}$ \\
\hline $\begin{array}{l}\text { Mar. } 1, \\
1991\end{array}$ & Task Force committee constituted. \\
\hline $\begin{array}{l}\text { Apr. 22, } \\
1991\end{array}$ & Orientation/Briefing of Task Force Committee. \\
\hline $\begin{array}{l}\text { May } 1 \\
1991\end{array}$ & Educator's Hearing to Task Force. \\
\hline $\begin{array}{l}\text { May 7, } \\
1991\end{array}$ & Public Hearing to Task Force. \\
\hline $\begin{array}{l}\text { May } 2- \\
17,1991\end{array}$ & Staff write Draft I of report for Task Force. \\
\hline $\begin{array}{l}\text { May 21, } \\
1991\end{array}$ & Task Force reviews Draft I. \\
\hline $\begin{array}{l}\text { Jun. } 14 \text { - } \\
\text { Jul. 19, } \\
1991\end{array}$ & $\begin{array}{l}\text { Draft I sent to educators for review and } \\
\text { response. }\end{array}$ \\
\hline $\begin{array}{l}\text { Jul. } 22 \text { - } \\
\text { Sept. } 1 \text {, } \\
1991\end{array}$ & Staff write Draft II of report for Task Force. \\
\hline $\begin{array}{l}\text { Sept.16- } \\
\text { Sept.27, } \\
1991\end{array}$ & Task Force reviews Draft II. \\
\hline $\begin{array}{l}\text { Oct.10, } \\
1991\end{array}$ & Task Force reports to Full board Meeting. \\
\hline $\begin{array}{l}\text { Oct. - } \\
\text { Dec. } 1991\end{array}$ & Methods of assessment developed. \\
\hline $\begin{array}{l}\text { Jan.- } \\
\text { Jun. } 1992\end{array}$ & Standards of students performance. \\
\hline
\end{tabular}


been through the most review activities by June of 1991 . Obviously, very little had been done by April. Further more, Mr. Washington pointed out, "the issue has gotten more complicated by Leader's Round Table discussion and maybe also by the United Front Special Task Force discussion [of widened missions]." With discussions regarding graduation standards, Mr. Poorman asked $\mathrm{Mr}$. Copelin "please call me to discuss our next steps."

\section{A confusion}

Mr. Copelin and Mr. Kennedy met with Mr. Poorman to discuss the next steps, as $\mathrm{Mr}$. Poorman requested. At the three-hour meeting, they discussed about the revised timeline and some details of the timeline. Mr. Copelin told Mr. Poorman that certain individuals from the district and higher education should be invited to be the members of a task force for further review of the graduation standards. In addition, Mr. Poorman should consult with Mr. Jefferson, the superintendent and then contact these individuals to inform them of the coming task. At the same time, Mr. Copelin himself would select and inform the representatives from the business community.

Mr. Bruce, the curriculum assistant director, followed Mr. Poorman's directions and informed the individuals on Mr. Copelin's list. A few days later, Mr. 
Poorman found out that $\mathrm{Mr}$. Copelin had a meeting with the community and contacted the representatives from higher education. At the community meeting, Mr. Copelin invited the comments and opinions on the review process.

Both incidents surprised and confused Mr. Poorman and Mr. Bruce. Not knowing what to do next, Mr. Poorman informed the superintendent through a memo for further directions. Since Mr. Jefferson always had a good relationship with the board members, including $\mathrm{Mr}$. Copelin, Mr. Jefferson found out that Mr. Copelin's new directions included a new list of names. Indeed, Mr. Copelin contacted some people himself. With Mr. Copelin's new direction, Mr. Poorman had to "sensitively communicate to those folks [on the first list] that they would not be on the task force." Since the names of both Mr. Adams and Mr. Lee were on both lists, their role on the task force was confirmed.

\section{The Responses}

On April 17, Washington High School held its Local School Advisory Committee meeting to discuss the review of graduation standards. On April 29, Lake View High School, an alternative high school, held its Local School Advisory Committee meeting and responded with 16 recommendations to the Task Force. On May 1, Riverside High School Local School Advisory Committee responded to the review process. 
The responses were written in various forms: Washington High School simply wrote their comments on Mr. Poorman's memo and sent the memo back; Easternville High School wrote pages of comments; and Franklin High school typed something between the lines of the memo.

Since the initiation of the decision process, the review of graduation standards lasted for about three years. The two directors, Mr. Truman and Mr. Poorman, finally worked out a plan to review the graduation standards and identified three specific steps to go through the process. In their memo to the high schools, they planned to go through step one which was an identification of the competency areas for high school graduates. They would like to report to the school board of education by october 10, 1991. This memo was written on March 29, 1991.

During the time between February and April of 1991, the high schools in the district were to confer with the Local School Advisory Committee (LSAC), an organization of parents and teachers, and write report for the "Task Force Committee" to review the graduation standards.

In March of 1991, Curriculum Department sent a memo to Local School Adversary Committee to prepare them for a discussion. The focus question of the memo was: "In what areas will all students have attained competence by the time they graduate from high school?" 
THE OUTCOME: THE FINALIZATION STAGE

In September 1991, Mr. Copelin announced at a board education committee meeting that the review of the high school graduation standards was "put on hold." Although very little happened between July 1991 to september 1991, his announcement marked the ending of this decision-making process.

\section{A NDR Qutcome}

The news generated a wide variety of reactions from the decision makers. Mr. Poorman was upset at the fact that the decision to end the process "had not been discussed, at least among the group that I was working with and I was involved with." Mr. Kennedy, who became busy with other issues, was not aware of the fact at all. Instead, he thought that the decision makers were "not anywhere yet." He also believed that the decision makers "sort of accomplished something," because he learned that the graduation standards were not anything "simple." Rather, it was a fundamental issue in education today. Mr. Truman, who had foreseen the NDR ending, pointed

out that the reason for a NDR was because,

It was a process which was based upon a very good idea and a good insight, but not enough of an understanding of what would take to get the job done well and then to implement the process. So it was full of surprises, because as people became aware of the scope of what they were involved in, especially the board members, they became somewhat surprised. So, there was not a definite outcome. 
The explanation given by Mr. Copelin about the NDR process, however, was the potential change of the state requirements about graduation standards,

[The state-wide development of the graduation requirements] was kept under the wraps for months. So there wasn't any good reason not to go forward until we saw first of all what it provided for. ... second, that it would in fact pass the legislature. I mean you cannot make policy, or you can't refrain making policy, simply because the state might do something.

\section{A Reflection on the Process}

Decision-making processes usually go through three stages: initiation stage, developmental stage, and finalization stage (see Figure 4). At the developmental stage, decision makers are well into the process and interactions are more directed and focused than at the initiation phase. The finalization stage, followed by a decision outcome, comes when information is sought and discussed, negotiation is conducted and some sort of solution is reached.

As observed by Hickson and his colleagues, sporadic decision-making processes are characterized by spasmodic and protracted episodes (Hickson 1986). In other words,

a decision made in a sporadic way is likely to run into more disrupting delays, due to all kinds of impediments, from having to await a report to meeting resistance. The information that came in 


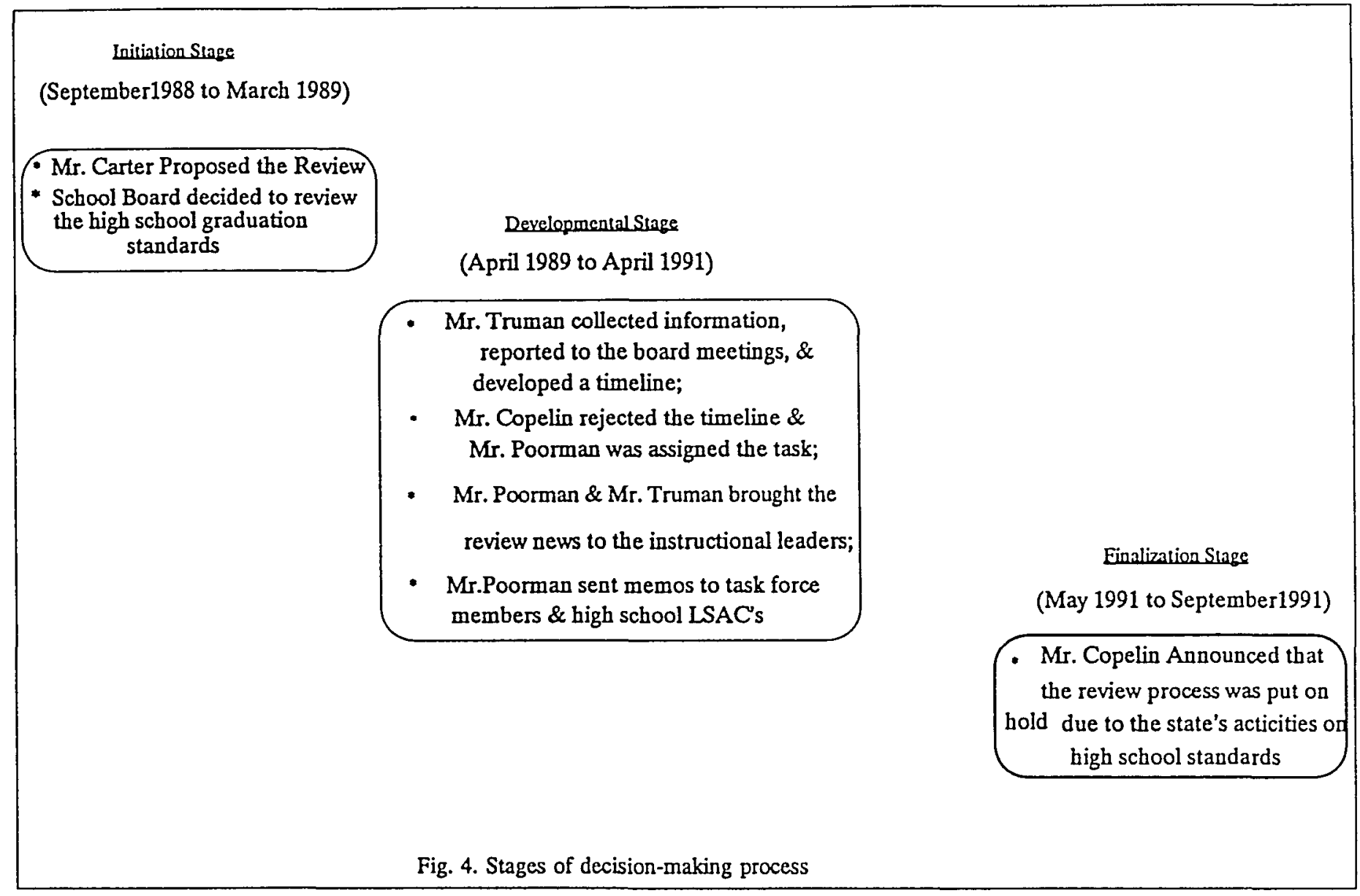


will have been of more uneven quality, for in some of it there was confidence and in some of it there was little or none, and it will have come from a wider range of sources.

The decision process regarding the graduation standards bears the characteristics of a sporadic process. While it took a year and a half for Mr. Truman to develop a plan, the developmental phase took more than a year. Then, as the external factors, such as the state, became more and more important, the process entered its finalization phase within a few weeks. Thus, the complete process took three years.

Decision studies indicate that at the initiation and development phase, activities and interactions are the most frequent (Hickson, 1986; Mintzberg, 1987). At the developmental phase, many issues need to be cleared and new division of labor have to be in place before any decision can be reached. The "process of making a decision is a response to the problems and interests inherent in the matter for decision, a response to their complexity and politicality. It is set in motion, by those who have the power to do so, when they signify their recognition of a decision topic" (Hickson 1986).

The decision process (see Figure 4) regarding the graduation standards died before any decision was reached. This result was expected by $M r$. Truman and his staff, but unexpected by the school board members and some other 
administrators. By October of 1991, the state legislatures passed the House Bill 2000 and the state department of education was getting ready to take the lead in the education reform generated by this bill.

The impact of this legislative decision was not yet clear but felt by many district administrators. With the newly proposed Certificate of Initial Mastery at grade 10 and the Certificate of Advanced Mastery at grade 12, high school students in the state were going to face a set of new requirements to graduate. The requirements or the standards of the local school districts would be replaced or changed. To review the local graduation standards in an attempt to change it not only became unnecessary but also seemed senseless on the part of the local school district. With less and less control over its own financial situations than before, local school districts were gradually losing its control over education-related issues as well.

Mr. Truman expressed his frustration with a remark: "I hate to say this. But I told him so two years ago." The review of graduation standards was not completed and the "hold" was forever. The school district was facing tremendous budget cut due to the tax limit on school funds. The state department formed two dozen committees to develop curriculum and assessment details of the new bill. Mr. Copelin did not plan to run for re- 
election. Many new goals were put in the Goal Book. The review of graduation standards was not one of them. 
RATIONAL CHOICES IN THE REVIEW OF HIGH SCHOOL GRADUATION STANDARDS

The decision to review high school graduation standards was most of all a problem solving process. In order to increase the public confidence and the accountability of the public education systems, the school board of education at Roseville School District initiated the review process. This goal, political in nature, was clearly identified in the objectives developed by the school board of education. By taking on the role of decision makers, the players "think and act logically with clear common sense" (Coleman 1990).

The intent and the purpose of the board action can be best understood within the framework of rational choice model, which believes "what human beings do is at least 'intendedly rational' " (Allison 1967). The "goaldirected" (Allison 1967) behavior of the board in first reviewing the graduation standards and then stopping the review process was typical of value-maximizing by rational actors under the circumstances (Allison 1967). 
GOAL-DIRECTED RATIONALITY

"There are strong a priori grounds for assuming that people, by and large, behave rationally. We all want to be rational" (Elster 1986). So did the board members at Roseville School District. The goal was clear: in response to the warnings about the "nation at risk," and the criticisms of the business community, the high school graduation standards should be reviewed and possibly changed to improve the quality of the high school graduates at Roseville.

According to Elster, three elements in the choice situation can be identified to demonstrate rational behaviors,

The first element is the feasible set, i.e., the set of all courses of action which (are rationally believed to) satisfy various logical, physical and economic constraints. The second is (a set of rational beliefs about) the causal structure of the situation, which determines what courses of action will lead to what outcomes. The third is a subjective ranking of the feasible alternatives, usually derived from a ranking of the outcomes to which they (are expected to) lead. To act rationally, then, simply means to choose the highest-ranked eiement in the feasible set (Elster 1990).

\section{The Motivation of the Board}

Improvement of students' academic performance was always the top priority of the school board of education at Roseville School District. Under this general goal, 
there were a series of sub-goals that focused on many areas of the student academic achievement. These subgoals served as objectives for the district staff members to implement throughout the year. At the same time, these goals were published in the Board Goal Books which were available to the general public. Although the board set up annual goals such as "increase the percentage of students meeting the high school graduation standards," the standards were set about ten years ago. In addition, Mr. Copelin was concerned that the process through which these standards were set was "not intellectually defensible." As the rapid changes occurred in society, these standards needed to be reviewed and possibly changed.

Mr. Carter's personal experiences raised his concerns in regarding to the quality of high school education at Roseville district. His own children were in one of the high schools, and oftentimes they were "not challenged." He noticed that the curriculum was not consistent at the high school level throughout the district.

Criticisms from the business community and the media concerned Mr. Copelin the most. Although he was aware of the fact that these criticisms were not necessarily targeted at Roseville district, he believed that "it was 
pretty important that these criticisms had been leveled at public education in general." In particular, he was worried that high school graduates

were not ready to work, and the business owners had to either reject them, in which case they became not employable in useful jobs, or business had to train them for business own purposes. In other words, these were not useful products that we were producing, and I thought that a legitimate goal of education was to see what the needs of the economy were, and what we were producing, and we had to be sure that those matched up.

It was Mr. Carter's concern over high school education and Mr. Copelin's fear of criticisms from business that motivated the two board members to invest their time and energy in a search of something that would "fix" the situation.

A review of the high school graduation standards stood out among many possible actions as the most feasible way to fix the situation. These graduation standards were based on a standardized test that had been in place for ten years and were based on measurable cut points. As the final standards for $\mathrm{K}-12$ education at Roseville, these cut points were significant indicators of students achievement. Also, since the rate of high school graduation partially depended on these standards, the process of setting these standards was very important. 


\section{A Shared Belief}

Both Mr. Carter and Mr. Copelin had strong motivations to initiate the review process. Yet individual desires needed to be justified and shared by other board members before the board made these suggestions into board goals.

The presence of a strong desire to review the graduation standards and the belief that a change of these standards would lead to a happier business community were clearly reflected in the interview data. This is an important point because the second element specified by Elster rejects the notion that the presence of the belief itself is sufficient to cause the behavior. Instead, there must be proof that an action would lead to a desired outcome. In other words, the decision maker "must choose among a set of alternatives displayed before him in a particular situation" (Allison 1971).

Both Mr. Carter and Mr. Copelin phrased their concerns with sufficient philosophical and political reasoning to put the graduation standards into a broad and meaningful perspective for the rest of the board members. The review of the graduation standards was understood to be the feasible action to be taken under the circumstances. A changed standard, possibly a higher one 
than before, would raise the expectations of the district regarding its high school graduates.

Mr. Carter was grateful that Mr. Copelin and Mr. Kennedy shared his point of view of the graduation standards. As a social worker at a nearby university, Mr. Carter became interested in academic issues of public education and was ready to look at "what we are teaching." But at the time, Mr. Carter was under the impression that "school boards really shouldn't look at things related to academics because we are not educators." Then his trip to a national conference of school boards changed his mind. "I was really reinforced and helped to understand that it really was my role to be looking at these [academic] questions," said Mr. Carter.

Yet, the time was not right for Mr. Carter. "Luckily after that, Mr. Copelin came on the board and then Mr. Kennedy followed him -- and they both have been very interested in the area of curriculum. So, some other forces -- political forces -- on the board really then helped me to say 'let's devote some energy to this process'."

Mr. Copelin specified very clearly why he agreed that a review of the graduation standards was an important issue for the school board. He argued that 
[the review of the standards] was a terrific issue and it was a terrific issue politically, because I felt that the education establishment, or those who were full-time education professionals had become somewhat insulated and that this would be an opportunity for them to be accountable to society, because, after all, it is not what educators necessarily think is good for kids, it is also what society says that it needs from schools.

Mr. Copelin hoped that the review process would make the school district more responsive to the needs of today's society and the business community. He believed that the academic world must be "responsible to society" and should not "go off by itself." Otherwise, it would become "self-reinforcing, and it would lose touch with what it is happening in the outside world." Since school boards were publicly elected bodies representing the general public, Mr. Copelin's concerns and articulation on these concerns clearly reflected a general tendency of the school boards: to satisfy the constituencies that put them in the position.

Mr. Carter believed that attention was badly needed on high schools at Roseville district. Although his motivation to review the graduation standards was "mostly personal," he was concerned that at the high school level,

it was not clearly articulated what they needed to know and so they got kind of mixed messages. I have seen students sliding through our system, ... especially high school kids. ... I do zero in more on our high schools because I think that we do a better 
job in elementary and middle schools, generally, and that high school is where we need to do the focusing on.

The successful initiation of the review process of graduation standards reflected the priority of the school board of education to reach a rational choice in policy making. The stimuli that provoked the process included the right timing, additional support to Mr. Carter from other board members, and a successful translation of a good idea into board actions. It was logical for the school board of education to include this goal in the board objectives.

Finally, Mr. Carter and Mr. Copelin convinced the board to make the choice: a review of the high school graduation standards would lead to an improved image of the school district and to an increased public confidence. Due to the controversial characteristics of the high school graduation standards and the publicity attached to them, it is obvious why the school board chose the review as one of the important tasks of the year.

Figure 5 shows two alternatives perceived by the school board. One was to "review the standards" and the other was "not review the standards." To "review the standards" was the preferred alternative of the board. Both Mr. Carter and Mr. Copelin expected that the review 


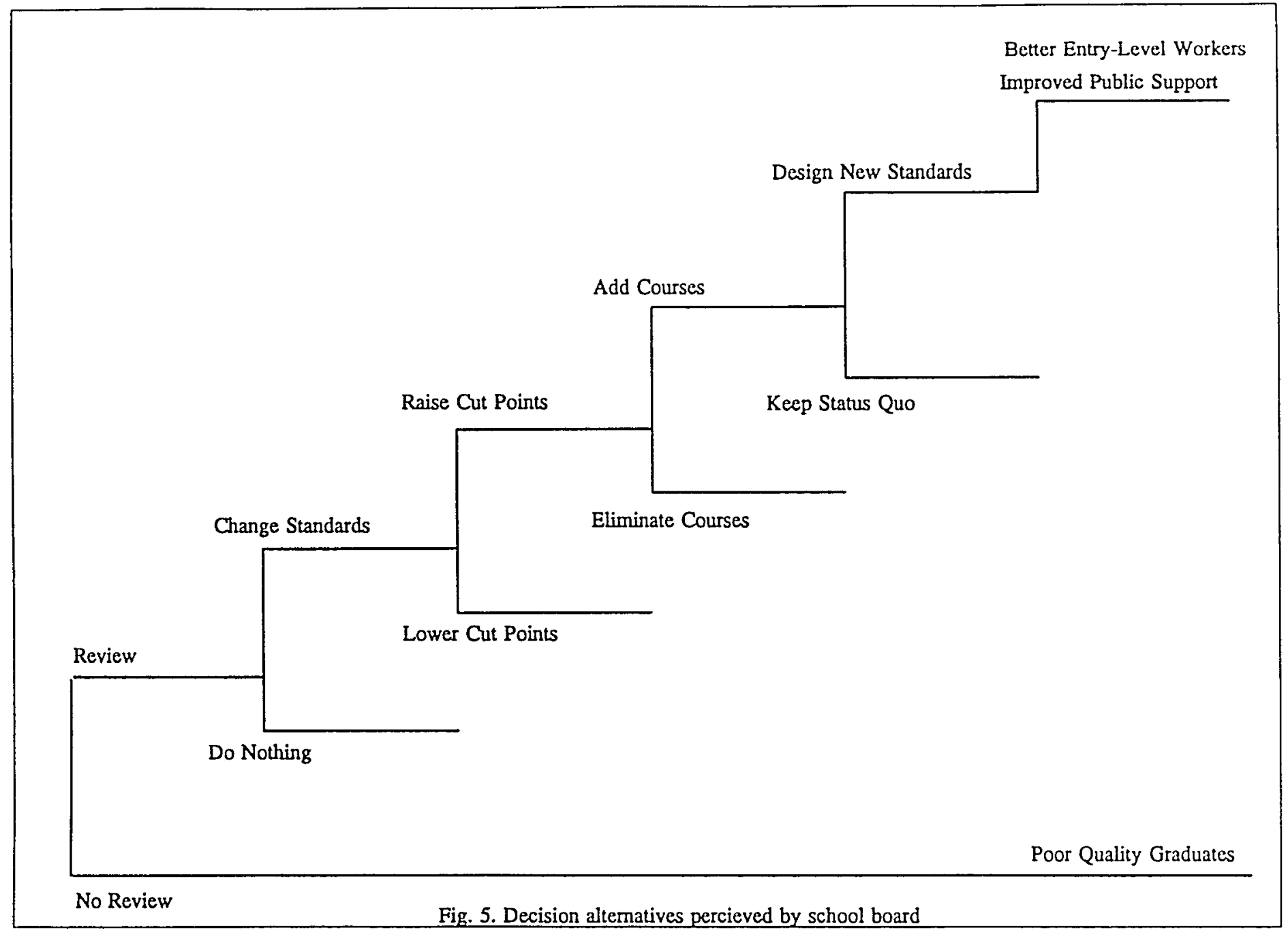


would lead to certain changes of the current standards, although, keeping the status quo was also an alternative. The two possible changes were "raising" or "lowering" the cut points. If the cut points were raised, it was logical to change the number of courses that students took at the high school levels. The preferred alternative was to add some more courses so students would be challenged.

With the changes of the scores and new courses, the preferred alternative would be to redesign the high school graduation standards, which needed to be applicable to the new courses. The new standards would lead to improved high school graduates and better entry-level workers.

As the alternative tree indicates, the board members believed that the choice of a review of graduation standards would lead to high expectations of the graduates and the ultimate improvement of the public perception of the Roseville School District. Under this circumstance, both Mr. Carter and Mr. Copelin believed that review was a value-maximizing choice.

\section{REVIEW CHALLENGED}

Although the school board of education specified the objective of examining the graduation standards, the purpose of the review and the intention of the board members were challenged by the district staff members. In 
specific, the rationality of the board members to review the graduation standards remained unclear to the district staff members. As Mr. Bruce pointed out again and again in the interview, "What was it that they wanted to have happen ... , they meaning Mr. Copelin. What did he really want to have happen? Many of us felt that we needed to drag our feet a little bit because we weren't sure what we were doing."

The district staff members shared very little in common with the board members in regard to the review. In fact, they did not believe that the review was necessary or was it reasonable. Such discrepancies between some players' perception and others' in viewing the same problem are common phenomena in decision-making situations (Linstone 1984; Elster 1990). As Elster explains, "an intentional explanation of a piece of behavior, then amounts to demonstrating a three-place relation between the behavior (B), a set of cognition (C) entertained by the individual and a set of desires (D) that can also be imputed to him" (Elster, 1990). The school board of education and the district staff had two different rational beliefs regarding the review process. The board initiated the review process because the graduation standards attracted public attention and a change of these 
standards would improve the accountability of the school. district. Yet the district staff believed that the change of the standards would not lead to any substantial improvement in the district. Merely raising the cut points of the standards would not lead to an improved education program in high schools.

\section{Board's Initiation ouestioned}

Mr. Truman had many questions regarding the board's intentions to initiate the review of graduation standards. As an assessment expert, Mr. Truman believed that assessment was only one piece of the education reform. other pieces, such as curriculum and classroom instruction, should be examined before any changes of standards should occur. In addition, without any solid information regarding the success and failure of the high school graduates, the board's assumption about the appropriateness of reviewing graduation standards was illogical. Plus, Mr. Carter's personal experiences did not provide a representative picture of high school education at Roseville.

Although the district staff members agreed that poor performances of the high school students were problems of today's public education, they believed that the solutions to these problems could not be found in a review of the 
standards because a review of the standards was too simplistic and short-sighted an approach to a serious problem. While Mr. Copelin was extremely concerned over the social and political impact of and the public opinions on education, the professional educators in Roseville district strongly believed that public education should produce educated persons. In order to reach this goal, the assessment and the curricula components of the Roseville district should improve the assessment methods and the curricula construction to assist the classroom instruction. Thus, district staff believed that the review process could be meaningful only if it lead to an improvement of assessment, curriculum, and instruction in the district.

The two sets of goals, one by the board members and the other by the district staff members, created two sets of alternatives (see Figures $5 \& 6$ ). This in turn created a difficult situation for the review process. As Mr. Truman pointed out in retrospect,

It seemed to me that it [the review process] was going to be an enormous waste of time and a source of frustration for everybody who was involved. Things like this, in my opinion, should be done more like an open process that takes time, lets the public in, lets the professional staff in, and then, after we have listened and the policy makers have listened, then get direction from the policy makers and present something to them for their review and gratification. 


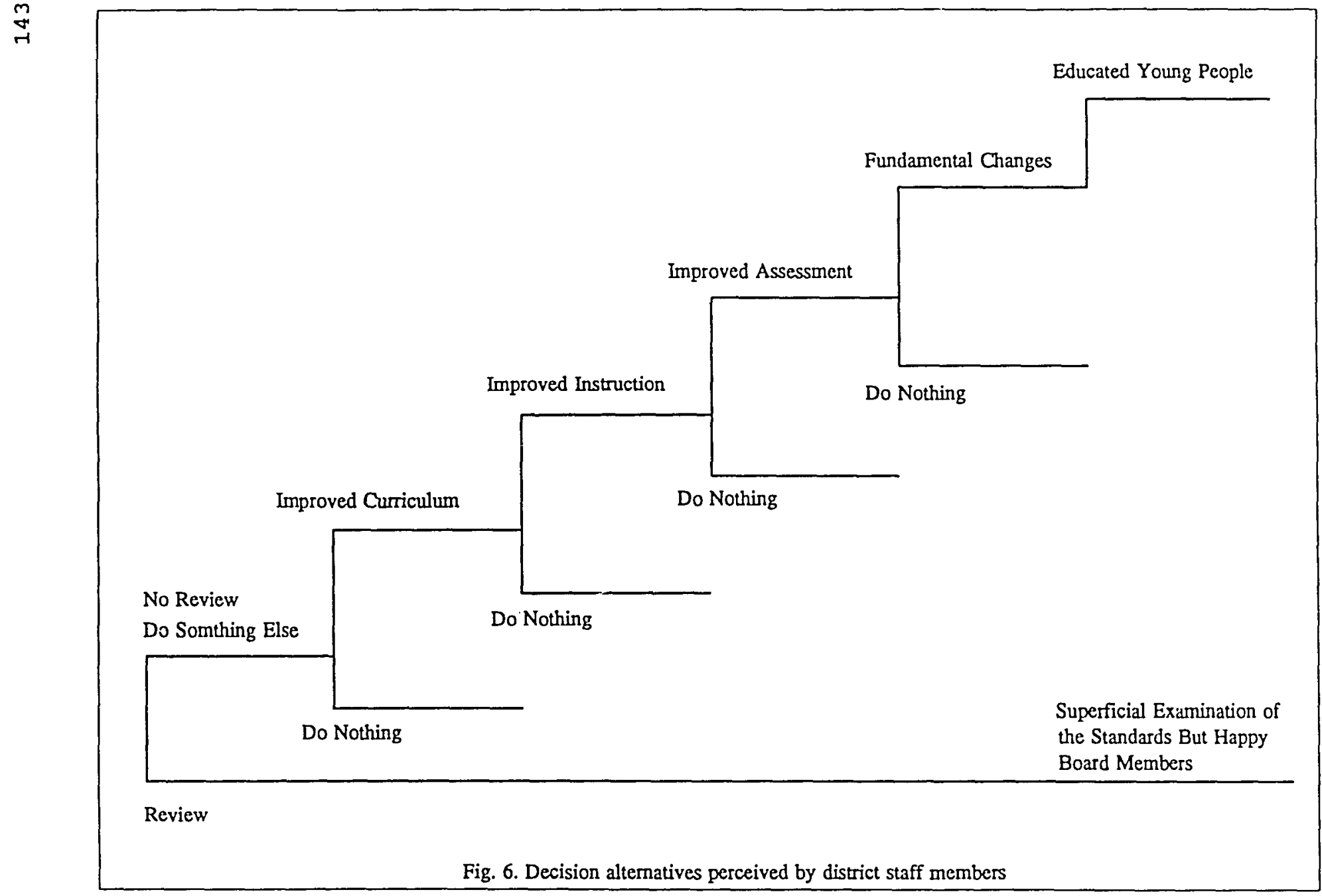


Mr. Truman's beliefs were shared by his colleagues in the district. As Figure 6 shows, the district staff members had a different set of alternatives in mind. To most district staff members, the impact of the graduation standards on students was questionable. In fact, "[the impact of the graduation standards] is really nonexistent" on high school students, according to Mr. Adams. In many high schools, most students entered high schools with passing graduation standards scores which could be achieved as part of middle school education. As to the criticism from the business community, the district staff members reacted differently too. Again according to $\mathrm{Mr}$. Adams,

I don't know that I hear truly directly from the business community that was negative in nature about the kids that graduated. You hear those general comments made and most of the comments were [about] kids that had gone to work for them, ... that they were surprised how good the kids were.

The negative comments came from the media that generalized national information which did not apply to Roseville.

\section{A Different Set of Alternatives}

The uncertainty regarding what to do was overwhelming to Mr. Truman and his colleagues who perceived a different set of alternatives in the review of graduation standards. Recognizing the limits and the problems of the review 
process, the district staff foresaw the problematic nature in the logic and the reasoning of the school board. They indicated a set of different alternatives that better illustrated the expectations of the district staff members (see Figure 6).

Figure 6 consists of the alternatives perceived by the district staff members regarding the review process. The initial alternatives included "review or do something else," a set that is similar to that of the school board. The preferred outcome perceived by the district staff members, however, was "do something else." They believed that the school district should choose to improve its curriculum, then instruction and assessment. With these preferred choices, some fundamental changes would be expected to happen in the district. Eventually, the preferred outcome of this review would be an improvement to graduate educated persons who were ready to do or to be anything, in addition to be entry-level workers.

The review was not preferred by the district staff members because they perceived it an attempt to look for a quick fix to solve a serious problem in education. Since the review process, as intended by the board, focused on standards only, it was meant to meet the political need of the board members. It was not a worthwhile task. 
OBSTACLES IN THE REVIEW OF GRADUATION STANDARDS

obstacles play an important role in rational choice model. In fact, the concept of specified obstacle goes hand in hand with the concept of being rational decision makers. "The rigorous model of rational action maintains that rational choice consists of value-maximizing adaptation within the context of a given payoff function, fixed alternatives, and consequences that are known" (Allison 1971). In other words, decision makers are likely to make rational choices if consequences are known and alternatives are certain. Obstacles, such as unknown consequences, competing interests, and uncertain alternatives, make rational choices a difficult task. Several obstacles can be identified in the review of high school graduation standards.

\section{Obstacle one: Lack of Resources in the Review Process}

Resources carried by decision makers are important factors in rational choice situations. To say the least, resources can create constraints and open up new opportunities for decision makers whose tasks and goals depend on the amount of resources that are available to them (Coleman 1993). A rational decision maker must take his resources into consideration in taking any actions or making alternatives. 
The decision participants, the core decision makers in particular, carried resources that included each participant's position in the organization, seniority in that position, knowledge or experience, and other factors such as personality.

Three individuals carried the most resources in the process: Mr. Copelin, Mr. Carter, and Mr. Truman. Although both Mr. Copelin and Mr. Carter participated in the review process on a part-time basis, they were instrumental in the original initiation and forcefully pushed the process to a full scale. As veteran board members, both were experienced and skilled in dealing with the implementation issues of board's goals. Mr. Truman was an experienced administrator who was very skillful in dealing with the board demands. His participation in the setting of the original graduation standards gave him a unique background on the topic. His access to the large amount of information was also an advantage to him. Four individuals carried less resources than the above three but more than the others. Mr. Kennedy was a new board member when the process started. His eagerness and enthusiasm made him an active player, but his lack of personal investment and experience made him an outsider as well as an objective observer. His remarks indicated that 
he was an open-minded board member who believed that "miscommunication or no-communication" made the review process a failed endeavor. Mr. Madison, the deputy superintendent, was never an active player in the process yet his influence was felt throughout the process. The official appointment of the instructional leaders to participate in the review process was directly at his command. In addition, his open resistance to the review process was representative of the resistance of the district staff members. Time and again, his name was mentioned as the source of influence for the decision makers. Mr. Poorman, new to his position, was an unwilling leader when he was assigned the task after Mr. Truman was labeled as a "foot dragger." The circumstances made him ineffective in many instances. He relied heavily on Mr. Truman for information and support. Mr. Poorman's assistant director, Mr. Bruce, was also new to his position. But, Mr. Bruce had the advantage of being a former high school vice-principal, which provided him with first hand information on graduation standards. Mr. Bruce was well informed on the curriculum issues and effective in communicating with instructional leaders.

The various levels of resources carried by each player created an obstacle in the review process: no 
decision maker had the predominant resources necessary to determine the direction of the review process. In fact, the resources were scattered among the decision makers. To carry on the review process, compromises were needed and a concentration of energy was vital.

While the school board of education, Mr. Copelin in particular, was the most motivated group in the review of graduation standards, this group did not have sufficient resources to carry on the review without the assistance of the district staff members. The district staff members, on the other hand, were not motivated to put their resources into the process since they believed that the review of the standards was a wrong approach to a serious problem.

Lack of resources in decision-making processes creates obstacles and sets limits for decision makers. The board's perceived alternatives were feasible when the review was first initiated. But, when the district staff members were not willing to put in any resources, "review" was no longer a feasible action.

The structure of the system, namely Roseville School District, was the determining factor of the situation discussed above. Since the major function of the school board was policy making, the district staff members were 
under the direct supervision of the superintendent and deputy superintendent. The school board had little, if any, authority overseeing the daily operations of the district. When the district staff members had assigned responsibilities as area-superintendents or principals, their participation in the review of high school graduation standards became secondary priorities. Without any direct supervision authority over the district staff members, Mr. Copelin could only put pressure on other decision makers in a haphazard fashion. As a result, the cooperation of the district staff members was minimal throughout the three years. In fact, the review of graduation standards appeared to be Mr. Copelin's project in its developmental phase. Consequentially, the limited resources of the school board allowed few alternatives for Mr. Copelin.

\section{Obstacle Two: Activities of Department of Education}

In addition to the lack of resources, the review process faced increasing uncertainties from the environment. The state department of education was in the process of developing a new education bill which would change the current high school graduation requirements. Although the impact of the bill was not clear, the necessity to review the graduation standards needed to be 
revisited. However, one thing was clear: the graduation standards at Roseville School District were subject to change accordingly once the bill was passed.

other events also drained the energy of the decision makers. The voters challenged the tax base for school funding. If the new funding initiative was passed, the state would become the sole funding source of the public education. These uncertainties in the environment became another obstacle that eventually lead to the termination of the review process. As the direct authority to Roseville School District, the state department of education was more than a factor in the environment. It set the requirements for high school graduates in the state and local districts were obligated to comply with these requirements. Although graduation standards at Roseville school District were extra requirements of its graduates, this local control might be challenged if the state department did obtain resources to distribute education funding statewide.

$$
\text { NDR OUTCOME -- THE BEST ALTERNATIVE }
$$

The discrepancies between the alternatives perceived by the board members and by the district staff members created a difficult situation for the review process of the graduation standards. On the one hand, the board 
members perceived a set of alternatives that would meet a political need of the district; on the other hand, the district staff members perceived a different set of alternatives that would lead to an improvement in the overall educational achievement in the district. The board members ranked the review as the best choice to achieve their goal, and the district staff members ranked review process as the least preferred choice.

\section{The choice situation}

The frustration of the decision makers reflected the "subjective nature of the choice situation" (Elster 1986). In other words, the subjective ranking of the feasible alternatives by individual decision makers in a group decision is the key to shaping the decision outcome. When this decision-making group perceived two different sets of alternatives, it became impossible for this group to reach any outcomes.

Although the board members and the district staff members worked together as a decision-making group, each side had their own set of alternatives. Each set was reasonable and logical for the group that developed them. However, these alternatives (Figures 5 and 6) were more expectations than reality. The board members expected to have the graduation standards reviewed and possibly 
changed; the district staff members were not willing to review the graduation standards at all. In reality, the review process was initiated as the board planned but was terminated as the district staff members hoped.

The most unexpected factor in the review process was a set of obstacles: the lack of resources and the external distractions from the state department of education. These obstacles created an uncertainty of the alternatives and thus increased the cost as well. To overcome these obstacles, the district had to consume a tremendous amount of organizational resources since the process would delay the routine organizational operations, and burden the key players with extra responsibilities. Plus, it was unknown to the decision makers how long this process would last.

\section{The Ultimate Alternative}

Rational decision makers are expected to achieve the optimal alternative based on criteria that maximize payoffs. These criteria can be identified as expectations, constraints, and the interdependence of the decision makers. A rational decision maker considers the "total goodness and badness associated with a solution" (Robertshaw 1978) based on specified constraints. The optimal decision payoff would be the ultimate alternative. Mr. Copelin's announcement to terminate the review 
process came after the revelation of the specified obstacles became obvious to him. By evaluating the whole picture, he believed that "there was an intentional effort to put the process of graduation standards on such a long time table that it would basically not happen." The long time table was not acceptable to anyone, since it would take a tremendous amount of district resources. The best alternative, under the circumstance, was to stop the review process. Although nothing was achieved, the termination of the review process would prevent any further waste of the district resources. Figure 7 indicates the ultimate alternative that $\mathrm{Mr}$. Copelin chose. Mr. Copelin's new set of alternatives reflected the interdependence of the decision makers. Although the initiation to review the graduation standards was wellintended, the school board of education failed to anticipate the scope and the complexity of the process. Meanwhile, the district staff recognized the flaw of the review process, yet they failed to stop the board from carrying the review at an early phase. In such a situation, "each agent has to anticipate what others are likely to do, which may require an estimate of what they 


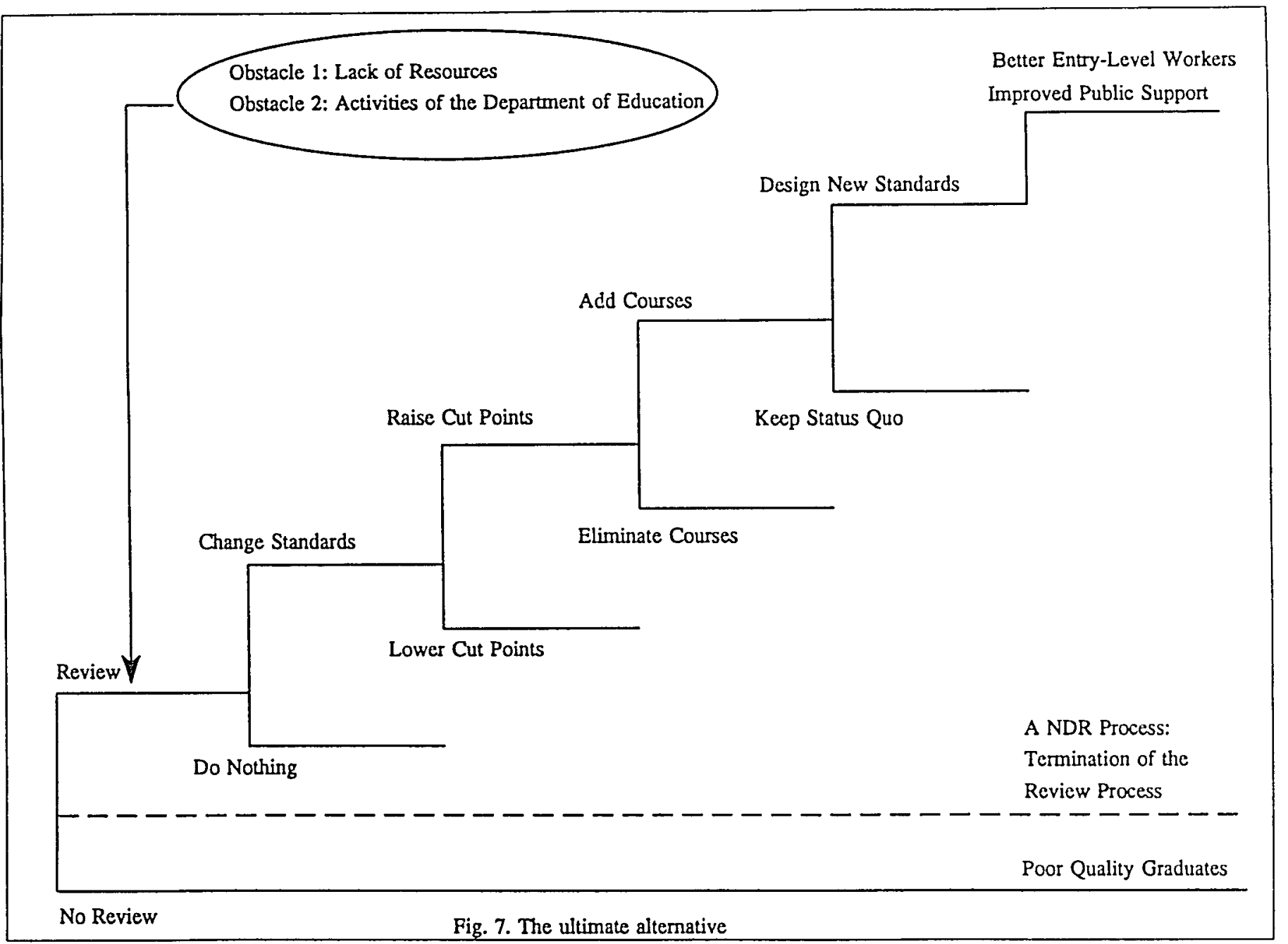


anticipate of what he will do" (Elster 1986). Everyone else's decision "enters as part-determinant of the constraints that shape his decision" (Elster 1986). The interdependence of all players was obvious and felt by all the decision makers at Roseville. Although the school board of education "called all the shots," the cooperation of the district staff members was vital to the success of the board goals. The three obstacles, the diverse resources, the disjoint relationship between the board members and the district staff, and the activities of the state department of education, created a new set of feasible alternatives. What was feasible before was no longer feasible then. So, as a rational decision maker, Mr. Copelin changed his subjective rankings of the alternatives, and terminated the review process before any outcome was achieved. Under the circumstance, it was the best choice. 


\section{CHAPTER VI}

THE TOPIC, THE PROCESS, AND THE ORGANIZATIONAL CONTEXT

The process model of organizational theory perceives organizational decision-making from two basic angles: decision interests and decision problems. The topic of the process determines the nature of the decision-making process. A vortex topic leads to a sporadic process. The characteristics of the decision-making process in review of the graduation standards were reflective of the decision topic -- the high school graduation standards.

THE DECISION INTERESTS AND PROBLEMS

Concerns over certain matters in an organization are usually the beginning of an inquiry into the state of affairs of the organization. Such an inquiry becomes an initiation point for the decision-making process when decision makers share the same concern. A decision topic borne out of this shared concern matters the most in organizational decision-making (Hickson 1986; Mintzberg 1987). Since the decision topics and the situations vary in organizations, the nature of the decision-making 
process is determined by the nature of the decision topic.

\section{controversies over Graduation standards}

The review of the high school graduation standards

was identified as the topic of the decision-making process of this case study. The nature of this topic was an important factor in this decision-making process. The problems and interests generated by this topic created several controversies:

1. Requirements made by the state

2. Criticisms from business community

3. Pressure added to the district staff by board goals

4. Question over the mission of education

5. Potential for more dropouts or push-outs

6. Public demand for education accountability As discussed in Chapter IV, the high school graduation standards became a requirement for high school students at Roseville School District in addition to the state requirement mandated in the early 1980s. At the time, the standards functioned as a partial requirement for high school graduation as well as a political statement by which to gain a tax base for the school district.

The nature of the high school graduation standards was the first controversy over the graduation standards. 
The board members, who initiated the decision-making process, focused on the political impact of these standards. Mr. Carter, the board member who raised the issue of reviewing the standards, felt strongly that high school education at Roseville was not consistent in terms of quality and standards. The current standards, which were normed at the ninth grade level in the early 1980's, became too low for many high school students. In fact, as Table 11 indicates, many students passed graduation standards at sixth grade. Such low standards, to Mr. Carter, were not the best indicators of the education quality in the district.

In 1989, fifty percent of the fifth grade students already reached the passing level of the reading graduation standards for high school. By 1992, this had increased to sixty percent. So the graduation standards that targeted the eighth graders in the early 1980 s were no longer measuring the eighth grade level achievement. In other words, the students at Roseville school district had made tremendous progress since the high school graduation standards were introduced. 
TABLE 11

PERCENTAGE OF STUDENTS PASSING GRADUATION STANDARDS IN READING $1989,1990,1991,1992$

\begin{tabular}{lllllll} 
Year & Grade 3 & $\begin{array}{l}\text { Grade } \\
4\end{array}$ & Grade 5 & Grade 6 & Grade 7 & Grade 8 \\
\hline 1989 & $17 \%$ & $35 \%$ & $50 \%$ & $60 \%$ & $70 \%$ & $80 \%$ \\
1990 & $18 \%$ & $36 \%$ & $53 \%$ & $62 \%$ & $74 \%$ & $82 \%$ \\
1991 & $21 \%$ & $33 \%$ & $59 \%$ & $64 \%$ & $75 \%$ & $83 \%$ \\
1992 & $21 \%$ & $45 \%$ & $60 \%$ & $67 \%$ & $77 \%$ & $81 \%$ \\
\hline
\end{tabular}

Meanwhile, the achievement information published by the district indicated considerable progress in high school graduates in meeting the graduation standards since 1989. More students had passed the graduation standards at earlier grades in the past few years (see Table 12).

TABLE 12

AVERAGE GRADUATION STANDARDS PROGRESS REPORT $(\%)$

\begin{tabular}{lrrrrrrrrr} 
Grade & 181 & .82 & .86 & .87 & .88 & .89 & .90 & .91 & .92 \\
\hline Freshmen & 62 & 67 & 74 & 75 & 76 & 78 & 78 & 77 & 79 \\
Sophomore & N/A & 66 & 81 & 82 & 85 & 85 & 84 & 84 & 83 \\
Junior & N/A & N/A & 87 & 89 & 89 & 91 & 90 & 87 & 89 \\
Senior & N/A & N/A & 91 & 93 & 93 & 94 & 94 & 93 & 92 \\
\hline
\end{tabular}

However, the achievement information also indicated 
a big discrepancy between the high schools. This was the second controversy of the decision process. For instance, 87.3 percent of the freshmen in Westernville High School passed graduation standards in 1981 and the percentage rose to 93.1 percent in 1992 . Yet only 35.6 percent of the freshmen in Easternville High school reached the cut points in 1981, and that percentage increased to 58.8 by 1992 (see Tables 13 and 14). Such a discrepancy indicated a potential problem for the review process: the graduation standards provided controversial measures of high school graduates. For Westernville, the standards were too low; but for Easternville, the standards were too high.

TABLE 13

GRADUATION PROGRESS REPORT OF WESTERNVILLE HIGH SCHOOL FRESHMEN AND SENIORS ( $\left.\frac{\circ}{2}\right)$

\begin{tabular}{lrrrrrrrrr} 
Westernville & 181 & .82 & .86 & .87 & .88 & .89 & .90 & .91 & .92 \\
\hline Freshmen & 87 & 89 & 87 & 90 & 89 & 91 & 87 & 91 & 93 \\
Seniors & N/A & N/A & 97 & 98 & 98 & 97 & 98 & 96 & 98 \\
\hline
\end{tabular}


TABLE 14

GRADUATION PROGRESS REPORT

OF EASTERNVILLE HIGH SCHOOL

FRESHMEN AND SENIORS ( $(8)$

\begin{tabular}{lrrrrrrrrr} 
Easternville & .81 & .82 & .86 & .87 & .88 & .89 & .90 & .91 & .92 \\
\hline Freshman & 36 & 45 & 64 & 62 & 55 & 55 & 58 & 50 & 59 \\
Seniors & N/A & N/A & 82 & 87 & 87 & 90 & 90 & 82 & 84 \\
\hline
\end{tabular}

The third controversy was the political impact of the standards. When asked if the school district was pressured to review the standards, Mr. Carter referred the pressure from the general public as one of the factors leading to the review process,

We have to help the levy, the tax base. The administration is concerned that if we look at it in the negative -- kind of what haven't we done -- that will come across. They are nervous about the headlines [which] will say "look at what Roseville School District hasn't been doing." On the other hand, I think generally the public definitely is asking for more accountability, and that certainly is coming from the business community, who in one sense has been our biggest advocates.

Mr. Kennedy, another board member in this process, perceived the graduation standards as not only too low but also too narrow. To Mr. Kennedy, it was a minimum standard. Instead of measuring the students' performance, it merely represented "a low limit on a control chart." The students who did not pass the graduation standards needed some remedial services. A "mastery oriented 
examination" was needed to determine if "a student actually accomplished what he needed to accomplish in high school in order to get a diploma."

The concern that the standards were too low was not shared by Mr. Roosevelt, a high school principal, whose students came from low socio-economic families. For Easternville High School, the number of seniors not passing the graduation standards was as high as 16 percent in 1992,8 percent higher that the district average. According to Mr. Roosevelt, the standards were not too low. For those students who did not pass, "there were too many other obstacles going on with kids lives that impeded the delivery of instruction."

Mr. Harding, the principal of Westernville High school, did not think the review process was necessary, because "the Graduation Standard Tests were really no longer even meaningful for 60 percent or more kids in Roseville Public Schools." Further,

I didn't find it a particularly meaningful exercise because the standards are already set so low for district-wide testing, and they were so different from school to school. The content of an Advanced Humanities class at Westernville compared to that of other high schools are so disparate. I mean the difference is so enormous yet they carry the same amount of credit and they would allow a student to graduate. So, it [the review process] is a meaningless exercise, unless something is done about it much more fundamentally. 
The fourth controversy was the potential dropout rate if the standards were raised. Mr. Poorman, the administrator in charge of curriculum, was concerned about the consequences of the review process. He feared that "the standards would be set so high that we would push students out." In his opinion, the review process was a situation

where the process may be as important as the outcome. If enough people have an opportunity to be involved in that and to buy into it, as we are addressing the questions, then I think they will feel committed to it and move on to it. If it is seen as something from on high, that's handed down and forced down people's throats, I think it's going to be difficult. I was concerned with the process that I felt like the board was asking for because their primary approach was to ask business people and parents. I think that they are important players, but involving only them, ... it is not sufficient.

The consequences were viewed as both political and educational. Yet, the board members were more interested in the agenda of public opinion while the school administrators viewed the students' learning as the priority. However, both sides viewed their priority as the fundamental issue in today's education. The review of high school graduation standards was a vortex matter, with all the characteristics defined by Hickson and his colleagues (1986). 


\section{Decision Interests}

The topic of reviewing graduation standards was borne out of strong interests from the concerns of the school board, although the decision makers had very specific purposes in mind for the review process.

Mr. Copelin, a board member who was very active in the review process, wanted to achieve the following through the review process,

1. An intellectually defensible graduation standard by looking at the areas we consider sufficiently in our definition of either the utilitarian or humanistic goals of education that we want to educate students in those areas.

2. What are the different means of assessing competence, skill, or achievement in those areas? And which of those means reliable and cost effective?

3. And now that we know what areas are our core, and what assessment techniques are practical, do we want to establish the norm or the cut point?

Mr. Copelin's interest in this review process was two-fold: define a graduation standards that "ensure employability [of the graduates]" and "ensure an educated person." The educated person, Mr. Copelin added, "whatever that means," should be defined "in terms of a sense of a culture, a sense of history, a sense of values."

Mr. Kennedy had one simple interest: define the graduation standards at a mastery level. For those students who could pass it, a standard diploma would be 
handed out, and those who could not, a different kind of diploma would be given.

School administrators, on the other hand, did not express any interest in the review process. Many of them pointed out that they were doing it because it was their job. To Mr. Lee, the review process "was yet one more task for us to do, and people were already very busy dealing with a lot of things, and so they had to work this in along with all of the other things that they were doing."

Mr. Adams pointed out that the passing of graduation standards was not meaningful to the high schools because the majority of students had passed the test before they entered high school. At their best, the graduation standards "are a minimum entrance [standards] to high schools." Mr. Jefferson, the superintendent, had two interests in the review process. One was to "cause students to strive higher, to work harder to try harder." The other was to have standards that "must be realistic, must be reachable; and yet it must be challenging and meaningful, useable and sensible."

Mr. Truman, a key player in the process, had a very different attitude toward the issue. After he learned about the pros and cons of the review process through the 
large amounts of information his staff gathered on a fulltime basis, his main interest became to "achieve holding/buying enough time to find out what the state was going to do, so we would know what we were responding to." Although his concerns over the consequences of a changed graduation standard was largely ignored by other decision makers, he himself believed strongly that the review process was not necessary at that time. It was "too big a project for us to handle locally."

The diverse interests in the review process further proved the vortex nature of the decision topic.

Decision Problems

The decision topic with diverse interests generated several problems in the review process. The number one problem in the review of high school graduation standards was the lack of interest the school administrators had in the review process itself. Although the school administrators strongly believed that the review process was not a bad thing to do, they did not have the time to make the process a priority in their daily operation. Further, they perceived the process one more thing to do in addition to their daily routines.

The second problem of the review process was the different perceptions of the function of this process. To 
the school administrators, the review process was first of all a political one and had "little to do with kids." Although they agreed this political need should be fulfilled, the fundamental issues in education was still the academic achievement of the youngsters. As a result, the unwillingness and reluctance of the district staff members to carry on created tensions and conflicts during the process, adding more frustration to an already complicated process.

The third problem in this process was the vague statement of the "review" process. Just what topic to be reviewed was and how far the decision makers should go to "dig things up," was never clearly defined. Due to this uncertainty, the district staff members approached the issues with procrastinated caution. The "uncertainty avoidance" (Hickson et al. 1986) created the "foot dragging" behavior on the part of the district staff members.

The topic also generated a few controversial issues that the decision makers had to deal with. The responsibility of today's educators and the common social problems that occur within the boundary of schools were debated over and over again among the decision makers. Many of these debates had no easy answers. Potential 
problems such as "dropouts" or "push-outs" raised more fundamental questions. The impact of these issues was more than what educators could handle. The result was a nonreconcilable situation among the decision makers. The biggest problem of all was the diversity of the decision problems.

THE PROCESS: SPORADIC

The review process was a vortex matter characterized by a highly consequential, highly political and highly complex nature. It also had impacts on many parties if the standards were reviewed and changed. Due to these characteristics, the review process was slow, bumpy, and full of surprises to many decision makers. It was a typical sporadic process (Hickson et al. 1986).

The Phases of the Review Process

The review process went on for about three years, during which the decision makers identified the topic, developed the procedures to carry it out, and put a stop to it before any outcome was achieved. Although there was no clear cut line between one phase and another, this process could be roughly divided into three phases which were characterized by the initiators and the decision makers working together in an ad hoc committee, with 
different players flowing in and out at various times.

The identification phase was limited to the decision initiators, who were school board members. After $\mathrm{Mr}$. Carter proposed the review, the school board of education went through some discussion regarding the topic. During the discussion, the board members focused on the political impact of the standards and agreed that this topic was worth looking into.

Since the school board of education had quite a few topics to discuss and each board member had his own focus, the topic of the graduation standards was not the only item on the agenda. Rather, it was a sub-goal of a general goal, which was "to increase the percentage of students graduating from high school." Although the specifics were not identified, the school staff were obligated to implement it.

The lack of specificity in the board goal made the developmental phase of the process a long and tedious one. Mr. Truman and his staff worked very hard to define the problem among themselves, without much success. As a matter of fact, throughout the review process, many decision makers were not sure they understood the intention of the school board at all. In retrospect, Mr. Bruce thought that the "vagueness of the mission" became a 
focus for the school staff for a long time in the developmental phase. Mr. Kennedy, who became the chairman of the board Education Committee, was frustrated. He said,

Especially once the discussion got going, it was pretty obvious that the board nembers were not getting [it], what the staff thought the board wanted and what the board thought what it wanted were not the one and the same. So there occurred some rounds of meetings. And the nature of the meetings was one of the staff bringing to the board committee, like bringing in a rock, like they brought several rocks. They would say, "do you like these rocks?" And you wold say, "no, we don't like those rocks. Go away and bring us some more rocks." So, they would go away and bring us more rocks. And on the part of the staff [they were] struggling trying to figure out what it was that the board members were saying. It was not a real clean discussion.

The process at the developmental phase was full of discussion regarding "what rocks" the board really wanted.

Further into the developmental phase, the school administrators were at a loss because of the tremendous amount of work involved. Since the task was vague, the attempt to satisfy the board members was never successful. Mr. Truman, the assessment expert and the leading administrator in the review process, prepared Briefing Book I and Briefing Book II, then he developed the plan to review the graduation standards. His briefing books contained several hundred pages and took two full-time staff to finish. Yet, very few decision makers ever 
quoted the briefing books as their information source, and Mr. Truman's concerns were completely ignored.

Toward the end of the developmental phase, little interest existed to continue the process. Meanwhile, the voters passed a measure to limit school funding and the tax base for Roseville School District could face a major financial crises. In addition, the measure put the state as the major funding source for local school districts in the state and limited local control in many ways. The decision makers were polarized at the later part of the developmental phase. As Hickson and his colleagues point out, when delays and interruptions occur, the review process was no longer a priority. When the state department of education announced its own attempt to design high school graduation requirements, the review process was put on hold. Thus the finalization phase led to the result of the three-year review process: no outcome. The finalization phase of this review process lasted about two months and was completed in two hours: at a board education committee meeting in september 1991, Mr. Copelin announced that the process was stopped. Only a few decision makers were present at the meeting. Most of them learned about the outcome by reading the board meeting minutes months later. 
There was a diverse reaction to the "on hold" announcement among the decision makers. Mr. Poorman was surprised that process was stopped without any discussion among the decision makers. The state department of education, should not be the reason at all to terminate the process, according to $\mathrm{Mr}$. Poorman.

Mr. Adams, the high school principal on the review committee, believed that the outcome of this "aborted decision-making" was "not surprising" to him. "Although the school board wanted to raise the standards," he said, " some other people thought we should eliminate it all together." Since Roseville School District had had a high school standard that "was valid and feasible and it had worked," decision makers came to a conclusion that it was not an ideal
situation but not all that bad. So we had decided to
stay with it. We sort of wanted to see what happened
around us. Since then, the budget has become very
important for us and [the review process] was just
dropped. People now are more concerned about
survival than about validating kids'learning. The
process had stopped because it had became unnecessary
to continue.. . There wasn't anything written to
say that let's stop it. But the concern of the
school board had shifted and the topic was dropped.
other things were going on.

\section{Interruptions and Delays in the Process}

There were internal and external interruptions throughout the process. Internal interruptions were 
mainly caused by the many other things that needed the attention of the decision makers. "Time was always an interrupter," many decision makers pointed out. Daily routines at the departments or schools of the decision makers were major internal interruptions of the review process. For instance, Easternville High School had gang activities that constantly needed attention of the principal. At Westernville High School, parents were concerned about their college-bound children and the academic issues related to high income families. Mr. Davis remembered that "time of people [was a problem] ... it was yet one more task for us to do." So "meetings were postponed and rescheduled."

The unclear picture of the review progress was an interruption for Mr. Bruce, the curriculum assistant director whose major responsibility at that time was the review process:

I dian't know from week to week whether we were "on" or "not", "on" meaning we were going to continue with this project, because the clarification was not forthcoming or we were talking to $\mathrm{Mr}$. Copelin and he wasn't quite sure what he wanted to happen. So it would languish for a week or so, and then all of a sudden, it came back with gusto. It was a very bumpy road.

Mr. Bruce further identified Mr. Copelin as part of the internal interruption. "We were unable to get a 
consistent statement of the purpose or even goal" [from Mr. Copelin]. Although many other district staff members never articulated this as clearly, they shared Mr. Bruce's opinion.

The state department of education was one of the external interruptions to the process. In addition to many internal interruptions, $\mathrm{Mr}$. Truman had warned $\mathrm{Mr}$. Copelin and other board members of the coming education reform at the state level. If the state redefined the requirements of high school graduation, the new requirement would have some impacts on Roseville School District. Therefore, "we should be cautious about taking on a local redefinjtion of goals and objectives," suggested Mr. Truman. Yet, to Mr. Copelin and other board members, Roseville School District was one of two districts in the state that had independent high school graduation standards and enjoyed local control. Several other events could also be included as the external interruptions. The voters passed a tax limit on school funding. A local ethnic organization boycotted Roseville School District. A high power "Leaders' Round Table" volunteered to develop the high school graduation requirements. These events, not directly but indirectly distracted the decision makers' attention and energy. 
THE AD HOC COMMITTEE FOR THE REVIEW PROCESS

Decision-making in organizations reflects first of all the nature of the organization. At Roseville School District, the procedure to make policy decisions usually started with an ad hoc committee. Mintzberg shows that ad hoc group was a common phenomenon in organizational decision-making. According to Mintzberg, the ad hoc committee was an organization within the organization and it can deal with one topic at a time. Also, an ad hoc committee is a manageable size for organizational decision-making. At the same time, an ad hoc committee also creates problems for decision makers because it is temporary and its members come with a diverse backgrounds and interests.

The Nature of the Rosevilie Ad Hoc committee

The group that actually carried on the review process for three years at the Roseville School District was not at all formal. Instead, it was a combination of a few school board members and representatives of assessment, curriculum, and instruction. This group was formed under the circumstance of necessity and convenience: some were assigned the task and some had personal interests. Working together was not a choice but 
a given situation.

Mr. Copelin was the chairman of the board education committee, and he was personally interested in the issue of high school education. He had well thought out ideas on high school graduation and he was able to articulate his points during the interview. However, he was never very clear to other decision makers in regard to his own opinions. According to copelin, he would rather leave "the door open." As a result, he was willing but not able to lead the review process.

Mr. Truman's department was in charge of the assessment issues. As the director of the assessment department, he was assigned to lead the process. Yet his closeness to the relevant information made him aware of the problems before anyone had any grasp of the situation. This advantage created a dilemma for him: if he informed everyone what he knew, he was a "foot dragger"; if he held all the information to himself, he was frustrated. He did inform everyone quite a few times and he was perceived as "the foot dragger" of the review process.

Mr. Poorman was the leader of the curriculum department which was in charge of the curricula issues of the standard setting. As a new director, Mr. Poorman was not familiar with the director-level procedures of the 
district. In addition, he took the lead of the process unwillingly, only after $\mathrm{Mr}$. Copelin insisted. He relied heavily on Mr. Truman and his own assistant director, Mr. Bruce, who was also new to the job.

Both $\mathrm{Mr}$. Lee and $\mathrm{Mr}$. Adams were instructional leaders, appointed by the deputy superintendent Mr. Madison, to participate in the review process. They were absent from the meetings a few times due to their own responsibilities in the schools.

This ad hoc committee was characterized by several traits. First of all, it was established according to the pre-existing organizational rules and standards at Roseville. The official positions of the decision makers required that each fulfil his own responsibilities in the ad hoc committee with his own understanding and expectation of the task. Since all group members held different positions in the district, their priorities were sorted according to their own units and departments. Second, their closeness to the issue was determined by their official positions, but these official positions were not as important as their participation in the ad hoc committee activities. For instance, although Mr. Copelin was the chairman of the board education committee, his participation in the review process was not frequent 
enough for him to understand the other decision makers or the whole picture of the decision process. On the other hand, Mr. Truman was the key player and carried a lot of weight in the process. His behavior, perceived to be "foot dragging" at times, was a key factor to the result of the NDR process.

\section{The Environment of the Ad Hoc committee}

An important factor in the review process was the close connection of the ad hoc group members to their peers outside the committee. These connections became an immediate environment that was very difficult for the decision makers to ignore. With responsibilities to review the standards, the decision makers needed to focus on the decision topic. Yet, as representatives of their departments and subunits, these decision makers had also to consider the interests of their departments. As a result, they were constantly balancing decision interests and their routine responsibilities as principals, directors, or area superintendents. When they had to make a choice, they put their routine responsibilities as priorities.

This environment created complexity to the review process. For instance, Mr. Poorman took the review process to several high school principal meetings, for 
fear that a new standard would be developed without sufficient "buy in" of the necessary parties. These discussions and information sharing sessions were not important part of the review process, yet they were significant events for Mr. Poorman who felt that he was doing his best to "involve everyone." "Although they were not directly involved," said Mr. Poorman, "I want to make sure that they were indirectly involved."

Mr. Truman was also concerned that insufficient communication in the review process would be a problem in the future. He, too, brought his plans to review the standards to the high school principals' meetings and area superintendents' meeting. In particular, he solicited the opinions of these important players who were not decision makers. Although he heard very little from them, their "lukewarm" response was a strong indicator of their attitudes. These important players were not interested in the review process.

Mr. Copelin, another key player in the review process, had an information sharing session with the public. Shortly after Mr. Truman's plan was introduced, he held a meeting with the community representatives to share his thoughts on the review of the graduation standards. 
Information sharing sessions between the decision makers and their own groups outside the ad hoc committee created some misunderstanding within the committee. Mr. Poorman was upset at Mr. Copelin's community meeting, "I felt the board's primary approach was to ask the business people and the parents. I think those are key, important players. ... But only them, it is not sufficient."

The immediate environment of the ad hoc committee was both dynamic and complex, which created frequent dilemmas for the decision makers. Another striking characteristic of the ad hoc committee was its diverse and uncoordinated activities which were never planned. As a result, there was a lack of communication among decision makers and confusion throughout the process.

\section{The outcome}

The NDR outcome was inevitable for the review process since the topic was controversial and complicated: the problems were too difficult to solve and the interests were too diverse to reach any consensus. In addition, the operation of the ad hoc committee reflected the garbagecan phenomenon where players flew in and out of the activities in many directions. Figure 8 is a summary of the process model in explaining the NDR outcome. 


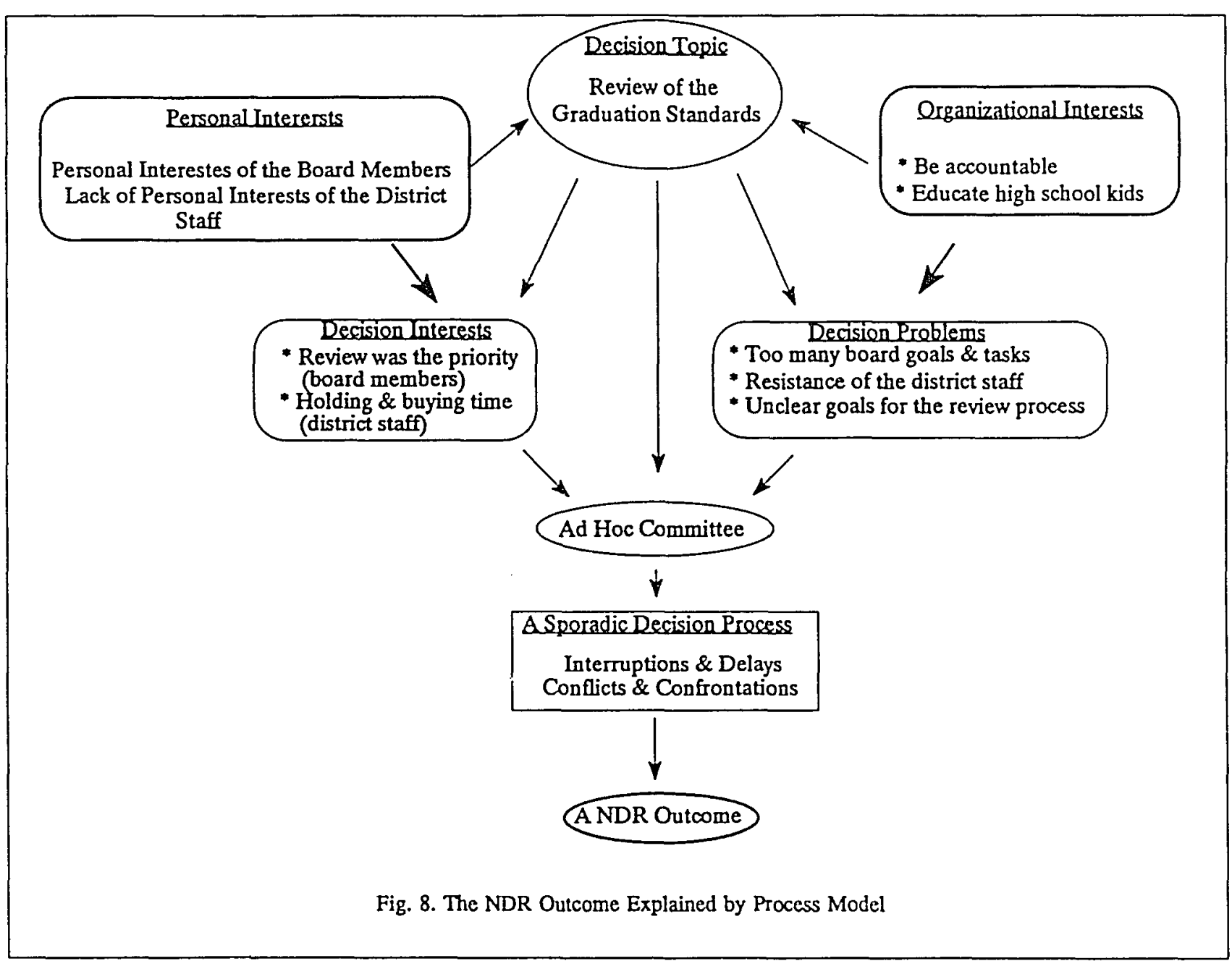


The numerous conflicts, interruptions, and delays also made the review process a very frustrating one for the decision makers. The debate over what to do in today's education was exhausting to the decision makers, who had a full load of daily operations to handle. Toward the end of the developmental phase, it became a difficult task to schedule a meeting. The process had become a burden. As Mr. Adams pointed out, "the need to continue was gone. So, when there was an opportunity to stop, it was stopped."

The "opportunity to stop" was identified as the activities at the state level and the coming budget cut of the school district. The board had to review the financial situation of the school district of the coming years. Energy was no longer available for the review of high school graduation standards.

\section{A Process oriented Tendency}

The interview data revealed that the district staff members felt that the reviewing of the graduation standards should be a process. This tendency to be "process oriented," which focused on the process rather than the outcome, was one of the concepts of the process model.

To understand the concept of the process-oriented 
phenomenon, one must understand an important distinction between problem solving and decision-making. For the former, one asks "how a problem is originated"; for the latter, one finds out "how a decision comes about" (Hickson et al. 1986). The process model holds that "since the means of getting there is important itself, the outcomes are almost besides the point, and the true focus and emphasis are instead on how one gets to them" (Hickson et al. 1986). The reason for a decision maker to ignore the outcome is due to this dual-rationality nature of the process of decision-making.

It is important to understand that the process of decision-making has two purposes. One is problem-solving and the other is interest-accommodating, indicating a rationality that is different from that of the rational choice model. According to the process model, there are needs within the organization to solve problems and there are also needs to accommodate interests. There are times when the needs to accommodate someone's interests far exceed the needs to solve any problems. There are also times that the accommodation of the interests is much easier than solving any real problems. The case at the Roseville School District was a typical example of the latter situation. 
Although the review process did not achieve any results, the process accommodated the needs of the board members to examine the graduation standards and brought several parties together to discuss an important issue in today's education. Both were worthwhile tasks. Therefore, many decision makers believed that the process itself was both positive and healthy. 
The organizational model of decision-making focuses on the decision-making behaviors from an organizational perspective. Decision-making process is first of all an organizational process. The decision-makers behave according to specific organizational procedures and standards. Organizational goals and interests predetermine the decision-making process and provide guidelines for decision makers in decision processes.

organizations make decisions to close the gap between an expected state of affairs and the reality. In many cases, this perceived gap indicates a problem for the organization to solve. To complete an organizational task, organizations need to address these problems. Which problems to solve and how to solve these problems are topics for decision-making studies in organization. Organizational structures, which represent the relationships of organizational power and politics, are indicators of such problem solving process. The decision-making process, a focus for the process 
model, is not a focus for the organizational model. Instead, the decision-making process is perceived as an organization procedure in a broad context. Individual decision makers are not independent decision makers but players who have other organizational responsibilities. No matter what they do in the decision-making process, their organizational responsibilities remain their priorities. In summary, a decision maker is first of all an organizational player.

organizational environment is an important variable in the organizational model. Although an organization has very little control over its environment, the environment shapes the organizational decision-making and raises new problems for the organization. So, organizational decision-making is effected by the organizational environment.

\section{THE ORGANIZATIONAL RULES AND PROCEDURES}

The process of graduation standards review reflected the complex nature of today's public education, Roseville School District in particular. Since the state government required certain standards for high school graduates, Roseville School District not only complied with the state authority but also created additional standards. The reason for the extra work was to make a statement to the 
public and guarantee school funding. The mission of graduation standards was two fold. One was to do more than the state requirements for the high school graduates. The other was to make a political statement. Both purposes were legitimate missions of the Roseville School District.

According to the model of organizational decisionmaking, the organizational rules and procedures provide a general guideline for decision makers in the decisionmaking process. The organizational routines are far more important than the decision-making activities. When conflicts occur between the two, the organizational rules are used to find a solution.

Although the board set goals for the district staff members to implement, the academic merits of these goals were frequently questioned. Since it was also a rule that the district staff members had very little input in these goals, many of these goals remained general and superficial. The implementation of these goals frequently became an open-ended question. For many principals, an end of year report addressing the goals was sufficient. Another informal rule at Roseville School District was the autonomy of the instructional staff in conducting the classroom teaching within the curriculum frameworks of 
the district. As long as "nothing was broken," business went on as usual regardless of the board goals.

\section{The Academic Merit of Standard-Setting}

The academic merit of standard-setting was a topic of debate during the review process. In particular, the decision makers had different perceptions about the functions of the standards. A higher standard, according to many decision makers, does not necessarily lead to better learning or better teaching in schools. In fact, "you have got to look at the curriculum that you are running these kids through that is being tested and how are the learning experiences in the [classroom] related to the measures themselves," pointed out Mr. Larry, an area superintendent.

The topic of curriculum was mentioned over and over again in the interview by many decision makers. Curriculum, not graduation standards, was considered one of the most important issues in standard-setting. Although graduation standards are considered as one of the major indications of the public education, the task of producing quality instruction to reach the standards depends upon a strong curriculum. A standard means nothing if the curriculum is not in place to help teachers focus on an effective instructional program. 
Unfortunately these two important pieces in education reform, curriculum and instruction, were missing in the review process.

Another issue with standard-setting is related to the cut points of the standards, especially minimum standards. These standards were minimum competency standards which students had to pass. At times, these minimum competencies were "unnecessarily minimum and they existed because they are measurable, not because they are the best minimum competencies," according to $\mathrm{Mr}$. Hoover, an area superintendent.

one major reason for these minimum competencies to exist was the pressure to decrease the dropout rate. As Mr. Harding pointed out,

We are caught in the classic conundrum. You have that 10 percent [of the students] at the bottom who are never going to study. They are never going to make any attempt to learn, and there is a lot of political presence trying to make sure they pass whether they put any effort into it or not. We are trying to lower out dropout rate and increase out high school graduation rate with kids who have no interests or investment in education at all. Some of them are so totally uninvolved with what is going on that they could not tell you how many credits they needed if their life depended on it. And those are the kids that we are pushing, straining, and struggling to get through these graduation standards tests. It is not sufficient that kids can graduate from high school and get a standard diploma and know the meager amount that they know. Then there are all the other critical questions over here that 'don't hold them back', 'don't fail them', don't injure their self-esteem', 'don't let the minority 
rates be high for dropouts' ... etc. So, with all of these political pressures competing against what you know is the right thing to do. ... That's why we end up in the middle.

In the middle is indeed the current situation of the minimum competency standards. When the majority of the students passed the graduation standards at eighth grade or earlier, the standards became a meaningless token. With two most important pieces missing, the review process became a meaningless exercise that did not fit the organizational procedures. Although the board members believed that the graduation standards could be addressed as an independent issue, the district staff members resisted that notion. To the district staff members, curriculum and instructional issies were far more important than the review of the graduation standards.

\section{The Political Aspect of standard-setting}

Although the political nature of the review process was unpleasant to many district staff members, none could deny the necessity to address the political aspect of it. The challenge was to find a balanced approach. The political aspect of standard-setting was full of questions and controversies, although the percentage of failures in graduation standards always raised the eyebrows of the general public; and there will always be failures. It is 
logical for politicians and administrators to minimize the severe political consequences of such failures and it is everybody's wish that students success year after year. Yet, the very purpose of setting the standards is to distinguish the successful from the failures. It is a dilemma.

The current graduation standards at Roseville were minimum competency standards so that the majority of the high school students could pass the test and graduate with a standard diploma. The lower a standard was set, the fewer the students who would fail.

The fear of political consequences made the board members very uneasy. During the board planning sessions, the first few goals of the district were about the academic standards of the students. To the school board of education, the standard-setting process was certainly an issue of school accountability. Most important of all, it was a political priority.

However, the emphasis on the political consequences of the graduation standards was upsetting to some district staff members. Mr. Bruce perceived the whole process as "political" and that "it had nothing to do with kids." Mr. Truman believed that "the current standards had gotten so low was a political concern for the policy makers and 
for the board. They were afraid that we would be

legitimately chastised for having such low standards."

Mr. Harding did not think that the political concerns

of the school board were well justified. Instead, he

believed that there should be consequences if a student

failed the graduation standards:

Well, maybe they have to drop out [if they fail the test]. Maybe there is consequence for not doing what you are suppose to be doing in a school. I mean if there were consequences for everything else in life, maybe there should be consequences [if they fail school]. Maybe the public, the board, and everybody else has to realize that being able to educate 80 percent and do a good job of it is a lot better than fumbling through with 90 percent and pushing out 25 percent who don't know anything.

Mr. Larry believed that the review process was partly

a result of the "education bashing that went on for quite

a few years." He started further that,

the business industry, the politicians, particularly those two groups, have made education, particularly K-12 education, a whipping boy, for lots of reasons. Business failure has been blamed on poor education of youth, which I think is ridiculous. Politicians grab it and run with it and make hay with 'I'll bring you a better education system'. The whole rhetoric about international competition, I don't believe that there is solid data for justifying that at all. The politicians run with it, people read somebody's book somewhere and they take it and beat us up about how well other foreign countries are doing better than our students.

The frustration experienced by the decision makers was a consistent phenomenon found by many scholars who have observed increasing problems in education 
organizations due to environmental issues (Wirt and Kirst 1982 ; Corwin 1982; Derr and Gabarro 1982; Boss and Zeigler 1982). As the political pressures increase to demand more on the public education, school districts are forced to address and deal with these political problems such as graduation standards.

\section{ORGANIZATIONAL ENVIRONMENT}

The diverse reaction on the part of the district staff members to the board's decision to review the graduation standards was not surprising in view of public education today. As many scholars demonstrated, today's public education is in the middle of many social and economic changes. These changes create an unstable environment for the organization and throw public education into many controversies and dilemmas. Several institutions that directly created such controversies and dilemmas can be identified in the environment of the review process.

\section{The State Authority}

Scholars have identified several factors of curriculum policy-making that effect the classroom practice and situation. The first factor is the nature of the legal authority that "determines the curriculum." For 
instance, the state department of education was in the process of developing an educational reform bill. If passed by the state, this bill would transform the public education into a new system characterized by new graduation standards at the high school level. The proposed new graduation requirements included foreign language proficiency, a senior project, and a performance assessment for high school graduates. Although Roseville School District was known to have more requirements of its school graduates than the rest of the state, the political impact of this new bill was overwhelming to the staff and administrators of the district. Potentially, this new bill might require Roseville school District to change its curriculum and graduation standards completely. The areas of the importance would be different, and additional areas would have to be identified. Further, performance assessment might be used to replace the traditional standardized testing.

This situation challenged the board's goal to review the current graduation standards and the review process. Mr. Truman, who learned about those activities at the state level shortly after the beginning of the review process, warned the board members at an educational subcommittee meeting. In addition to his concerns about 
dropouts and push-outs if the standards were raised, Truman pointed out that the state might pass the bill and then a new graduation requirements would be in place. When that happened, Roseville School District would have to review many curriculum and assessment issues. The fact that state authority was looking at this issue indicated the significance of the graduation standards and also indicated that the scope of the project was beyond the ability of a local school district.

Mr. Copelin, however, perceived that situation differently. The activities at the state level were important events and would definitely have some impacts on Roseville. However, Roseville always had its own requirements and standards. As to the fundamental issues in curriculum and assessment, Mr. Copelin believed that local districts should always have their own choice. The argument between $\mathrm{Mr}$. Truman and $\mathrm{Mr}$. Copelin reflected a "war between central tendencies and the desire to preserve local rights" (Schaffarzick et al. 1979).

\section{The General Public}

The second factor in curriculum and standard-setting reflects "the political influences on such a policymaking" (Schaffarzick et al. 1979) by the general public. In discussing the political pressures on policy-making, 
scholars believe that the key issue is "whether the schools should help maintain or change the society" (Schaffarzick et al. 1979). To maintain the society requires an ability to respond to the changes in society accordingly. To change the society is perceived as risky by many in education (Shaffarzick et al. 1979). Therefore, the dominant pattern of decision-making in education is by incremental change. Because of the tendency to avoid explicit value judgements, the strong sense of uncertainty and lack of information, the long wait to be able to evaluate results, and education's dependence on its environment, few decisions are reached by long-range planning methods of stating goals, looking for alternatives, and forecasting their possible costs and benefits (Shaffarzick et al. 1979).

The review of graduation standards was a typical example of an "incremental" decision process. According to Mr. Carter, the reason for him to raise a curriculum issue at the board planning session was because his memo to the superintendent did not generate much of a response. Such a slow response, pointed out Mr. Carter, was very typical of the district. It was typical of the district administrators to wait for things to happen. The district administrators never took a proactive role in starting 
anything new. Therefore, he and several other board members had to step in and "stir things up" a little. However, Mr. Carter did not stir too many things up. The review process met some implicit yet strong resistance from the district staff members. Consequential, the board members had to come in and push the process. At the same time, Mr. Truman's strategy was "to hold things up and buy more time until things were clear at the state level for the district to respond to." $\mathrm{Mr}$. Truman's "foot dragging" behavior, perceived by Mr. Copelin, was not unique in this process. Mr. Poorman, the curriculum leader who took on the task after Mr. Truman was removed from the leadership position of the review process, had the same attitude. Both Mr. Truman and Mr. Poorman believed that a process such as graduation standards should go through a long open process with teachers, principals, parents, and other interested parties. Both had the attitude of you-push-I-move during the review process. Without any forceful push from Mr. Copelin, neither of them initiated anything. Both believed that a review process such as graduation standards should "be [a] tradition-bound, slow sequence of incremental changes" (Schaffarzick et al. 1979) and a clear call to respond to. 
The tendency to keep the status quo on the administrators' part upset Mr. Copelin tremendously. over and over again, he pointed out that "the society is changing, the technology is changing, education has to change too." It took the district staff members a long time before they "got the idea that we were serious," said Mr. Carter.

The Business community

The third factor in curriculum and standards policymaking came from the pressure of the broad social, economical, and political determinants on curriculum changes and stability. Specifically, corporate industrialism, progress, work force and economic recession are social factors that contribute to the complexity in the areas of competencies. Closely related to the second factor, schools today are asked to be "an engine for progress and reform," but at the same time are also expected to "maintain the society" (Shaffarzick et al. 1979). The result is an ever "more cumbersome context and structure for decision-making, making incremental policymaking increasingly likely" (Shaffarzick et al. 1979). Another question raised was related to the business's needs. Although decision initiators, the board members in this case, voiced a lot of "business's concerns" in their 
discussion, there was no concrete data to demonstrate the specific needs. Finally, the information did not answer some fundamental questions in today's education. For instance, what is the boundary of today's education? Should schools teach reading and mathematics? or should schools teach everything that a student needs to know to be a functional individual? Can schools teach everything? With more questions in mind, Truman asked his staff to search for more information. Since the questions were more focused than before, the search was in the competency areas for graduation standards.

Mr. Truman's report on "A Review of the Literature on High School Graduation Competency Requirements," identified

1. Areas of competence of schooling

2. Areas of competence of state tests

3. Areas of competence of districts tests

Mr. Davis pointed out that business leaders had become increasingly concerned about the lack of a sound education system and quality work force and a fear that "Us productivity will decrease" (Natrillo 1990). The claims were that "many entry-level workers lacked pre-requisite knowledge, skills, and attitudes." The inadequacy of the entry-level workers was caused partly by the rapid 
development of technology and partly by the insufficient pool of entry-level workers. Mr. Davis also examined the areas of competence defined by businesses: reading skills, mathematics, writing, problem solving, employability, organizational effectiveness, creativity, and analytical skills. As the terms indicated, some of these areas were extremely difficult to measure. Further, these terms reflect more of the varieties of definition than an adequate description of competence areas for entry-level workers.

Mr. Davis also found out that the areas of competence defined and tested currently in schools did not match what the business community defined. The only matching competence areas were reading skills, mathematics, and problem solving. Schools defined social studies, health, global studies, career education, culture and arts, and history and government as important areas for graduates (see Table 15).

Mr. Davis' report and the reality at Roseville School District matched almost perfectly: the school administrators and the board members had different perception of competence areas for high school graduates. Mr. Hoffman, who was in charge of career education in the 
TABLE 15

COMPARISON OF COMPETENCE AREAS

\begin{tabular}{|c|c|c|c|}
\hline $\begin{array}{l}\text { Areas Identified by } \\
\text { Business }\end{array}$ & $\begin{array}{l}\text { Number } \\
\text { of } \\
\text { Studies }\end{array}$ & $\begin{array}{l}\text { Areas Identified } \\
\text { by Public Schools }\end{array}$ & $\begin{array}{l}\text { Number of } \\
\text { States } \\
\text { Testing } \\
\text { the Areas }\end{array}$ \\
\hline Reading & 7 & Reading & 18 \\
\hline Mathematics & 7 & Mathematics & 19 \\
\hline Writing & 7 & writing & 15 \\
\hline Problems Solving & 7 & Language & 6 \\
\hline $\begin{array}{l}\text { Employability/Work } \\
\text { Attitude }\end{array}$ & 7 & Science & 5 \\
\hline Speaking & 6 & Social studies & 4 \\
\hline Listening & 4 & Citizenship & 2 \\
\hline Ability to Learn & 4 & Problem Solving & 2 \\
\hline $\begin{array}{l}\text { Interpersonal } \\
\text { Skills }\end{array}$ & 4 & Health & 1 \\
\hline Science/Technology & 2 & Career Education & 1 \\
\hline $\begin{array}{l}\text { Social/Economic } \\
\text { Studies }\end{array}$ & 1 & Global studies & 1 \\
\hline Creativity & 1 & $\begin{array}{l}\text { History and } \\
\text { Government }\end{array}$ & 1 \\
\hline Analytical Skills & 1 & Culture and Arts & 1 \\
\hline $\begin{array}{l}\text { Organizational } \\
\text { Effectiveness }\end{array}$ & 1 & & \\
\hline
\end{tabular}

district, pointed out that,

The state requirement does not include preparation for employment. We are not required to make kids ready to go to work. I don't think that in a four-year high school program that we are going to 
train too many students for a specific job -- welding or going to work in an office and being a professional secretary right then.

on the other hand, Mr. Copelin believed that,

our graduates were not graduating ready to work. In fact, they were not ready to work, and business had to either reject them, in which case they became unemployable in useful jobs, or business had to train them for business own purpose. In other words, there was not a useful product that we were producing, and I thought that was a legitimate, but not sole, or only goal of education. [The goal of education] was to see what the needs of the economy were and what we were producing .... , we had to make sure that those match up.

The fact that "those" goals do not match up was reinforced by Mr. Davis' report. School administrators were proud that other educators in the nation shared same opinion with them, and the board members were happy that they presented the interests of the business community. The disagreement was hard to reconcile.

Many groups with various intentions and diverse interests play an active role in curriculum policy-making. Also, "many of these groups mediate between the sharp probes of social change in schools, softening jagged points, smoothing rough edges, and selecting what is important that needed doing" (Shaffarzick et al. 1979). The active roles of these groups certainly made the task of reviewing the graduation standards very difficult for school administrators. With charges coming from many 
directions and with interests pointing to many directions, school administrators were at a loss. For instance, students from low socio-economic families needed help in basic skills areas, the business community demanded that high school graduates learn work skills, higher education required that high school graduates maintain high levels of academic skills, and ethnic organizations threatened a boycott unless the district narrow the gap between majority and minority students. At the same time, schools have to deal with an increasing number of students who need food and clothing.

THE ORGANIZATIONAL STRUCTURE

The dilemma regarding fundamental areas of competency was not the only one in the review of graduation standards. The organization of public education in America has some built-in structural dilemmas.

The Board and the District staff Members

The school board of education is one of the most intriguing part of the education organization today. Although school boards of education are as American as "mother's apple pie," many scholars, as well as educators, challenge the existence and the functions of the school boards. While the school board of education depends on 
professional educators for important decisions and the daily operations of schools, the board can be the most powerful entity of the educational organization. Acting as a vehicle of the general public, school boards of education have the authority to replace school superintendents in order to meet the desire and demand of the general public. Further, school board members are obligated to their constituencies and can be replaced through election.

The real functions of the school board of education are subject to debate. Profession dominant theory believes that professional educators dominate lay boards and communities. Specifically, "superintendents and other educational professionals insulate the school boards and the public from proposal development, recommendations, legislative actions, changes and implementations, and review processes" (Burlingame 1992). Since the board members are mostly lay citizens who are interested, but lack expertise, in educational issues, it is easy for professional educators to "insulate" them from real participation of policy-making. At times, some school board members use professional educators to "defuse some politically explosive issues" (Schaffarzick et al. 1979). other theories of school board of education, such as 
multivariate theory, present a "complex and interactive picture of local politics and education" (Burlingame 1992). According to the multivariate theory, the complexity of the picture is composed of the nature of the local community, the behavior of the superintendent, the composition of a particular board, and the type of issues or policy questions in consideration. In such a case, the interaction between the school board, the superintendent, and the district staff members is the key factor in educational decision-making. A strong board or a combination of a strong group of board members, such as Mr. Carter and Mr. Copelin at Roseville, could launch a decision process to review one of the most fundamental issues in education. The submission of the superintendent to the board, such as the case at Roseville, made the initiation possible. Even though Mr. Madison, the deputysuperintendent, raised strong protest against the board's demand to review the graduation standards, the process was initiated and launched into a full review. However, Mr. Madison's resistance to the review process was shared by the district administrators, who were closer to classrooms and students than the board members. While at the top of this educational structure, the school board of education is not a relevant factor in 
students' learning environment. A change in educational policy can only affect the lives of the students and teachers through a step-by-step involvement and implementation. In other words, policy change by school boards on paper may not mean much to the schools. The situation described above is termed "loosecoupling" by weick and is typical of educational organizations. By "loose-coupling," Weick refers to an organization that contains loosely connected parts or structures. The term "loose-coupling" carries "connotations of impermanence, dissolvability, and tacitness, all of which are potentially crucial properties of the 'glue' that holds organizations together" (Weick 1976) .

The Board and other Parts of the organization

A loose-coupled organization has several characteristics. First of all, the coupled events are responsive, but each event also preserves its own identity and some evidence of its physical or logical separateness. Thus, in the case of an educational organization, it may be the case that the counselor's office is loosely-coupled to the principal's office. The image is that the principal and the counselor are somewhat attached, but that each retains some identity and separateness and that 
their attachment may be circumscribed, infrequent, weak in its mutual effects, unimportant, and/or slow to respond (Weick 1976).

second, "to the extent that two systems either have few categories in common or share weak categories, they are independent of each other" (Weick 1976). If the board-superintendent-director is regarded as one system, and the principal-teacher-classroom-pupil is regarded as another, the superintendent can be regarded as looselycoupled with a teacher.

Finally, the image of the "loose-coupling" can be envisioned as building blocks that may "be grafted onto an organization or severed with relatively little disturbance to either the blocks or the organization" (Weick 1976). An example could be the unstable status of the position of the superintendent today. No matter how frequently a school district changes superintendents, activities go on within the classroom as usual.

The loosely coupled structures existed at Roseville School District. The world of the school board of education consisted of meetings with the superintendent and the district administrators. A teacher's life, on the other hand, was full of activities with students. The numerous board goals in the board planning sessions may be 
unknown to a classroom teacher at Roseville.

The same loose-connection could also be found between the school board of education and the district administrators, who shared the review of graduation standards at the time. This shared variable only occurred after the school board of education initiated the review process. And this initiation had no connection with the district administrators. The total disconnection of the decision initiation to the district administrators and the loose connection between the board and the district administrators created a unique and difficult situation for the decision makers.

The non-participation of the district administrators in the decision initiation made them outsiders to the decision process. Although many administrators agreed that the review was necessary, they also pointed out that the timing was not the most appropriate. As Mr. Jefferson, the superintendent, said at the meeting of the educational sub-committee,

I need to prioritize the items [on the planning book]. If graduation standards is the number one priority, I will do it. But [I will] not when there are fifty other things to do.

"Fifty other things to do" was a justifiable reason for Roseville School District not to review the graduation 
standards. The conflict over the priorities of the district was never solved. Meanwhile, the high school principals perceived the review of graduation standards as a non-impact issue on high school students. As a group, the principals felt that the problems at the high school level included low attendance, inappropriate tests, and lower achieving students. Looking at the graduation standards could not improve the situation. In general, the district administrators perceived the review of the graduation standards as the low priority for the district at the time.

A loose connection could be observed between the school board and the district administrators during the developmental phase of the review process. Since the two groups shared very little in common, the communication between them was impossible. Quite a few decision makers pointed out that they perceived a big distance between the school board of education and the district administrators. The poor communication and weak connection among the district leadership, the board and the administrators, was the most significant factor leading to the failure of the review process. This failure was a result of the structural dilemma. 
AN INEVITABLE OUTCOME

The image of "loose-coupling" reveals a novel phenomenon in organizations which are structural entities with an interrelatedness of the parts. Also, loosecoupling is found to be a frequent situation in educational organizations. As one of the most powerful ways to examine complex organizations, the concept of "loose-coupling" introduces categories such as organizational interests, subunit identity, and subunit independence.

The Review process and Organizational Rules

Organizational decision-making is predominated by rules which represent organizational structures. To coordinate large numbers of individuals and subunits, organizations follow standard procedures that provide guidelines. Decision-making processes in organizations reflect the nature of those organizations. Conflicts and confrontations during a decision-making process are continuations of the power struggles of the organization. The structures of the decision-making processes are a reflection of the organizational structures and the dynamics of these structures.

A loose-coupled structure, such as an educational organization, solves its problems in an incremental 
fashion (Sharffarzick et al. 1979). The loose connections between the parts often slow down the decision-making process and the incremental fashion of decision-making in turn reinforces the looseness of the parts.

In the review of high school graduation standards, there was a clear disconnection between the board members, who were the decision initiators, and the district administrators, who were decision makers. This disconnection was a reflection of an important characteristic of the loosely coupled organizations. That is, the structure of an educational organization is "not coterminous with its activity" (Weick 1976). Instead, a certain part of this structure is like a separate part of a building block. What is going on within this separate part has little or no impact on other parts of the same structure. Therefore, when the school board of education initiated the review process, the school business went on as usual and the impact of the review was only felt at Mr. Truman's level. A year after the review was in place, the impact of this process touched the high school principals and the area-superintendents only slightly. By the end of the three-year process, the teachers still had not heard of it.

The slow and weak response to the board's initiative 
to review the graduation standards also signaled another structural characteristic of educational organizations. A "cultural insurance" is a result of this slow and weak response. A loosely structured system "presents the identity, uniqueness and separateness of elements" by keeping its status quo as long as possible so that the system "can retain a greater number of mutations and novel solutions" to create a "cultural insurance" (Weick 1976), which is a resource to draw on in times of radical changes in the environment. Mr. Truman's "foot-dragging" was a strategy in response to the demand of the change iniliated by the board members. With tremendous amount of uncertainty in the environment, the best thing for $\mathrm{Mr}$. Truman was to "buy time" until things were clear. Therefore Truman's reaction to the board's initiative was a localized reaction to the idiosyncrasies of a particular board member.

It is important to point out the feasibility of $\mathrm{Mr}$. Truman's reactions to the board's decision to review the graduation standards. As part of the educational leadership at Roseville, the school board of education was not closely related in school operations. While the activities of the school board were important to the school district as a whole, they were insignificant to the 
teachers and students for whom graduation standards were daily encounters. Although the board of Education should react to new environment demands, the teachers could not afford the time and energy to do so. Instead, Mr. Truman's department, or anyone in his position, became involved in the response to the boards' request without disturbing the rest of the school system.

\section{A. Structural Explanation}

In addition to being a separate entity in educational organizations, the combination of school boards of education is constantly changing. Board members come and go as years go by. So, by buying time, Mr. Truman could have waited until $\mathrm{Mr}$. Copelin decided not to run for reelection. With Mr. Copelin gone, the interest of the board in the review process was also absent. Of course, Mr. Truman needed to respond to new requests of new board members in the future. As long as Mr. Truman occupied the position, part of his responsibilities was to respond to board's requests.

The impermanent interests and demands of the school board of education created a unique situation in the review process. Even though the school board of education initiated the process, it was obvious to Mr. Truman, who was an experienced administrator, that the board's 
interests in the topic were temporary, pertinent only to a specific board member. The fact that only one or two board members were interested in the review process greatly discounted the significance of the topic. The investment of the district administrators was perceived as a waste of time. The review process became an idiosyncrasy of Mr. Copelin's. With a built-in loose structure and the separateness of the school board of education, Mr. Truman's reaction was reasonable because it insured a minimal disturbance of other parts of Roseville School District. The cost of board-district interaction was greatly reduced.

Mr. Truman's behavior also helped reduce the complexity of the task and maintain the stability of the school operations. By slowly responding to the initiation call of the board, the process proceeded incrementally. With the district staff members involved only, the process was also simplified. The minimal involvement of the high school principals and area-superintendents reduced their time spent on the review process and insured their focus on their daily operations. The loose structure of the school district determined that Mr.Truman's department as the buffer between the board and the schools. So, even though the review process was a waste of time and was not 
productive, the loose structure kept the waste at a minimum level.

\section{The NDR outcome}

Figure 9 is a summary of the main concepts of the organizational model constructed as a result of this case study and an explanation of the NDR outcome.

The NDR outcome of the review process was not surprising when the above factors are considered. First of all, the weak connection between the school board of education and the rest of the school district generated some impossible missions for the review process. With very few common interests in the review process, the decision makers could not agree on the task of the review process. The debate regarding the areas of competencies reflected some fundamental discrepancies between educators and the business community.

Second, the structured dilemma created "foot dragging" behavior on the part of the district administrators, who acted as buffers for teachers who conducted daily operations in schools. Although the "foot dragging" was hard to accept for Mr. Copelin, it was reasonable and expected among the district administrators. By slowing down the process, Mr. Truman minimized the impact of the review process on the daily routine of the 
$\stackrel{-}{N}$

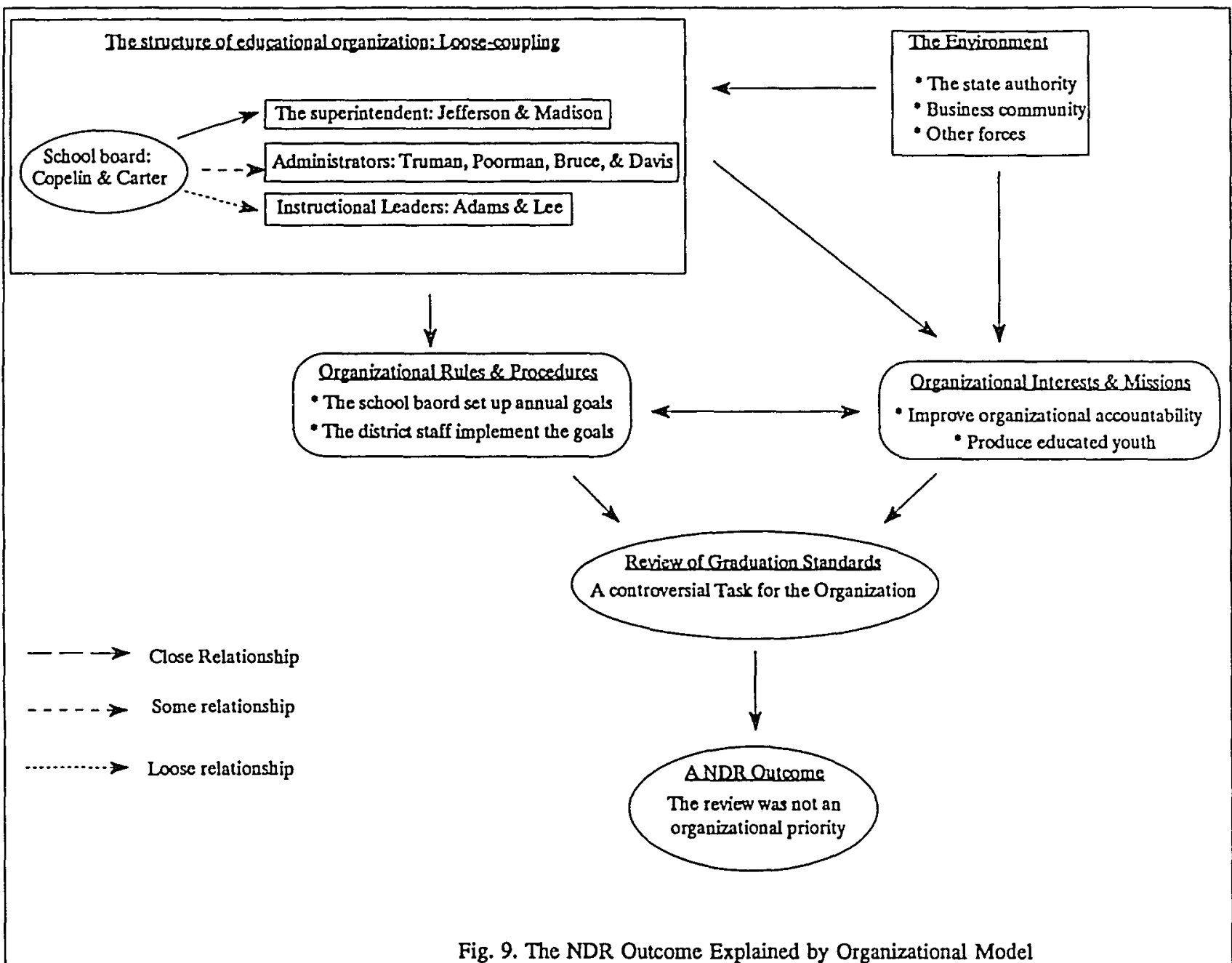

Fig. 9. The NDR Outcome Explained by Organizational Model 
Roseville School District. The NDR outcome was both logical and reasonable to the district administrators. Finally, the failure to reach any decision regarding the review process was due to the fundamental discrepancies about the mission of public education. Mr. Copelin and other board members were anxious to bring changes to and through public education. While that was a noble intention, it was not practical. As researchers observed, educational organizations are social control agents rather than social change pioneers. Keeping the status quo is not only an important but also a necessary task for educational organizations. 
CHAPTER VIII

\section{CONCLUSION}

This case study used three models, the rational choice model, the process model, and the organizational decision-making model, to answer three questions: Why would a decision-making process be terminated before any results are achieved? Under what circumstances do decision makers choose to let the process die? What do such decisionmaking processes reveal about the organization?

THE FINDINGS

The findings of this study were drawn from a variety of data sources:interviews, documents, observation notes, and other information from the organization. The conclusions are organized in terms of the questions.

\section{The Reasons}

The following reasons were found to be indicators why the review process of the high school graduation standards at Roseville School District was terminated.

First, the decision makers had fundamental

differences in their perception of the problem in question. While the school board members believed that 
the review process would achieve political accountability and improve the image of the school district, the district staff members perceived the issue as a non-priority. This difference, never reconciled throughout the three years, was a fatal blow to the decision process at an early time. Another finding indicated a loosely-coupled working relationship among the decision makers. This relationship, a situation existing prior to the review process, reflected one of the characteristics of the public education system in general: loosely coordinated organizational structures. The district staff members offered minimum cooperation to the board's initiative to review the graduation standards. As a result, the relationship between the two groups became strained and no outcome was produced.

This finding conforms with the conclusions of other scholars (Burlingame 1993; Weick 1976; Shaffarzick et al. 1979). This relationship, implicit most of the time, created confusion and inconsistencies within the organization. It was one of the major reasons why this review process failed.

The third finding indicated the constant impact of the highly unstable environment of public education. The decision makers were distracted many times by 
uncertainties in the environment and the review process was interrupted by activities of other interested parties. This also conforms with the findings of Hickson and his colleagues (1986) who found that "organizations-incontact" impact organizational decision-making processes at various degrees. However, the findings of this case study indicate a critical difference between these "organizations-in-contact." For instance, public sector organizations are directly influenced by government authorities, which control resources of the organization in question.

Finally, changing interests within the organization created ambiguous decision tasks for the decision makers in this case study. No investment was worthwhile in the review process since the interests were temporary and the problems would soon go away because of other processes subsequently enacted. Committing minimal organizational resources to this decision process was both reasonable and logical.

The circumstances and the characteristics of NDR Process The NDR process, by definition, is a process without any results. One of the original questions was to specify the characteristics of such processes. The NDR process under study bears the characteristics 
of decision-making processes specified by other scholars (Hickson et al. 1986; Mintzberg 1983; Allison 1967). This NDR process went through the initiation phase, the developmental phase, and the finalization phase. The decision makers also considered specific organizational goals and interests prior to their initiation of the process. Most activities occurred during the developmental phase and the whole review process lasted for three years.

The findings also indicate the diverse interests of the decision makers who perceived a wide variety of problems in the review process. In other words, the process was characterized by an absence of agreement among the decision makers regarding the solution of the problem (Hickson et al. 1986; Mintzberg 1979; Boss 1989). Consequently, the diverse interests contributed to the lack of a concentrated energy to produce an outcome. This NDR process was also characterized by contradictory information which provided a confusing picture of the fundamental issues in education. The mismatch of the high school competence areas, discussed in Chapter VII, provided no direction for bridging the gap between educators and the business community. This NDR process was highlighted by an ad hoc 
committee with a hierarchical structure. Among the decision participants, there was a core group of decision makers who were instrumental in directing the process. within the core decision makers, there were also a few key players who decided on the "ons" and "offs" of the review process. In fact, the termination of the process was a decision of one such key player. This finding provided some insights of such a group in organizational decisionmaking processes. Although ad hoc committees are frequently found to be "structureless" (Mintzberg 1979), this case study indicated a possible structure for such an ad hoc. This structure reflects the various interests of the decision makers in the decision topic. The more interested a decision maker was in the decision topic, the more active he/she was in taking the lead in the decisionmaking process.

\section{Implications to the organization}

Although the frequency of a NDR process is unknown, its existence reveals a lot about the organization in question. In the case of the high school graduation standards review, many decision participants perceived it as a disturbance of their daily routines. Since the sign of a NDR process was not obvious, it was difficult for the decision makers to terminate the review process at the 
best time. Activities relating to the process went on until the NDR process was terminated. Had the decision makers been able to foresee the results earlier, some organizational resources could have been saved.

The occurrence of a NDR process revealed some organizational problems which would not be obvious otherwise. Questionable working relationships between the decision makers, conflicts caused by the competing interests, and the tremendous uncertainty in the environment were serious barriers to smooth organizational operations. In other words, a NDR process was a symptom of some serious organizational problems.since decision-making usually involves organizational leaders at different levels, these organizational problems are frequently related to the organizational leadership.

THE HIGHLIGHTS OF THE THREE MODELS The three models offered different focuses and insights of this case study. While each explains the NDR process based on the same set of data, each yields "insights NOT available with the others" (Linstone 1983). This is important to social sciences where problems are complicated and multi-dimensional. In specific, when problems are not well defined, it is essential that researchers have the ability to shift from one model to 
another to deal with "plural perceptions, plural problem definitions, plural expectations and plural rationalities" (Linstone 1983) .

\section{Rational choice with obstacles}

Value-maximizing is the principle idea in the rational choice model. An alternative would be chosen if decision makers perceived it as the best choice. "An increase in the cost of an alternative reduces the likelihood of that action's being chosen," and "a decrease in the costs of an alternative increases the likelihood of that action's being chosen" (Allison 1971). The "costs" include a variety of valuable resources that decision makers need to make decisions: time, manpower, and opportunity. A rational decision maker weighs the pros and cons of the alternatives and chooses the one with maximum payoff.

In this case study, two obstacles were identified: lack of resources and the external interruption of the state department of education. These obstacles changed the values of the expected alternatives and increased the cost of the review process tremendously. The decision makers were forced to evaluate the alternatives and a termination of this review process was chosen as the best value-maximizing alternative. 
The Topic is the Most critical

The process model believes that decision topics lead to various types of decision processes: sporadic, fluid, or constricted. The case under study is characterized by controversies, complex environments, unanticipated consequences and numerous decision problems. These characteristics are typical of sporadic decision-making processes. The topic for decision-making was debated throughout the review process due to its highly controversial nature and was the source of many disagreements.

The process model perceives the NDR outcome as a normal part of organizational decision-making. Since a decision-making process must be both interest accommodating and problem solving, the process serves an important function in the organization. Some decisionmaking processes, such as the review of the high school graduation standards at Roseville School District, exist as processes to satisfy certain needs in the organization. These processes do not necessarily lead to any decision outcomes. Instead, a process is sufficient as long as it accommodates strong interests. It is not very important whether an outcome is ever achieved. In such a case, the NDR process is not a waste of the organizational 
resources. It is useful.

Human organizations deal with the NDR phenomenon by creating ad hoc committees that are not part of the permanent organizational structures (Mintzberg, 1983). Rather, these ad hoc committees are set up and abolished according to unique decision topics which represent different interests. As long as the decision interests are met, these ad hoc committees have accomplished their tasks. Frequently, these ad hoc committees are combinations of experts in or outside of the organization who offer their expertise to solve the problem in question.

Organizational Decision-Making as organizational Behavior

The third model, the organizational decision-making model, believes that the answer to the NDR outcome lies in the organizational rules, procedures, and the organizational structures. Organizational decision-making, most important of all, is an organizational behavior. Such a behavior, like any other organizational behaviors, can only be understood within the organizational frameworks. The mission of the organization and its environment are important factors in this framework. The NDR results of the review process was due to several reasons. First of all, it was a questionable task 
for the organization to take on. The review process was not recognized by the decision makers as worthwhile at the time. Second, the characteristics of the organizational structure created loosely-coupled or no-connection relationships among many parts of the school district. Within such a structure, decision-making processes are not coordinated, authorities are not specified and the daily routines of the organization are not disturbed. Finally, the organizational environment contributed to the NDR outcome in this case study. Influenced by many forces in the organizational environment, the school district terminated the process in reviewing the high school graduation standards.

\section{A COMPARISON OF DECISION-MAKING STUDIES}

The inquiry to the mystery of the NDR outcome leads to many more questions than this case study is able to answer. At best, the data provide some clues as to why a decision-making process was terminated before any results were achieved. The three theoretical models proved to stand alone in interpreting the NDR phenomenon in organizational decision-making.

\section{The Three Medels}

The three models are compatible with each other in 
the sense that each focuses on certain aspects of the decision-making phenomenon with different modes of inquiry and various approaches to these inquiries.

Ragin (1987) specified two basic methods to compare case studies. Although this dissertation is a single case study with multiple models, the author believes that Ragin's two methods are applicable to this study. "The method of agreement is a search for patterns of invariance. All instances of a phenomenon are identified, and the investigator attempts to determine which of the possible causal variables is constant across all instances" (Ragin 1987).

It is important to point out that this case study was an extreme case in decision-making processes: a NDR process, which is perhaps the least desirable case by social organizations. Although the frequency of such cases is unknown, the significance of the characteristics and implications of NDR process makes it an important phenomenon. The employment of the three models also offered bases for comparison. For instance, all three models identified the relationship of the decision makers as a contributing factor to the NDR outcome. Two models, the rational choice model and the organizational model, suggested the environment as part of the cause of the NDR 
outcome. The similar findings of the different models indicate important causal/analytical argument of NDR processes.

A second method of comparison is an indirect method of difference, "a method which attempts to approximate experimental design with nonexperimental data" (Ragin 1987). Unlike the method of agreement, "indirect method uses negative cases to reinforce conclusions drawn from positive cases" (Ragin 1987). In other words, indirect method eliminates weak conclusions by using negative cases/models. For instance, organizational interest was identified by the organizational model as a contributing factor to the NDR process. Yet neither the rational choice model nor the process model considered the organizational interest as important. Therefore, it should be eliminated as a possible conclusion.

\section{other-case comparison}

Ragin's method of comparison also offers an alternative methodology to construct a generalization of case studies. Although sensitivity to complexity and specificity is the strong point of the case studies, the wide varieties of the case studies share little in common. In such a case, the method of agreement offers a process of elimination to find a basic commonality of all cases 
(Ragin 1987). Such a commonality includes causal indicators, theoretical concepts, focus of inquiry, and finally the subject matter. For instance, "all instances of a phenomenon are identified, and the investigator attempts to determine which of the possible causal variables is constant across all instances" (Ragin 1987). Thus, a lack of consensus regarding the decision topic could be identified as one indicator of NDR decisionmaking processes if such a lack of consensus occurred in all NDR cases. The investigator/researcher can cite an example of secondary cases to support such an interpretation of the causal factors of NDR outcomes.

In the absence of other NDR case studies, a comparison can be made among decision-making studies, NDR or non-NDR. In such a case, similarities and differences between these studies can be identified to find insights of NDR cases. For instance, ad hoc committeres were found to be an important factor in both NDR and non-NDR decision-making processes (Hickson et al. 1987; Mintzberg 1981). The conclusion is that organizational decisionmaking is mostly carried out in ad hoc committees. The nature of such ad hoc groups shapes the direction of the decision-making processes.

Changing interests and motivations were found to be 
an unique factor of the NDR process in this case study and were not identified by other scholars. The changing interests have several implications to the organization: the organization is going through an unstable period; the interests that initiated the decision-making process were short-lived; the environmental factors were unpredictable. Special attention should be paid to the consistency of motivations in decision-making process for the purpose of comparison. It is possible that changing motivations produce different outcomes from the original intention of the decision makers. However, great caution should be taken in making such a comparison because a link between the cause, i.e., a lack of consensus, and the effect, i.e., the NDR outcome, may not be clearly demonstrated. In other words, other causal factors should be identified.

\section{Limitations of This case study}

Data were not ideal to provide answers to the three inquiries in this study. The author encountered difficulties similar to those experienced by other scholars (Hickson et al. 1986; Mintzberg 1979). Data collection remained the most difficult task for this study, as only few individuals were involved in the decision-making activities. A single refusal to participate, such as Mr. Madison's in this case study, 
carried tremendous weight. Data lost in such a fashion are hard to compensate.

Also, the transformation of the raw data to information proved challenging. Since the author collected a large amount of the data in bulky, narrative forms, obtaining information from the raw data was time consuming and labor intensive.

Finally, a comparison of NDR process cases is not available for the author to objectively evaluate this case study. Such a comparison is essential for any generalization of the characteristics and implications of the NDR process to the organization. Even though findings of this study contributed insights into the NDR process, a comparison would greatly improve the generability of this study.

With difficulties in collecting relevant

information and problems in analyzing the data, studies of decision-making processes lack empirical evidence in general. This problem creates difficulties for comparison and replication studies for other researchers. The methodology issues are vital under such a circumstance since the decision-making processes are a unique organizational phenomenon. Variations in methodology further increases the level of variations of the studies. 


\section{Recommendations}

organizational decision-making processes deserve more attention than they have received so far. The scarcity of the comparison studies and concrete models indicates a weak spot in understanding humen organizations. With rapid changes and increasing uncertainties surrounding human organizations, more and better understanding of how organizations react and act upon these changes is critical. 


\section{REFERENCE}

Blanchard, Paul D., and Kline, Robert L. "The Importance of Regionalism in the Decision-Making Style of Local Boards of Education," Paper Presented at the Conference on the Urban South: Perspectives and Retrospective, Maxch 1977.

Bock, R. Darrell, and Mislevy, Robert J. "Comprehensive Educational Assessment for the States: The Duplex Design", vol. 10, No. 2, Educational Evaluation and Bolicy Analysis, Summer 1988.

Boyer, Ernest L. High School, A Report on Secondary Education In America, The Carnegie Foundation for the Advancement of Teaching, Harper \& Row, New York, 1983.

Braybrooke, D., and Lindblom, C. A Strategy of Decision, New York: Free Press, 1963.

Clune, William H. "Institutional Choice as a Theoretical Framework for Research on Educational Policy", vol.9, No 2, Educational Evaluation and Policy Analysis, Summer 1987.

Clune, William H. "Research from Three Views of Curriculum Policy in the School Context: The School as Policy Mediator, Policy Critic and Policy Constructor", paper presented at a conference, The Effect of Reform on Secondary School Context, Michigan State

University, East Lansing, Michigan, 1988.

Cohen, D. "Policy and Organization: The Impact of state and Federal Educational Policy on School Governance," $52(4)$, Harvard Education Review, $52(4), 1982$.

Cohen, M.D., March, J.G. and Olsen, J.P. "A Garbage Can Model of Organizational Choice," 17, Administrative Science Quarterly, 1972.

Coleman, James S. Foundations of Social Theory, Harvard, 1990. 
Collins, Randall cenflict Sociology, New York: Academic Press, 1975.

Coser, Lewis The Social Functions of conflict, Glencoe, IL:Free Press, 1956.

Cross, K.P. "The Adventures of Education in Wonderland: Implementing Education Reform," 68(7), Phi Delta Kappan, 1987.

Elam, S,M. "A Decade of Gallup Polls of Attitudes Toward Education, 1967-1978," Phi Delta Kappa, Bloomington, Indiana, 1978.

Elmore, R.F., and Mclaughlin, M.W. Steady Work: Policy, Practice, and the Reform of American Education (R3574-NIE/RC), Santa Monica, CA: The RAND Corporation, 1978 .

Elster, Jon Ulysses and the Sirens, studies in Rationality and Irrationality, Cambridge University Press, 1984 .

Elster, Jon, ed. Rational Choice, New York University Press, 1986.

Gallup, G.H. The Gallup Poll: Public opinion 19351971, Random House, New York, 1972.

Gamoran, Adam "The Stratification of High School Learning opportunities," Seciolegy of Education, July 1987.

Glatthorn, A. A., "What About Youth At Risk?" Walberg, H.J. and Keefe, J.W. (Eds.), Rethinking Reform: The Principal's Dilemma, Reston, VA: National Association of Secondary School Principals, 1986.

Hickson,D.,Butler,R., Cray,D., Mallory,G., and Wilson, D. Top Decisions: Strategic Decision-making in organizations, Jossey-Bass Publishers, 1986.

Levin, Henry M. "About Time for Educational Reform," vol. 6, No 2, Educational Evaluation and Policy Analysis, 1984 .

Lutz, Frank w. "Elite-Arena Council Behavior and School Boards," Paper presented at American Education

Research Association, April, 1977. 
Lustick, I. "Explaining the Variable Utility of Disjointed Incromentalism: Four Propositions," 4, American Political Science Review, 1980.

MCDill, E.L., Natriello, G. and Pallas, A. "The High Costs of High Standards: School Reform and Dropouts," paper presented at American Educational Research

Association, 1986.

Mclaughlin, Milbrey w. "Learning From Experience: Lessons From the Policy Implementation", vol. 9, No. 2, Educational Evaluation and Policy Analysis, summer 1987.

Mcwhinney, W. H. "Organizational Form, Decision Modalities and the Enviroment", 21, Human Relations, 1968.

Meyer, J., Scott, W., and Deal,T. Institutional and Technical sources of organizational structure: Explaining the structure of Educational

organizations, stanford University: Institute for Research on Finance and Governance in Education, 1979.

Meyer, J., and Rowan, B. Environments and organizations, San- Francisco: Jossey-Bass, 1978.

Meyer, J., and scott, Robert, W., ed. erganizational Environment, Beverly Hills, CA:Sage, 1983.

Mintzberg, H. The Structuring of organizations, Englewood cliffs, New Jersey: Prentice-Hall, 1979.

Mintzberg, H., Raisinghani, D., and Theoret, A. "The Structure of 'Unstructured' Decision Process," vol. 21, Administrative science Quarterly, 1976.

Mintzberg, H., and McHugh, A. "Strategy Formation in an Adhocracy," vol. 30, Administrative Science

Quarterly, 1985.

O'Reilly, C.A. "The Use of Information in Organizational Decision-making: A Model and Some Propositions," vol. 5, In Research in Organizational Behavior, Greenwich, Conn:JAI, 1983.

Resnick, Lauren B. "Learning in School and Out," Educational Researcher, December 1987.

Robertshaw, J.E., Mecca, S.J. and Rerick, M.N. Problem Solving: A Systems Approach, Petrocelli Books, 1978. 
Rossman, Gretchen B. Pathways Through High School: Translating the Effects of New Graduation Reguirements, Research for Better Schools, Inc., Philadephia, 1987.

Schaffarzick, Jon, and Sykes, Gary, eds. Value conflicts and curriculum Issues: Lessons From Research and Experience, National Institute of Education, Department of Health, Education and Welfare, McCutchan Publishing Corporation, 1979.

Scott, W. Organizations, Englewood Cliffs, New Jersey: Prentice-Hall, 1981.

Simon, Herbert A. The Sciences of the Artificial, $2 d$ ed., MIT Press, 1984.

Simons, Herbert A. Getting To know Schools in A Democracy, The Falmer Press, 1987.

Sizer, Theodore R. Horace's compromise: The Dilemma of the American High Scheel, Boston: Houghton Mifflin Company, 1984 .

Timar, Thomas B. and Kirp, David L. "State Efforts to Reform Schools: Treading Between a Regulatory Swamp and an English Garden," vol. 10, No. 2, Educational Evaluation and Policy Analysis, Summer 1988.

Thompson, J. organizations in Action, New York: McGrawHill, 1967.

Toch, Thomas, "The Dark Side of the Excellence Movements," 66(3), Phi Delta Kappan, 1984.

Tucker, Harvey J., and Zeigler, Harmon L. "Responsiveness in Local Politics: A Comparative Analysis of School Boards," paper presented at American Education Research Association, Teachers College Conference, April, 1977.

Walberg, H. Educational Environments and Their Effects, Berkeley, CA: McCutchan, 1974.

Walter, B. Sociology and Modern Systems Theory, Englewood Cliffs, New Jersey, Prentice-Hall, 1967. 
Wiley, David E. "Explosion of a Myth: Quantity of Schooling and Exposure to Instruction, Major Educational Vehicles," Educational Researcher, April 1974 .

Wirt, F. M., and Kirst, M.W. The Political Web of American Schools, Little, Brown \& Company, Inc., 1972.

Wirt, F. M., and Kirst, M.W. The Pelitical and Social Foundations of Education, McCutchan Publishing Corporation, 1975. 


\section{APPENDIX \\ INTERVIEW QUESTIONNAIRES}

First Interview

1. What was your reaction to the board's initiation to review the high school graduation standards?

Facilitator:

Did you think that it was necessary to review the graduation standards?

Did you think the current graduation standards were too high or too low?

Did you think that it was the right time to do it?

2. What were your information sources concerning the review of the graduation standards?

Facilitator:

Where did you learn about the graduation standards?

could you name some specific factors/information that made you believe a change was necessary for the graduation standards?

Did you talk to any teachers/students/parents regarding the graduation standards?

Did you talk to any employers/business people regarding the graduation standards?

Did you hear anything from organizations such as PTA, OEA, PAT? Or any formal or informal meetings regarding the graduation standards?

Did you read anything from the media?

3. Did you have any organizational concerns regarding the graduation standards?

Facilitator:

The quality of the high school graduates; the image of the public schools; the financial issues of public schools; students should have basic skills by the time they graduate from high schools; school outcome issue; consequences regarding the changes of the high school graduation standards.

4. Did you have any technical concerns regarding the 
review process?

Facilitator:

Curriculum change; changes in classroom instruction; changes in push-out/drop-out rate; raise the cut points.

5. Can you identify some organizational interests that would be promoted by the review of the graduation standards?

Facilitator:

The needs to raise public confidence and ensure public funding; the needs to raise employer confidence in the high school graduates; the needs to address the accountability issue; the needs to provide guidelines for high school graduates.

6. Did you have any personal/professional interests that would be promoted by the review of the graduation standards?

Facilitator:

To improve public education; to achieve something as a board member/school administrator/educational professional; other.

7. Did you anticipate any problems with a change in current graduation standards?

Facilitator:

Issues regarding special education students; minority students; issues of test-driven curriculum; competency test might limit students growth.

8. Did you feel pressured to initiate a review of graduation standards in any way?

Facilitator:

By media/public opinion/ community/peers; personal feelings; information you gathered on the graduation standards.

9. Who do you think should be involved in the review process?

Facilitator:

Teachers, principals, \& other school administrators; business people, employers, \& other external parties; parents \& students. 


\section{Second Interview}

1. Can you name some "rules of game" in the decision process in review of graduation standards?

\section{Facilitator:}

Should everyone have specific responsibilities?

How would one define the relationship between school professionals and school board?

Did you think priorities should be sorted and agreed upon by all the decision makers?

2. How and when did the decision process start?

Facilitator:

Incidents mentioned/remembered. Circumstances of the starting point. Who were involved?

3. What did you initially want to achieve from the review of graduation standards?

Facilitator:

To raise the current test scores

To change high school curriculum

To raise the percent of high school graduates

4. Were there any interruptions to the decision process?

can you name some?

Facilitator:

external interruptions

internal interruptions

5. Was there a feeling during the process that a decision had been made?

Facilitator:

Did you ever feel that discussions were formalities. Was your participation recognized?

6. Were there any informal interactions between you and other decision makers during the process?

FaciliŁator:

Did you discuss the issues or the topic at a social gathering?

Did you talk to any decision makers outside the meetings? 
Did you talk to any other decision makers over the phone?

7. Can you describe the process in the review of sraduation standards briefly?

Facilitator:

It wes smooth.

There was (there was no) consensus throughout the process.

8. Can you tell me ONE event that you remember from your experience in the decision process?

Facilitator:

A meeting; someone's comment; an argument;

9. Can you tell me ONE conflict that occurred during the decision process.

Facilitator:

A meeting; someone's comment; an argument;

10. Can you tell me ONE problem that caused any delays or disruptions of the decision process.

Facilitator:

Too slow on someone's part

Too pressing on someone's part

There were too many things going on at the same time. There was no clear idea what should be achieved.

11. What was the outcome of the decision process? Was it what you expected?

Facilitator:

An outcome; a decision; no decision; the last activity: a meeting, a conversation or a phone call. 